\title{
The Nia Project: Baseline survey instruments
}

Karen Austrian

Population Council

Follow this and additional works at: https://knowledgecommons.popcouncil.org/departments_sbsr-pgy

Part of the Demography, Population, and Ecology Commons, Family, Life Course, and Society Commons, International Public Health Commons, Maternal and Child Health Commons, and the Women's Health Commons How does access to this work benefit you? Let us know!

\section{Recommended Citation}

Austrian, Karen. 2017. "The Nia Project: Baseline survey instruments." Nairobi: Population Council. 


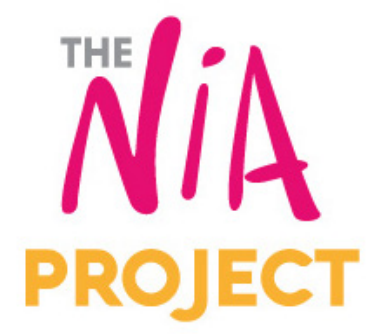

Baseline Survey Instruments 
ENGLISH

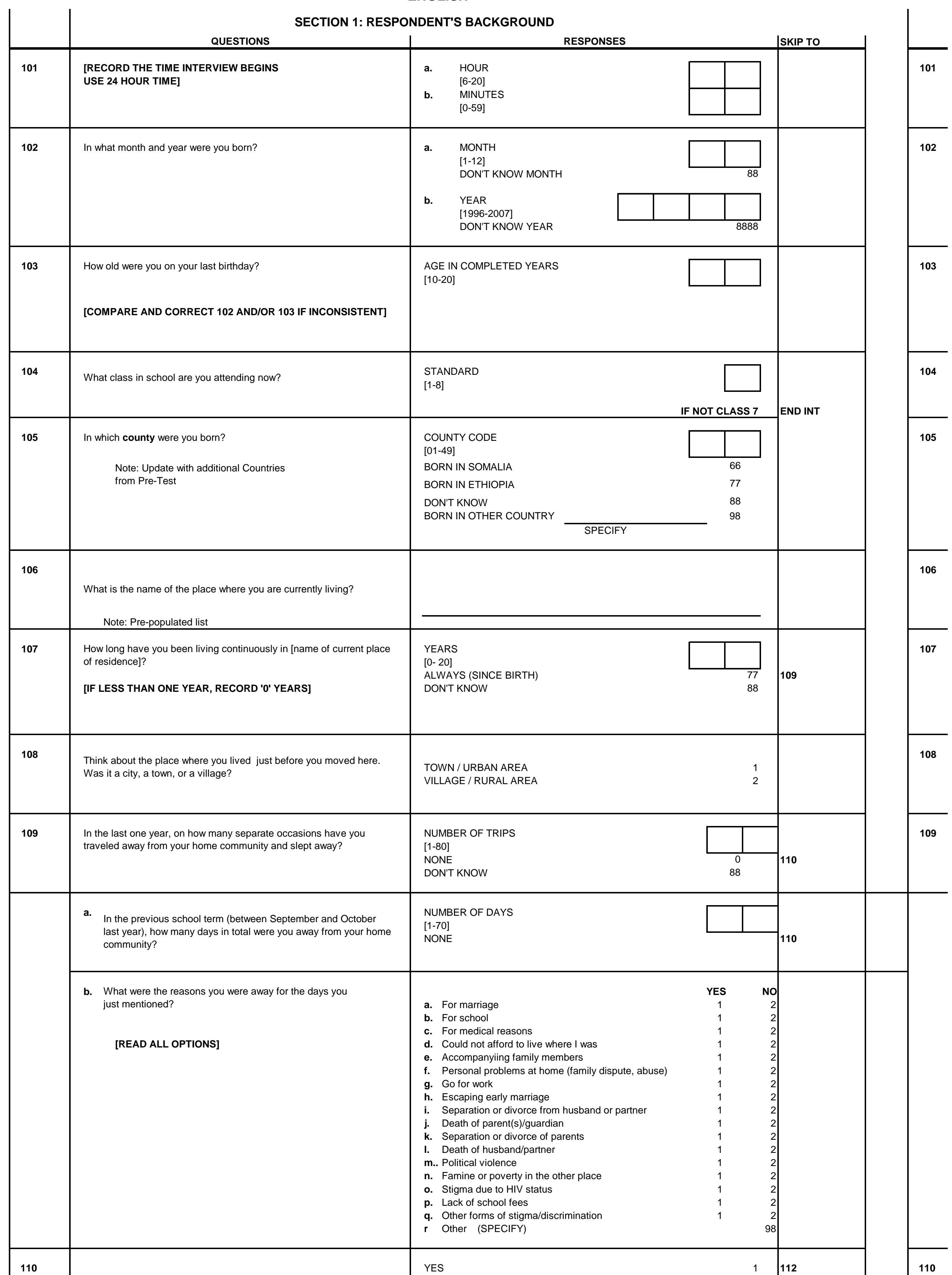




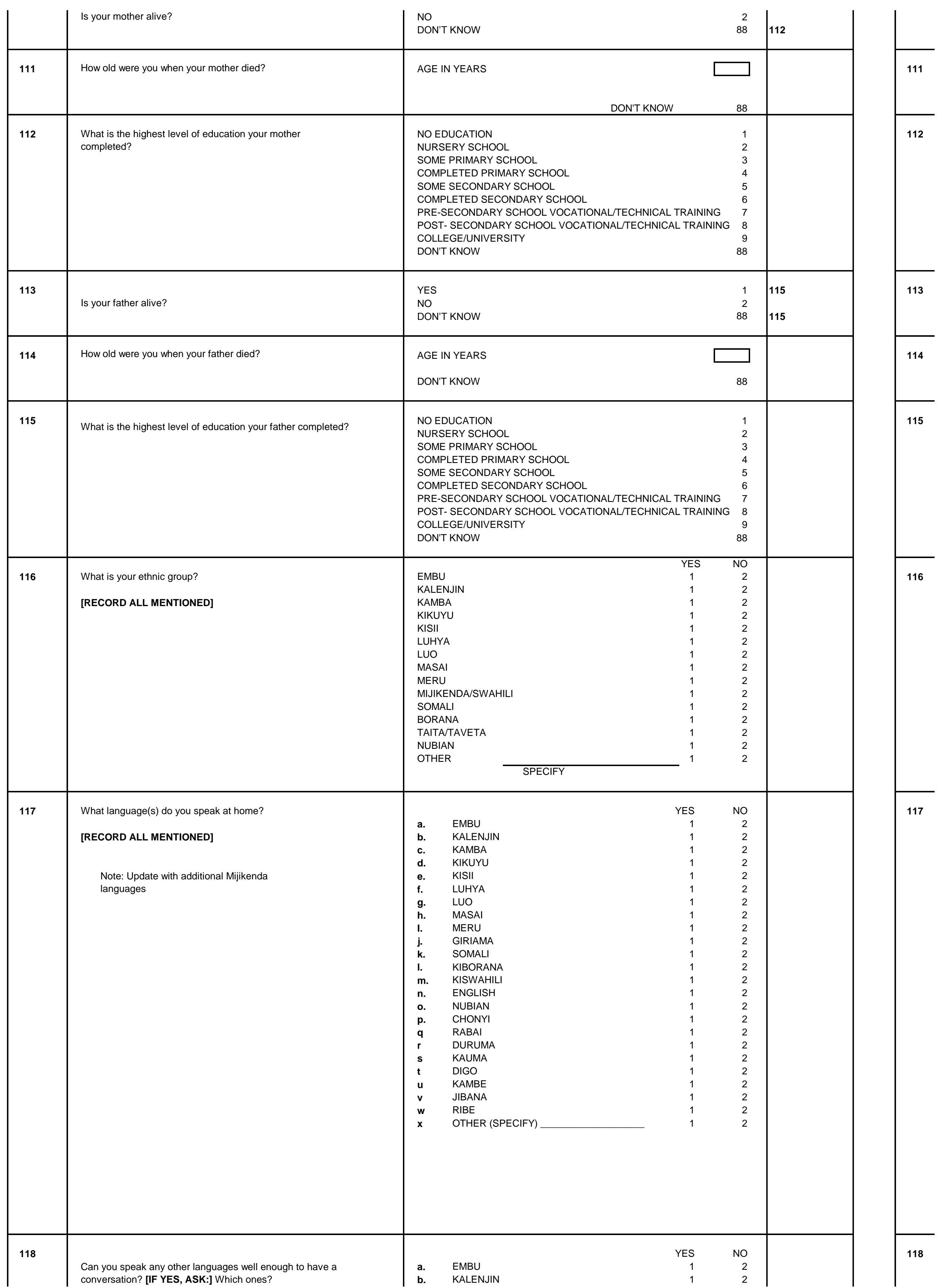




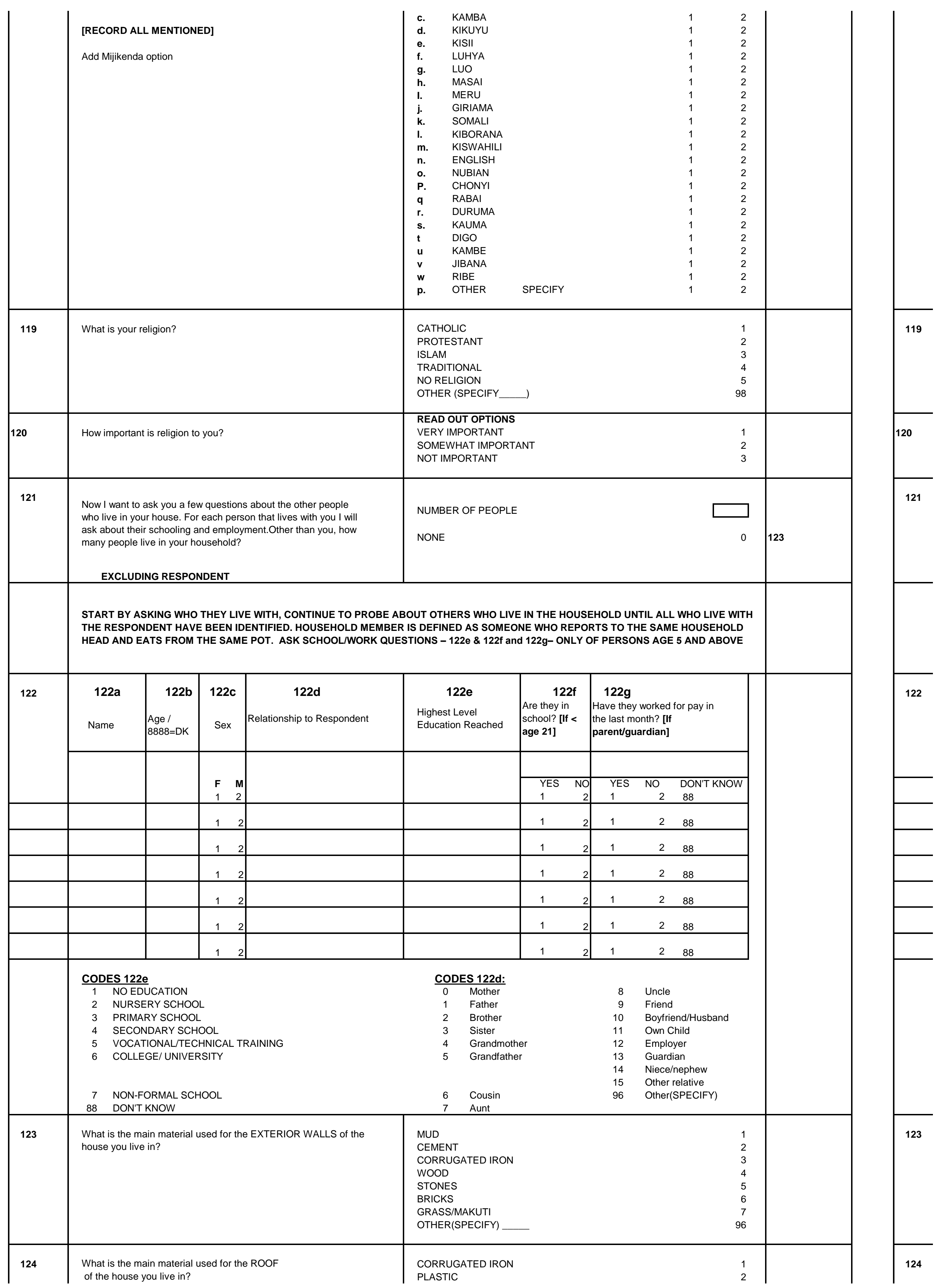




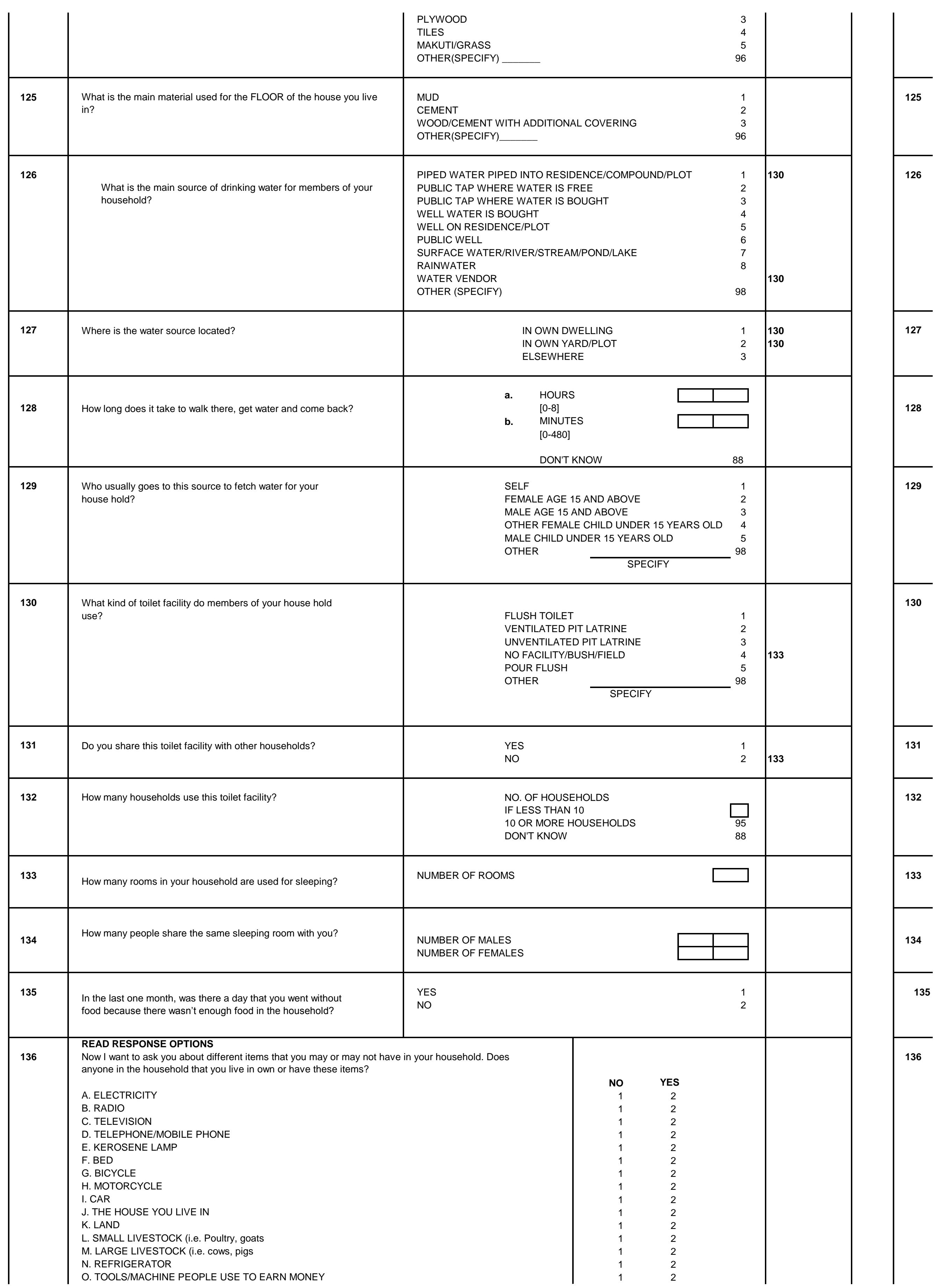




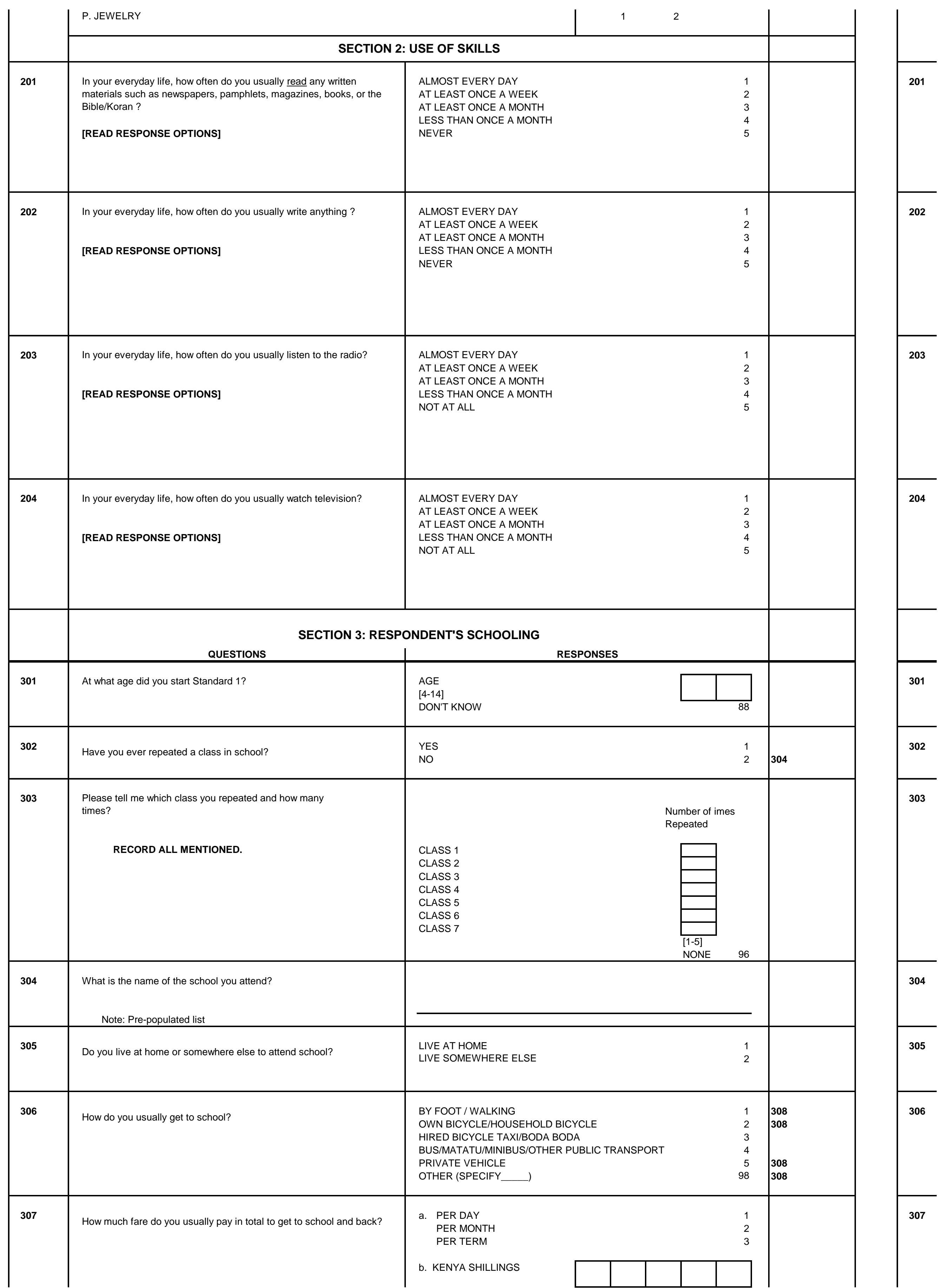




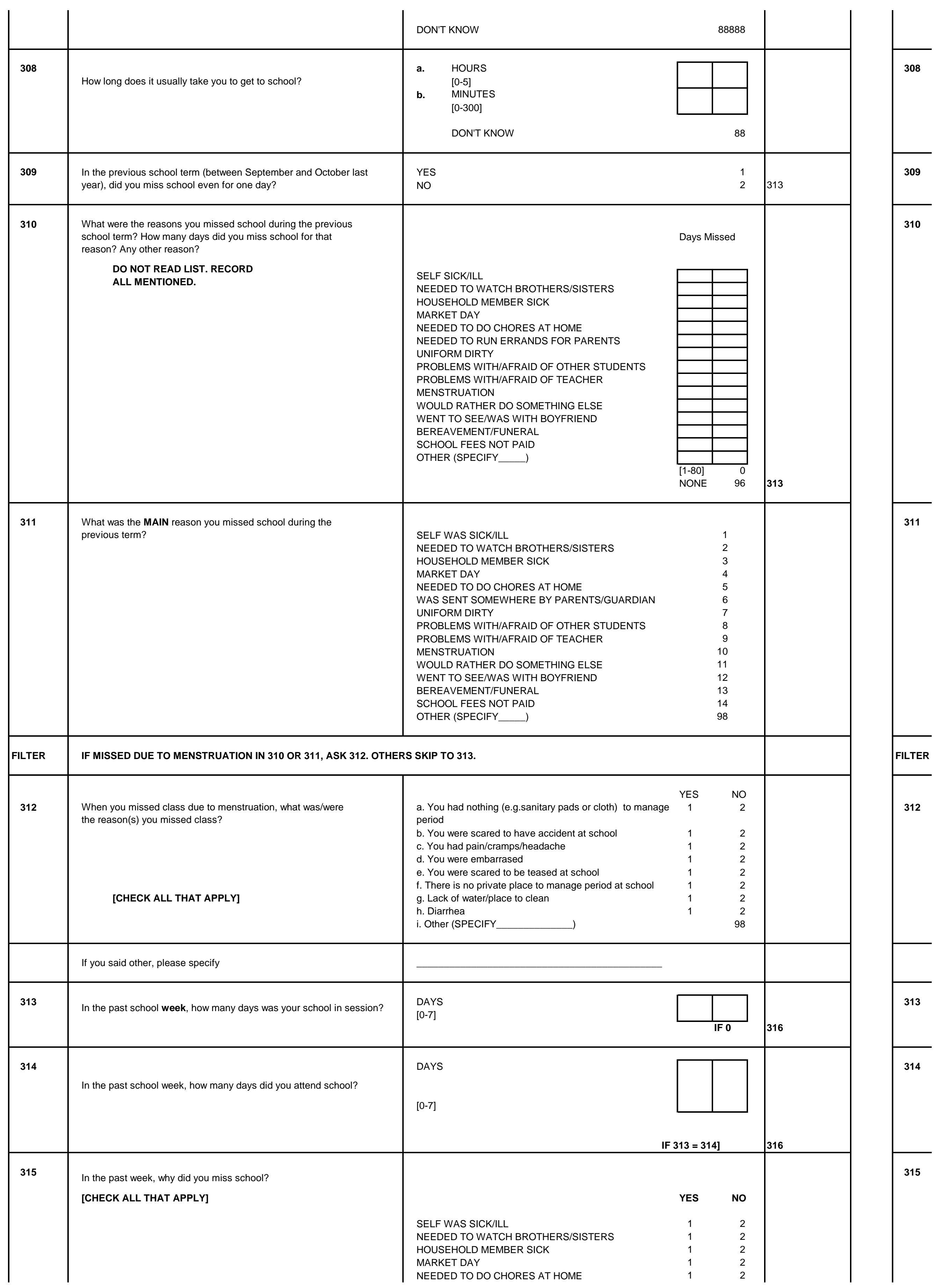




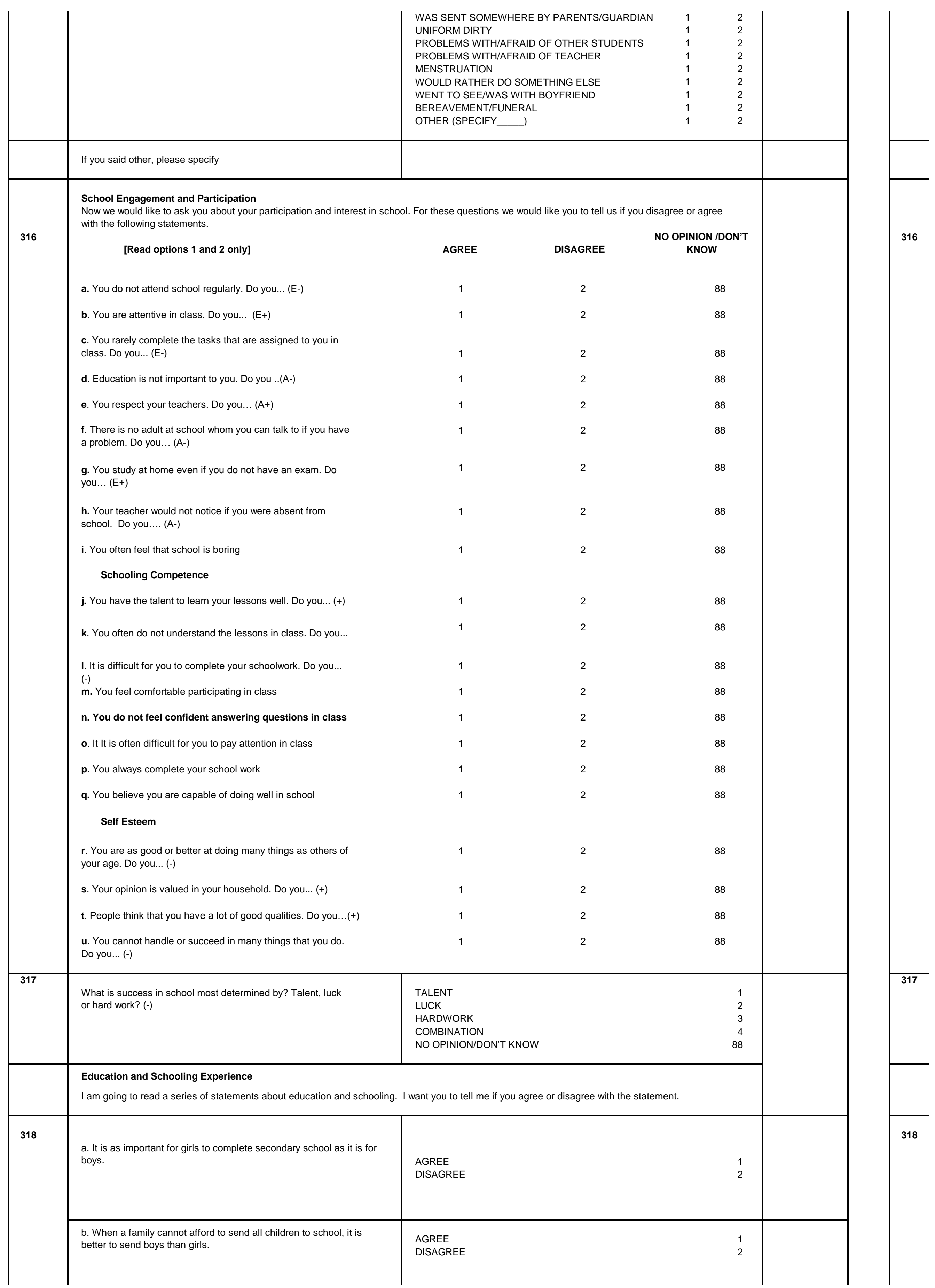




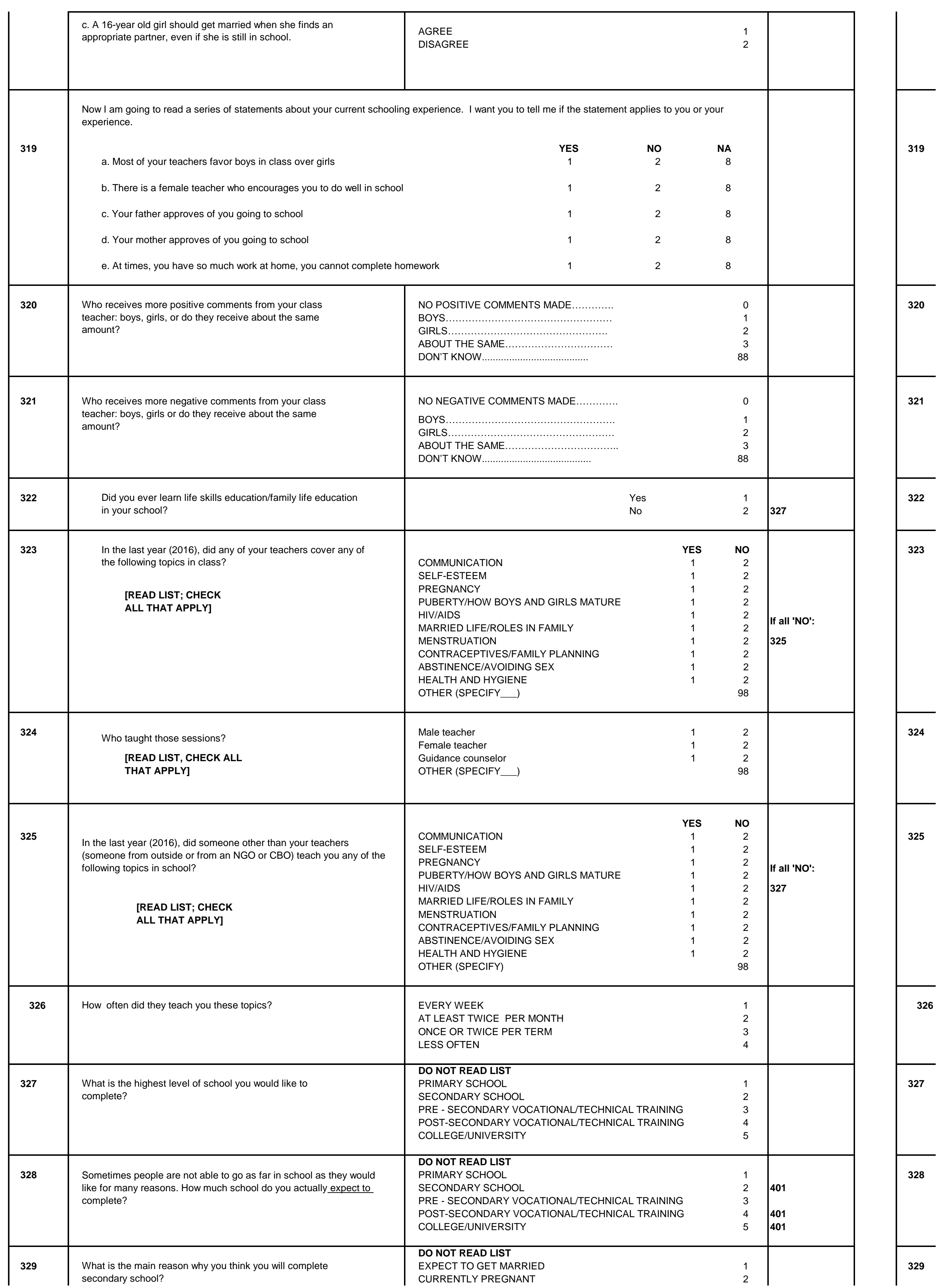




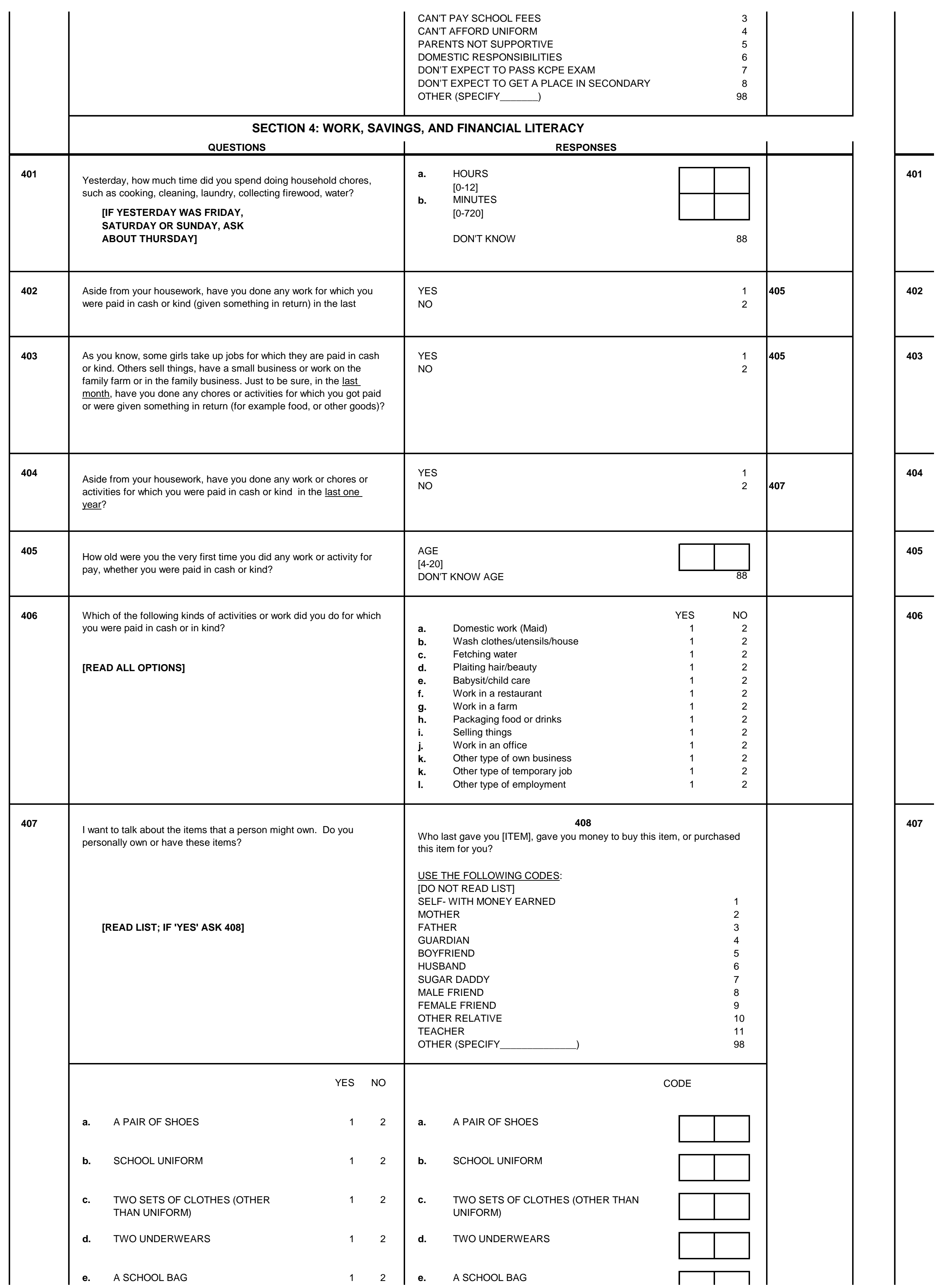




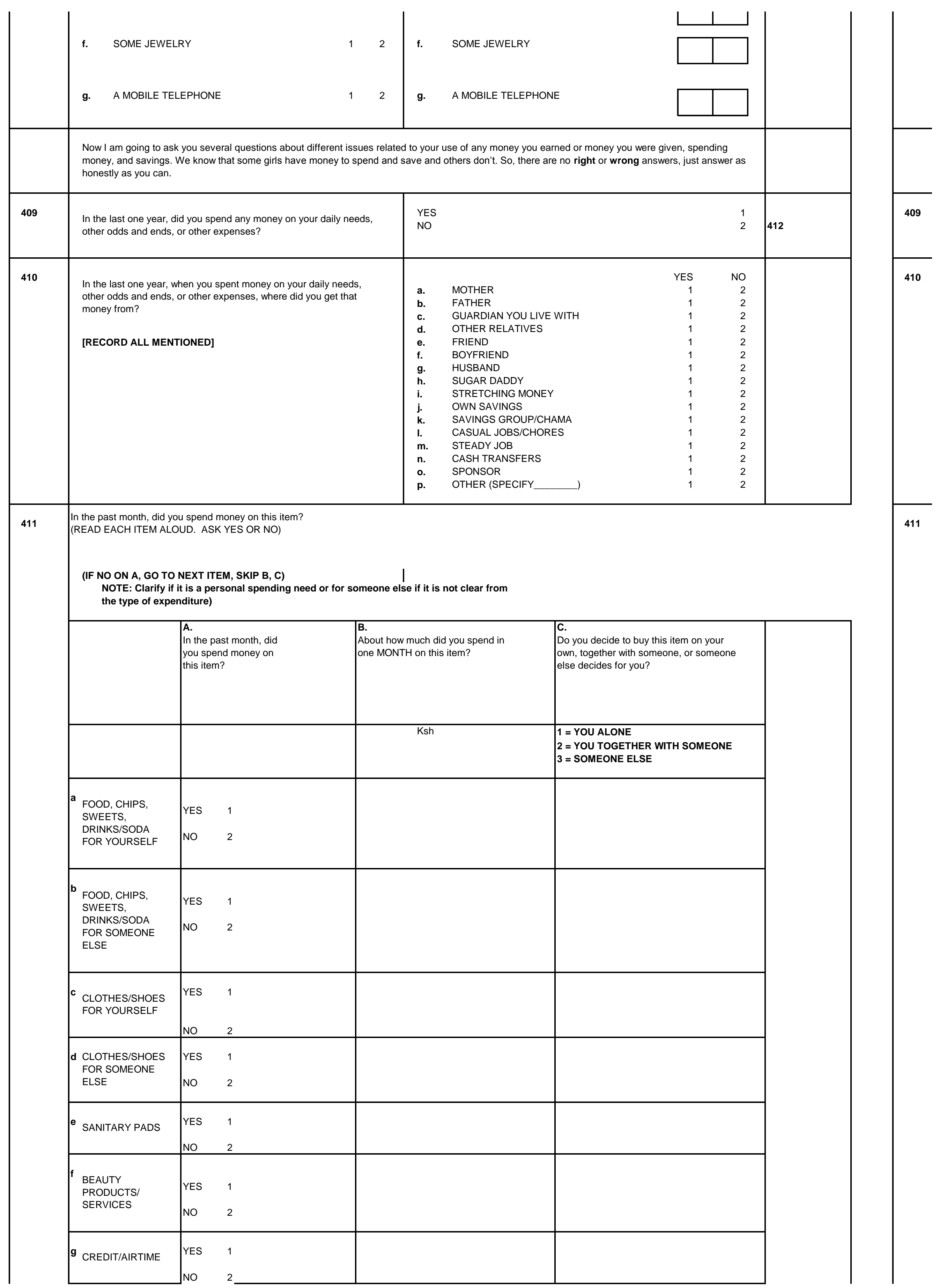




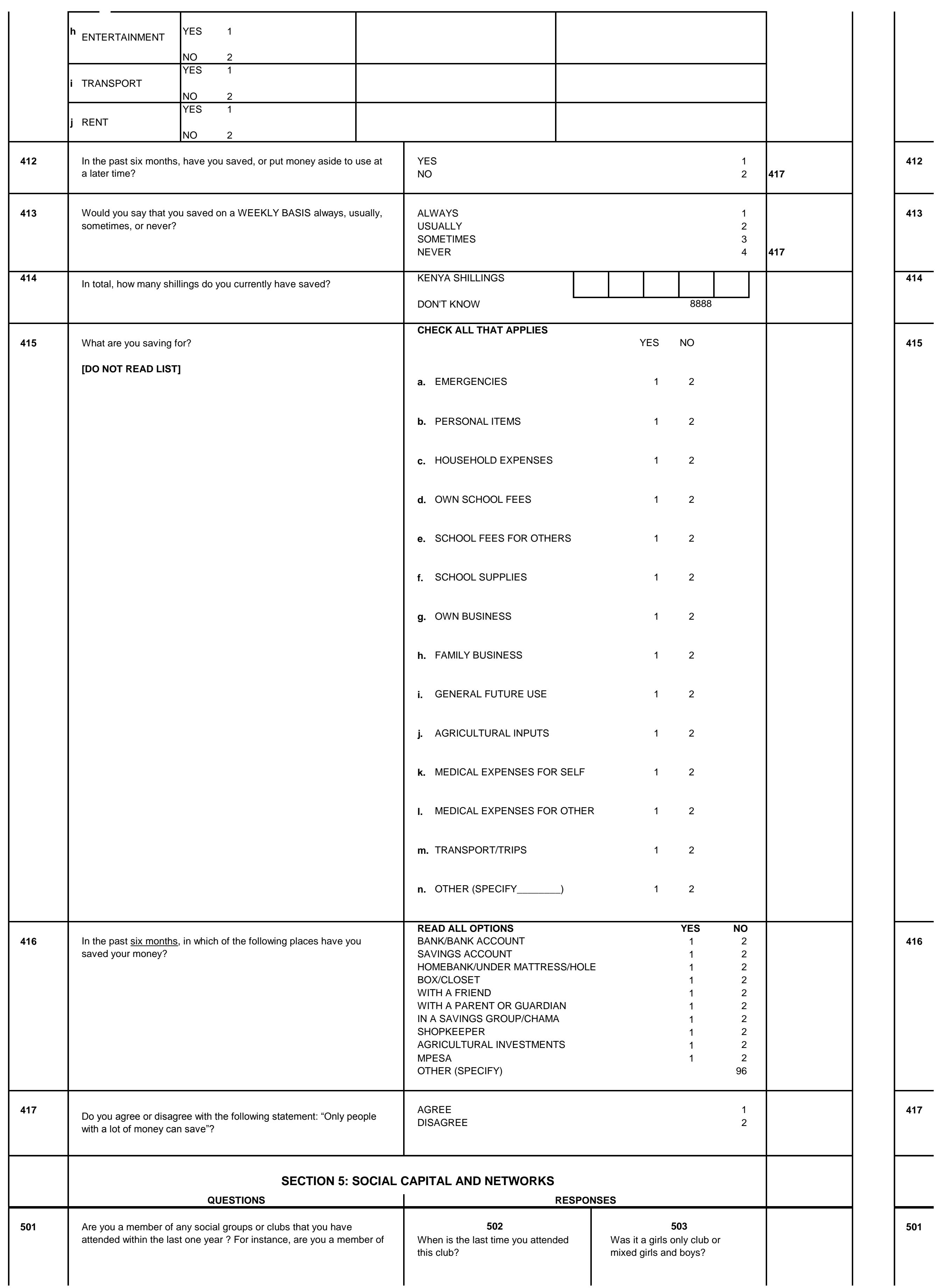




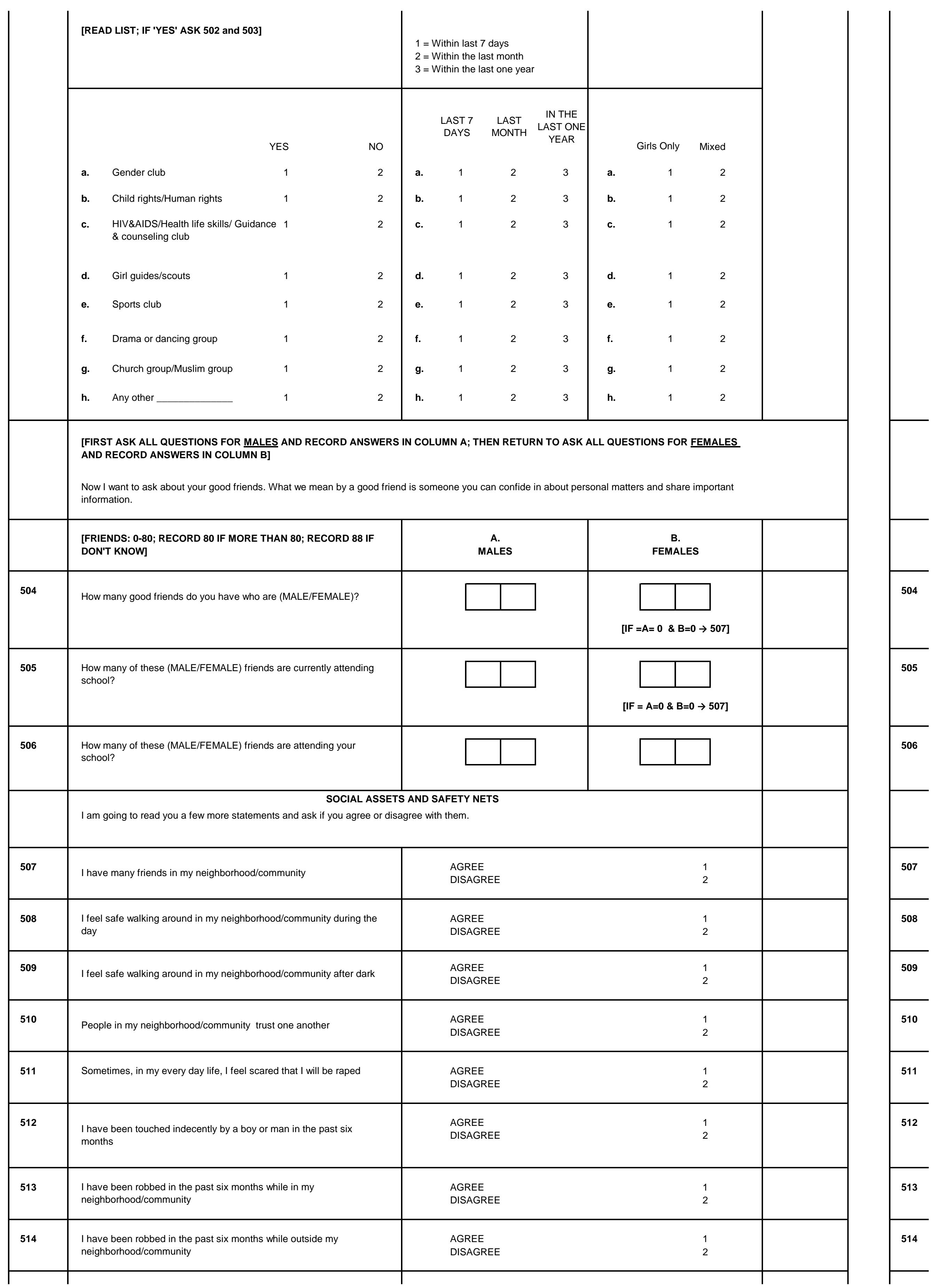




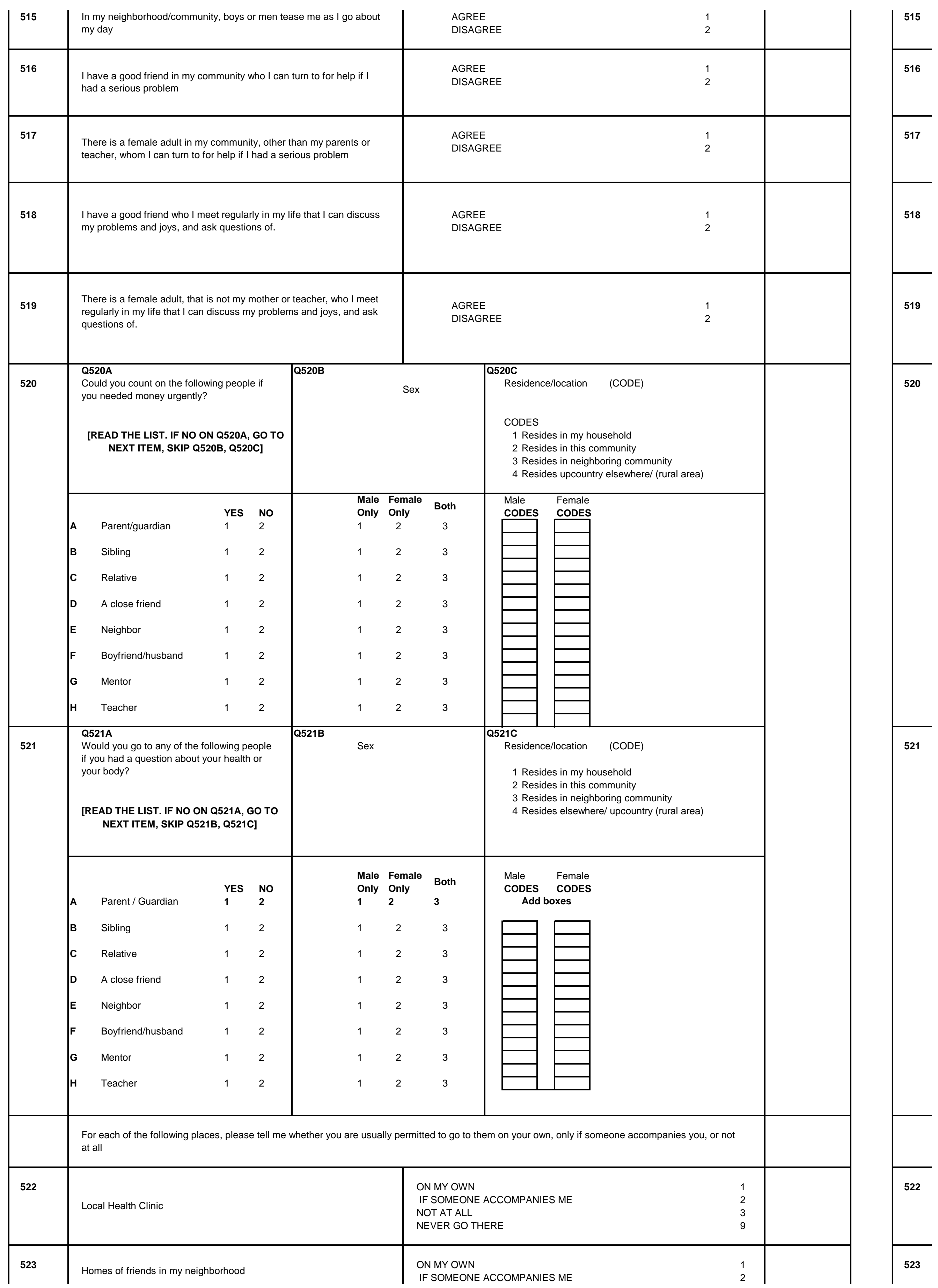




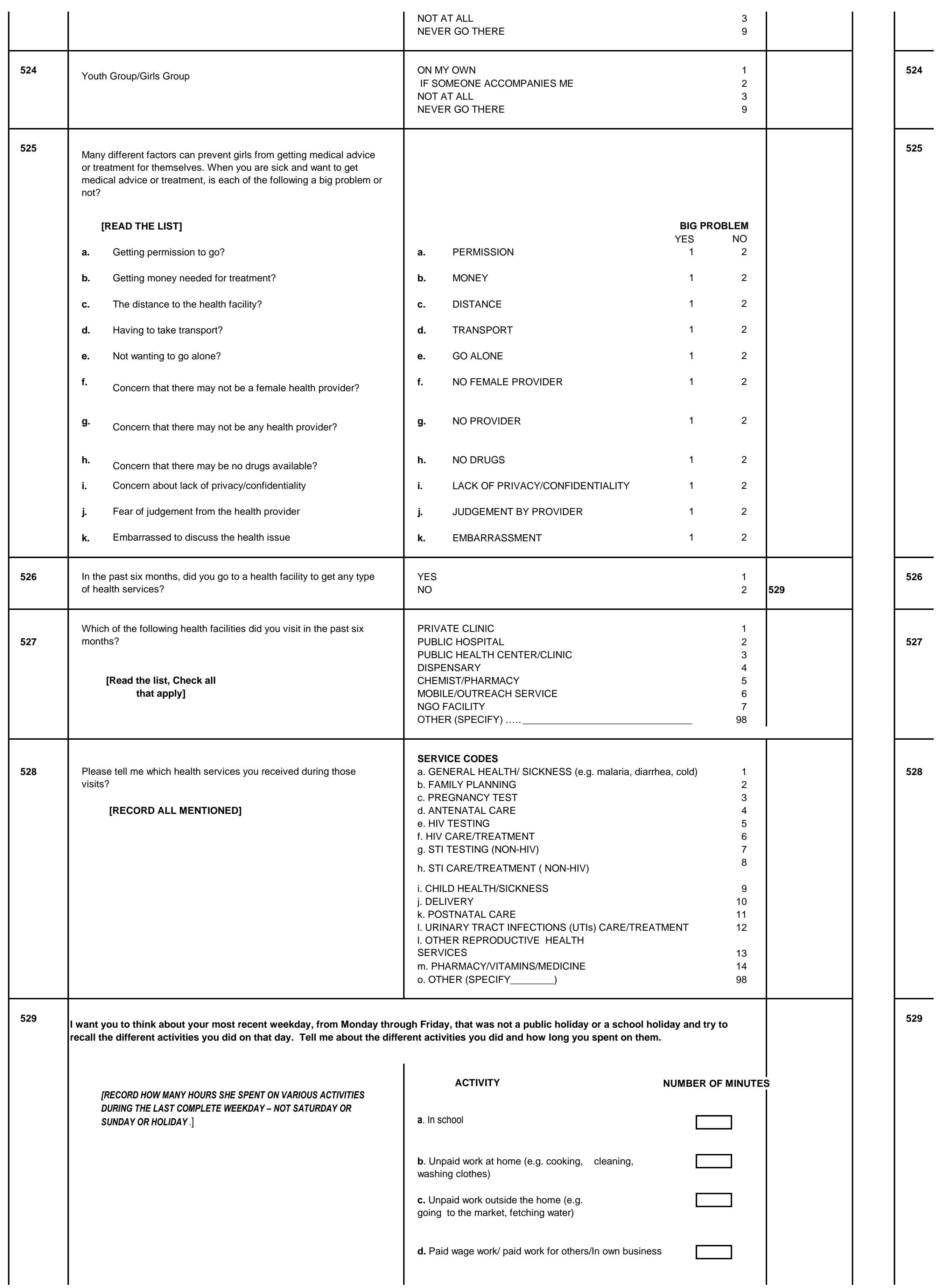



happen by chance (reverse scored).

b. If someone is against you, you can still find ways to get what you want.

g. Studying/homework

h. Travelling to and from school

i. Sleeping

TOTAL MINUTES [CHECK NOT MORE THAN 1440]

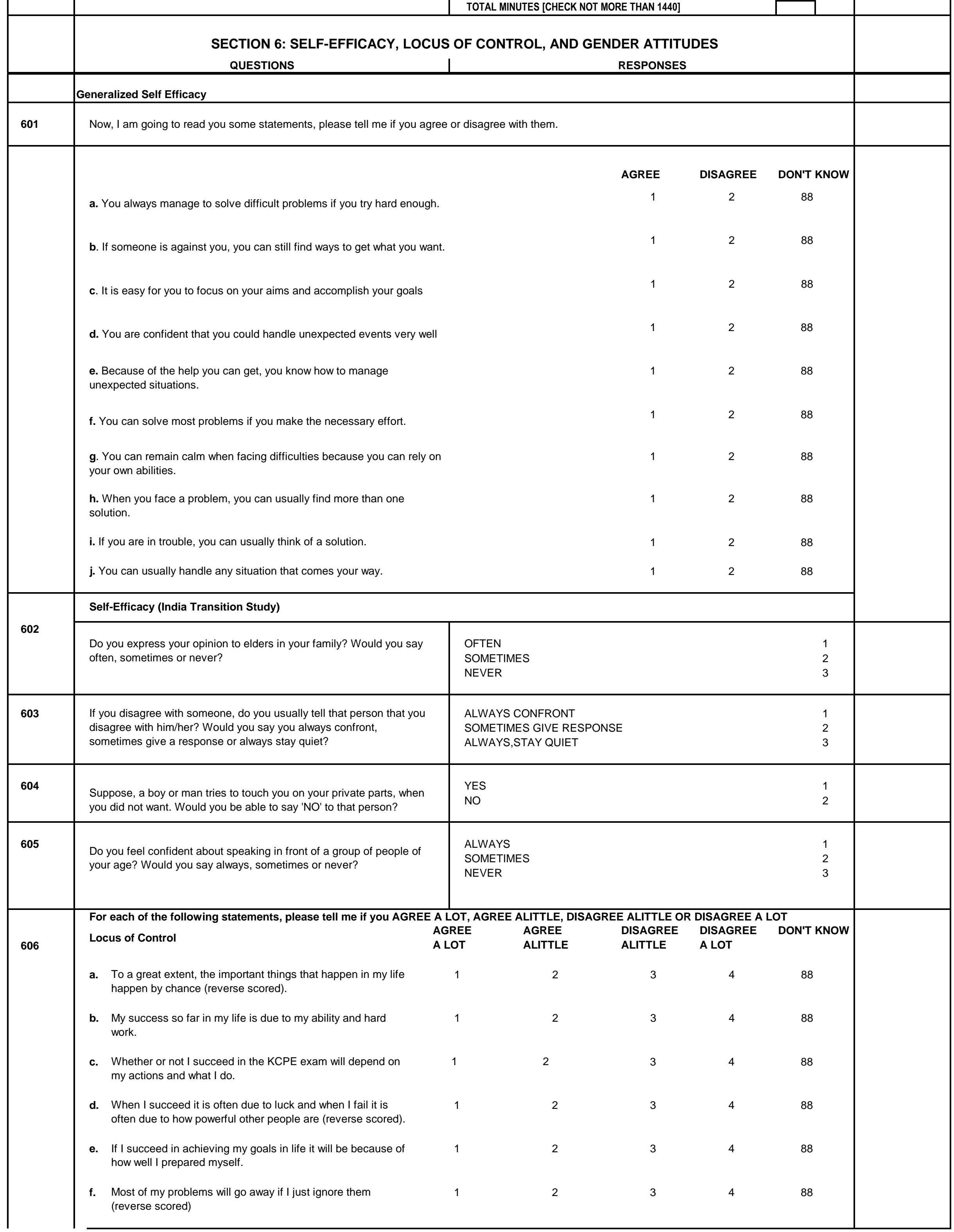




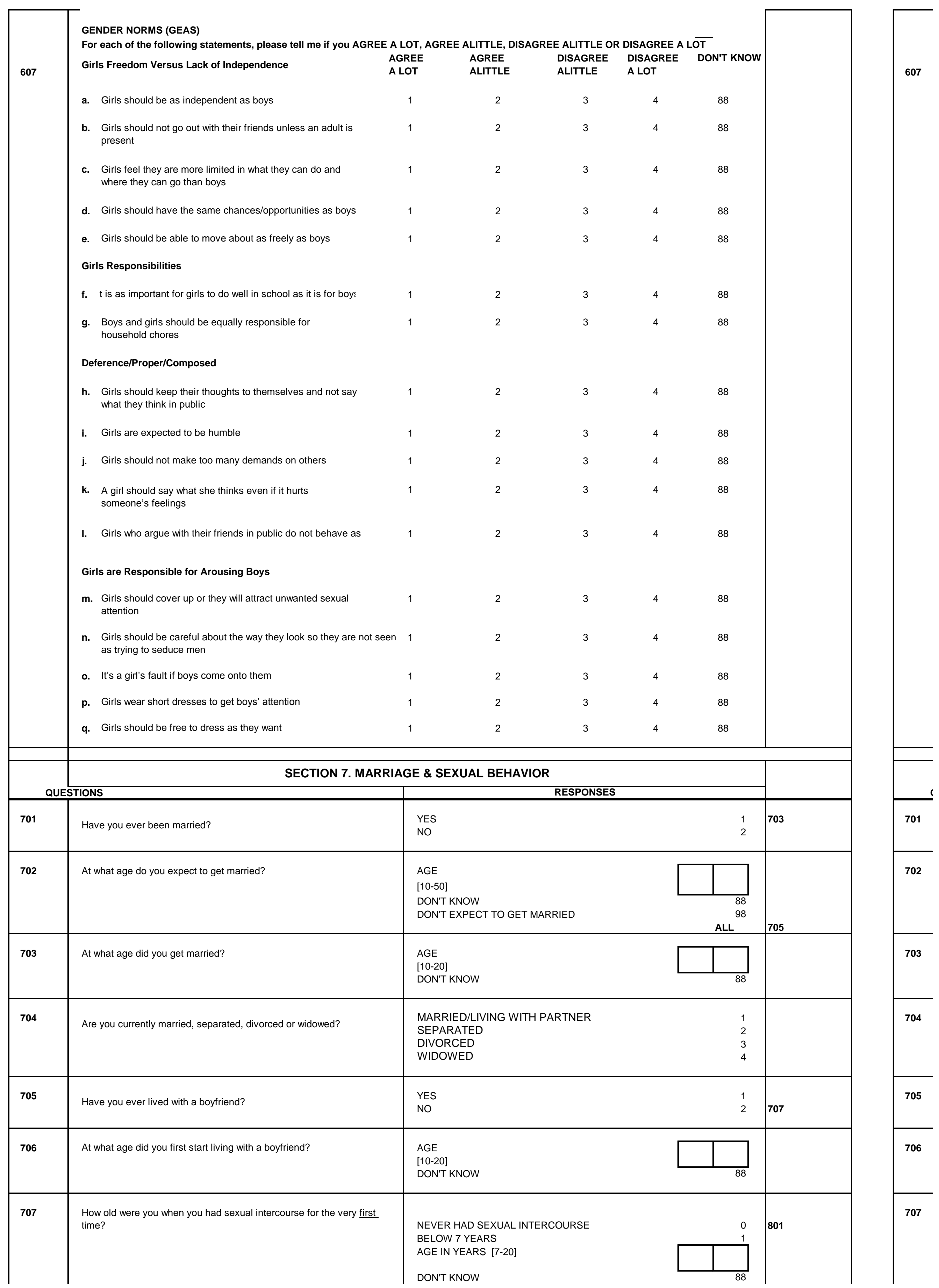




\begin{tabular}{|c|c|c|c|c|c|}
\hline 708 & $\begin{array}{l}\text { What was your relationship to the first person with whom you had } \\
\text { sexual intercourse? } \\
\text { [DO NOT READ OPTIONS] }\end{array}$ & $\begin{array}{l}\text { HUSBAND } \\
\text { BOYFRIEND } \\
\text { "SUGAR DADDY" } \\
\text { CASUAL ACQUAINTANCE } \\
\text { RELATIVE } \\
\text { TEACHER } \\
\text { STRANGER } \\
\text { SOMEONE ELSE }\end{array}$ & $\begin{array}{l}1 \\
2 \\
3 \\
4 \\
5 \\
6 \\
7 \\
8\end{array}$ & & 708 \\
\hline 709 & $\begin{array}{l}\text { Was the person you first had sexual intercourse with older than you, } \\
\text { younger than you, or about the same age as you? }\end{array}$ & $\begin{array}{l}\text { OLDER } \\
\text { YOUNGER } \\
\text { ABOUT THE SAME AGE } \\
\text { DON'T KNOW/DON'T REMEMBER }\end{array}$ & $\begin{array}{r}1 \\
2 \\
3 \\
88\end{array}$ & $\begin{array}{l}711 \\
711 \\
711\end{array}$ & 709 \\
\hline 710 & How many years older than you was this person? & NUMBER OF YEARS OLDER & 88 & & 710 \\
\hline 711 & The first time you had sexual intercourse, was a condom used? & $\begin{array}{l}\text { YES } \\
\text { NO } \\
\text { DON'T KNOW/DON'T REMEMBER }\end{array}$ & $\begin{array}{r}1 \\
2 \\
88\end{array}$ & & 711 \\
\hline 712 & $\begin{array}{l}\text { The first time you had sex did you want to have sex, not want to have } \\
\text { sex, or you were unsure if you wanted to have sex? }\end{array}$ & $\begin{array}{l}\text { WANTED TO HAVE SEX } \\
\text { DID NOT WANT TO HAVE SEX } \\
\text { UNSURE }\end{array}$ & $\begin{array}{l}1 \\
2 \\
3\end{array}$ & & 712 \\
\hline 713 & $\begin{array}{l}\text { Now I would like to ask you some questions about your recent sexual } \\
\text { activity. When was the last time you had sexual intercourse? }\end{array}$ & $\begin{array}{l}\text { TODAY/LESS THAN A WEEK AGO } \\
\text { A WEEK OR MORE AGO } \\
\text { A MONTH OR MORE AGO } \\
\text { A YEAR OR MORE AGO }\end{array}$ & $\begin{array}{l}1 \\
2 \\
3 \\
4\end{array}$ & $\begin{array}{l}716 \\
716 \\
716\end{array}$ & 713 \\
\hline 714 & In the last week, how many times did you have sex? & $\begin{array}{l}\text { TIMES HAD SEX [1-35] } \\
\text { DON'T KNOW }\end{array}$ & 88 & & 714 \\
\hline 715 & $\begin{array}{l}\text { Of those times you had sex in the last week, how many times did you } \\
\text { use a condom? } \\
\text { [Consistency check: Maximum = previous question] }\end{array}$ & $\begin{array}{l}\text { TIMES USED CONDOM }[1-35] \\
\text { DID NOT USE CONDOM } \\
\text { DON'T KNOW }\end{array}$ & $\begin{array}{l}77 \\
88\end{array}$ & & 715 \\
\hline 716 & $\begin{array}{l}\text { What was your relationship to the last person with whom you had } \\
\text { sexual intercourse? }\end{array}$ & $\begin{array}{l}\text { HUSBAND } \\
\text { BOYFRIEND } \\
\text { "SUGAR DADDY" } \\
\text { CASUAL ACQUAINTANCE } \\
\text { RELATIVE } \\
\text { TEACHER } \\
\text { STRANGER } \\
\text { SOMEONE ELSE }\end{array}$ & $\begin{array}{l}1 \\
2 \\
3 \\
4 \\
5 \\
6 \\
7 \\
8\end{array}$ & & 716 \\
\hline 717 & $\begin{array}{l}\text { Was the person you last had sexual intercourse with older than you, } \\
\text { younger than you, or about the same age as you? }\end{array}$ & $\begin{array}{l}\text { OLDER } \\
\text { YOUNGER } \\
\text { ABOUT THE SAME AGE } \\
\text { DON'T KNOW/DON'T REMEMBER }\end{array}$ & $\begin{array}{r}1 \\
2 \\
3 \\
88\end{array}$ & $\begin{array}{l}720 \\
720 \\
720\end{array}$ & 717 \\
\hline 718 & How many years older than you was this person? & NUMBER OF YEARS OLDER & 88 & & 718 \\
\hline 719 & $\begin{array}{l}\text { The last time you had sex did you want to have sex, not want to have } \\
\text { sex, or you were unsure if you wanted to have sex? }\end{array}$ & $\begin{array}{l}\text { WANTED TO HAVE SEX } \\
\text { DID NOT WANT TO HAVE SEX } \\
\text { UNSURE }\end{array}$ & $\begin{array}{l}1 \\
2 \\
3\end{array}$ & & 719 \\
\hline 720 & The last time you had sexual intercourse, was a condom used? & $\begin{array}{l}\text { YES } \\
\text { NO } \\
\text { DON'T KNOW/DON'T REMEMBER }\end{array}$ & $\begin{array}{r}1 \\
2 \\
88\end{array}$ & & 720 \\
\hline 721 & $\begin{array}{l}\text { On average, how often did you use a condom every time you had } \\
\text { sexual intercourse with this person in the last one year? Would you } \\
\text { say always, sometimes or never? }\end{array}$ & $\begin{array}{l}\text { ALWAYS } \\
\text { SOMETIMES } \\
\text { NEVER }\end{array}$ & $\begin{array}{l}1 \\
2 \\
3\end{array}$ & & 721 \\
\hline 722 & $\begin{array}{l}\text { If you were interested in obtaining family planning, do you feel it } \\
\text { would be easy, difficult or not possible to go to a place where you can } \\
\text { obtain family planning? }\end{array}$ & $\begin{array}{l}\text { EASY } \\
\text { DIFFICULT } \\
\text { NOT POSSIBLE } \\
\text { DON'T KNOW }\end{array}$ & $\begin{array}{r}1 \\
2 \\
3 \\
88\end{array}$ & & 722 \\
\hline FILTER & [SKIP Q728 IF Q713 IS A YEAR OR MORE AGO] & & & & $\overline{\text { FILTER }}$ \\
\hline 723 & In total, with how many different people have you had sexual & NUMBER OF PARTNERS IN LAS & & & 723 \\
\hline
\end{tabular}




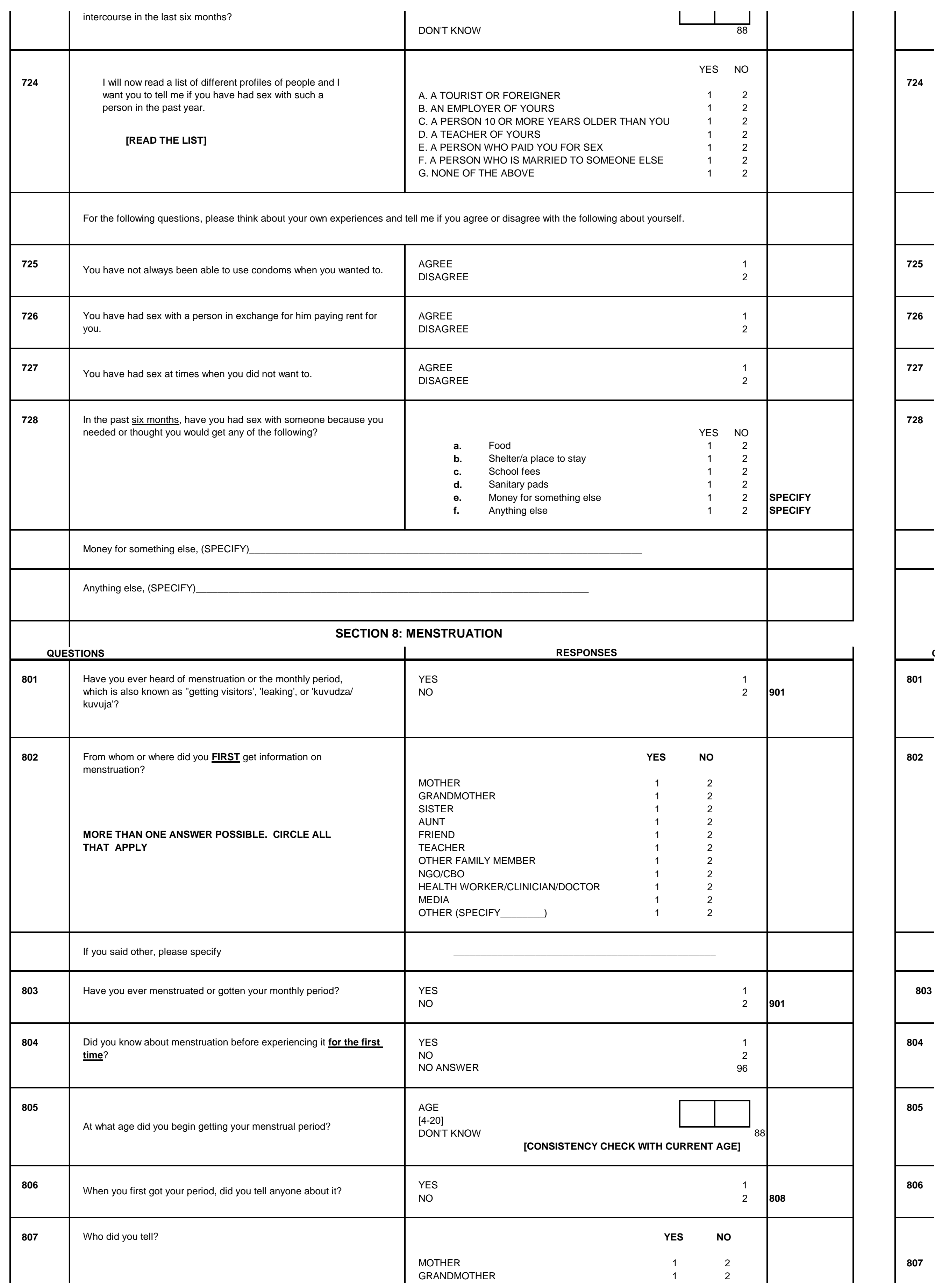




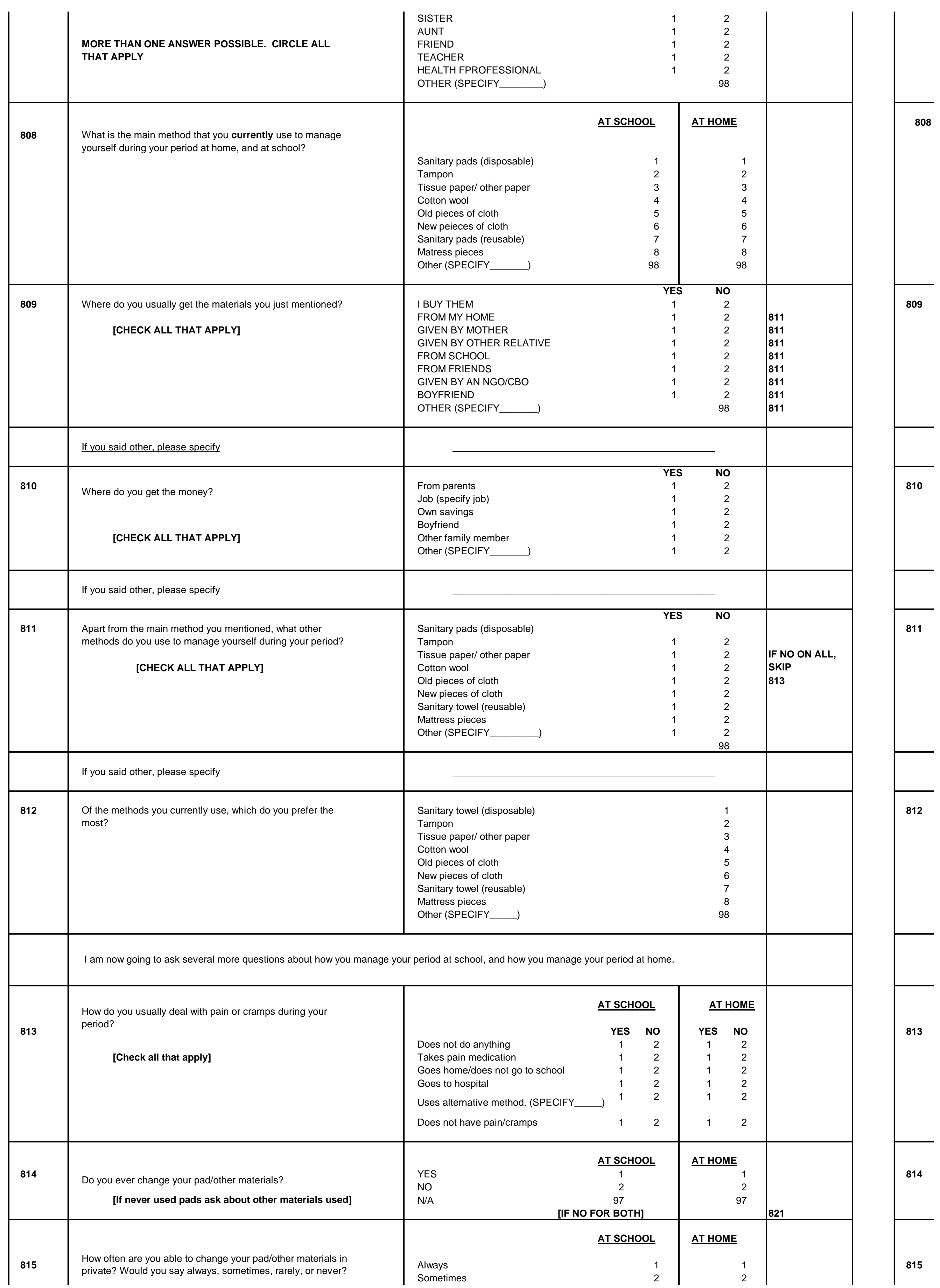




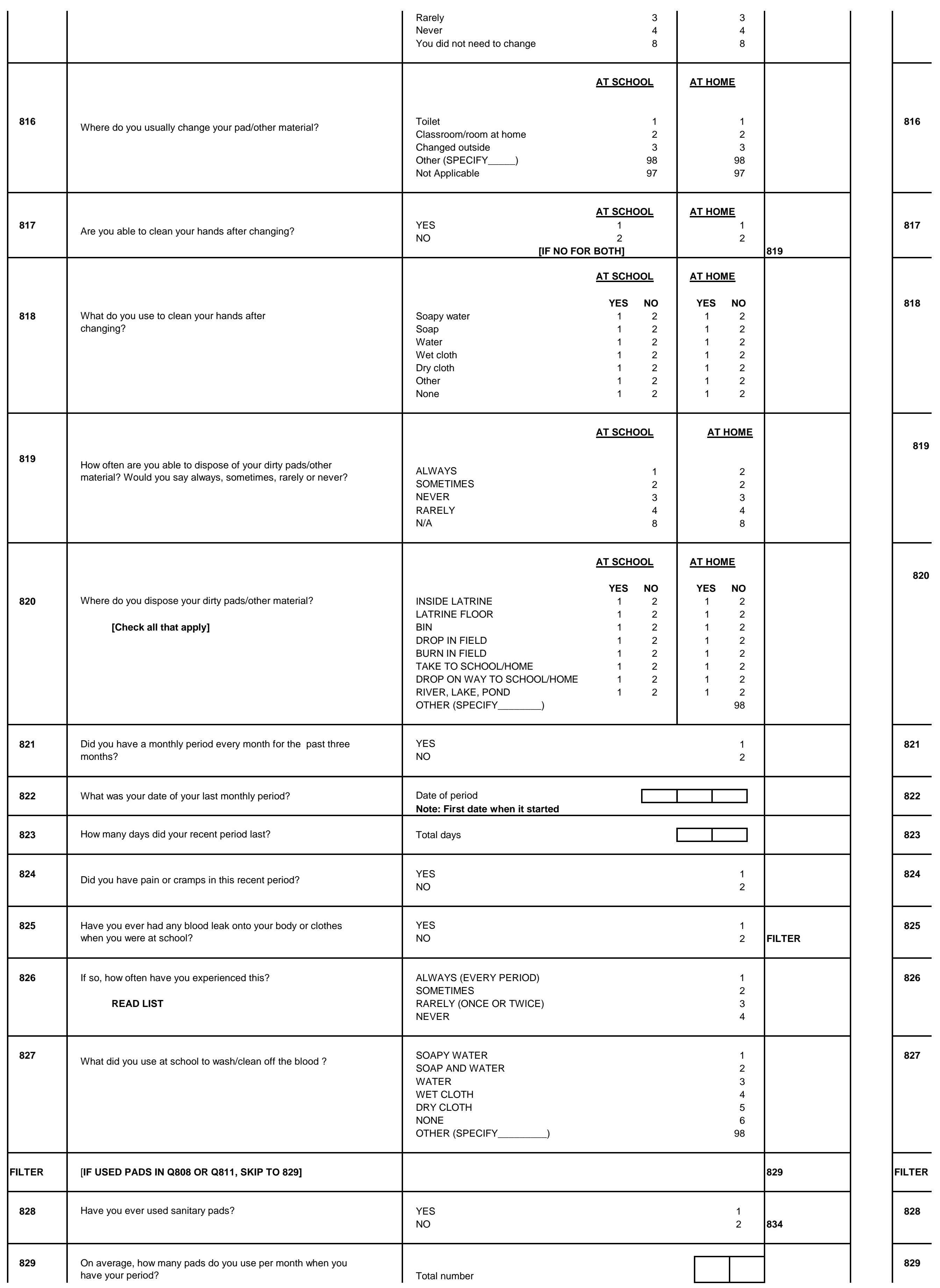




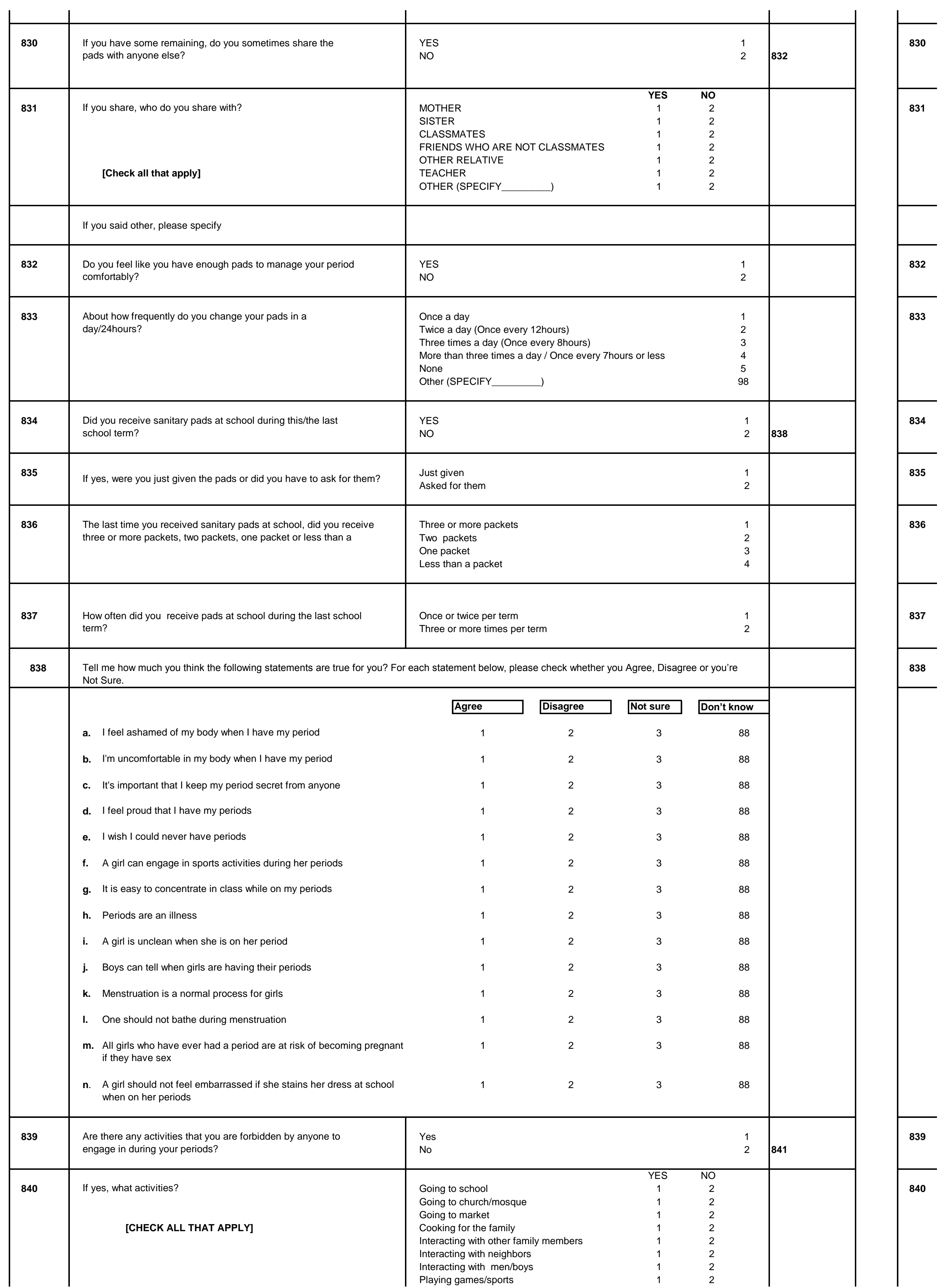




\begin{tabular}{|c|c|c|c|c|c|c|}
\hline & & $\begin{array}{l}\text { Fasting } \\
\text { Other (SPECIFY }\end{array}$ & $\begin{array}{l}1 \\
1\end{array}$ & $\begin{array}{l}2 \\
2\end{array}$ & & \\
\hline & If you said other, please specify & & & & & \\
\hline 841 & $\begin{array}{l}\text { Are there any activities that you choose not to engage in } \\
\text { during your periods? }\end{array}$ & $\begin{array}{l}\text { YES } \\
\text { NO }\end{array}$ & & $\begin{array}{l}1 \\
2\end{array}$ & 843 & 841 \\
\hline \multirow[t]{2}{*}{842} & $\begin{array}{l}\text { If yes, what activities? } \\
\qquad \text { [CHECK ALL THAT APPLY] }\end{array}$ & $\begin{array}{l}\text { Going to school } \\
\text { Going to church/mosque } \\
\text { Going to market } \\
\text { Cooking for the family } \\
\text { Interacting with other family members } \\
\text { Interacting with neighbors } \\
\text { Interacting with men/boys } \\
\text { Playing games/sports } \\
\text { Fasting } \\
\text { Other (SPECIFY }\end{array}$ & $\begin{array}{c}\text { YES } \\
1 \\
1 \\
1 \\
1 \\
1 \\
1 \\
1 \\
1 \\
1\end{array}$ & $\begin{array}{r}\text { NO } \\
2 \\
2 \\
2 \\
2 \\
2 \\
2 \\
2 \\
2 \\
2 \\
\\
98\end{array}$ & & 842 \\
\hline & If you said other, please specify & \multicolumn{3}{|l|}{ If you said other, please specify } & & \\
\hline 843 & $\begin{array}{l}\text { Within the past year, has anyone teased you about your } \\
\text { period? }\end{array}$ & $\begin{array}{l}\text { Yes } \\
\text { No }\end{array}$ & & & 901 & 843 \\
\hline 844 & \multicolumn{4}{|c|}{ SECTION 9: REPRODUCTIVE HEALTH KNOWLEDGE AND CONTRACEPTION } & & \\
\hline 901 & $\begin{array}{l}\text { Please tell me if the following statements are true or false? } \\
\text { Can pregnancy occur after kissing or hugging? }\end{array}$ & $\begin{array}{l}\text { TRUE } \\
\text { FALSE } \\
\text { DON'T KNOW } \\
\text { NO RESPONSE }\end{array}$ & & $\begin{array}{r}1 \\
2 \\
88 \\
96\end{array}$ & & 901 \\
\hline 902 & $\begin{array}{l}\text { Is it possible for a woman get pregnant on the very first time } \\
\text { she has sexual intercourse? }\end{array}$ & $\begin{array}{l}\text { TRUE } \\
\text { FALSE } \\
\text { DON'T KNOW } \\
\text { NO RESPONSE }\end{array}$ & & $\begin{array}{r}1 \\
2 \\
88 \\
96\end{array}$ & & 902 \\
\hline 903 & $\begin{array}{l}\text { Girls undergo pubertal changes. Can you please tell me, what } \\
\text { are the physical changes that a girl experiences in transition } \\
\text { from childhood to adolescence? } \\
\text { [CHECK ALL THAT APPLY] }\end{array}$ & $\begin{array}{l}\text { Hair grows in different parts of body } \\
\text { Breasts develop } \\
\text { Acne appears } \\
\text { Menstruation starts } \\
\text { Rapid physical development } \\
\text { Voice Changes } \\
\text { Don't know }\end{array}$ & $\begin{array}{r}\mathrm{YE} \\
1 \\
1 \\
1 \\
1 \\
1 \\
1\end{array}$ & $\begin{array}{r}\mathrm{NO} \\
2 \\
2 \\
2 \\
2 \\
2 \\
2 \\
\\
\\
\\
88\end{array}$ & & 903 \\
\hline 904 & $\begin{array}{l}\text { From one menstrual period to the next, are there certain days when a } \\
\text { woman is more likely to become pregnant if she has sexual } \\
\text { intecourse? }\end{array}$ & $\begin{array}{l}\text { YES } \\
\text { NO } \\
\text { DON'T KNOW }\end{array}$ & & $\begin{array}{r}1 \\
2 \\
88\end{array}$ & $\begin{array}{l}906 \\
906\end{array}$ & 904 \\
\hline 905 & $\begin{array}{l}\text { Is this time just before her period begins, during her period, right after } \\
\text { her period has ended, or two weeks after her period? }\end{array}$ & $\begin{array}{l}\text { JUST BEFORE HER PERIOD BEGINS } \\
\text { DURING HER PERIOD } \\
\text { RIGHT AFTER HER PERIOD ENDS } \\
\text { HALFWAY BETWEEN TWO PERIODS } \\
\text { OTHER(SPECIFY }\end{array}$ & & $\begin{array}{l}1 \\
2 \\
3 \\
4 \\
98 \\
\end{array}$ & & 905 \\
\hline 906 & $\begin{array}{l}\text { Please tell me if the following statements are true or false? } \\
\text { Menstruation typically occurs once a month? }\end{array}$ & $\begin{array}{l}\text { TRUE } \\
\text { FALSE } \\
\text { DON'T KNOW }\end{array}$ & & $\begin{array}{r}1 \\
2 \\
88\end{array}$ & & 906 \\
\hline 907 & $\begin{array}{l}\text { It is healthy to have some variation in vaginal discharge throughout } \\
\text { your menstrual cycle }\end{array}$ & $\begin{array}{l}\text { TRUE } \\
\text { FALSE } \\
\text { DON'T KNOW }\end{array}$ & & $\begin{array}{r}1 \\
2 \\
88\end{array}$ & & 907 \\
\hline
\end{tabular}




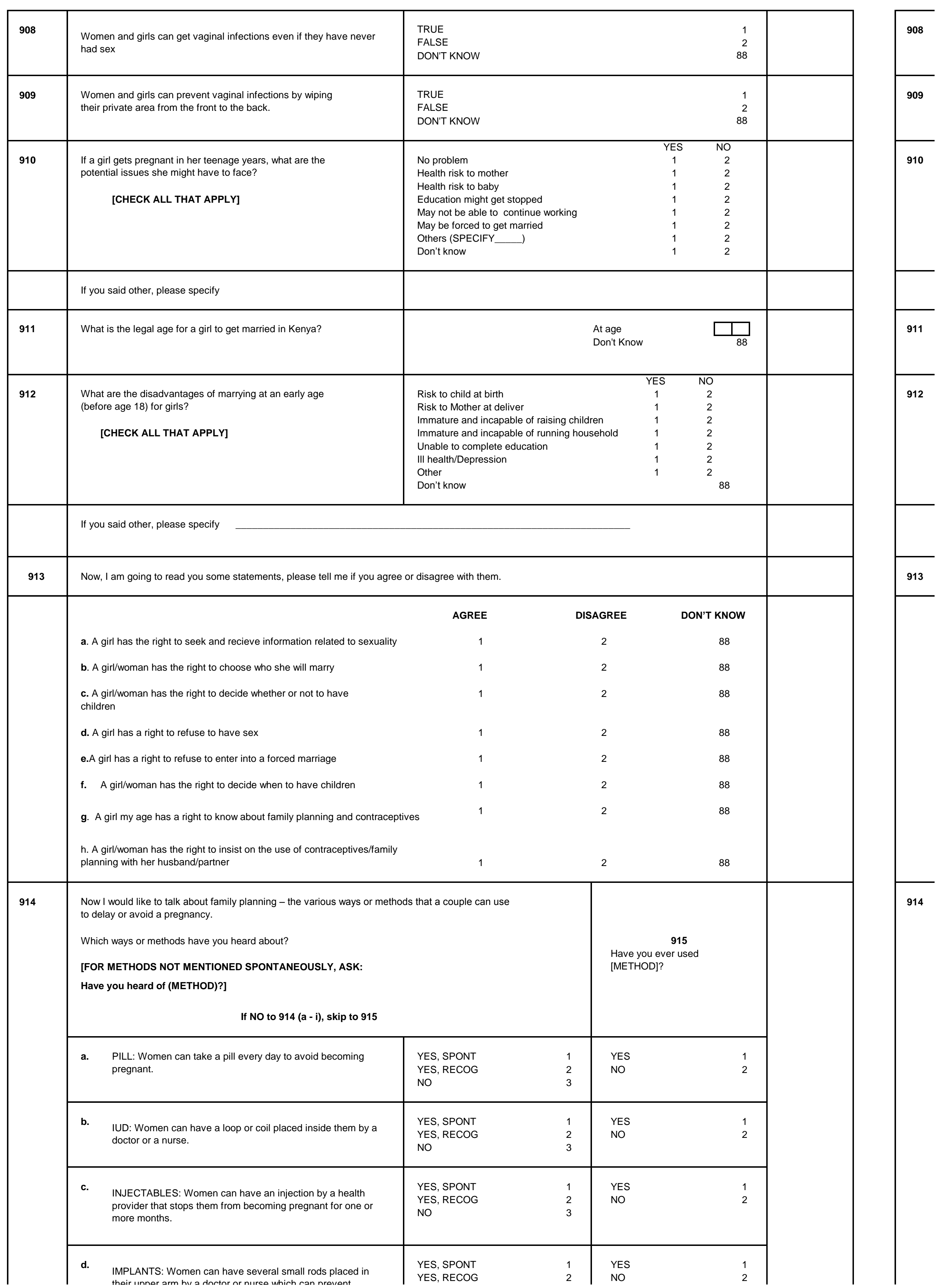




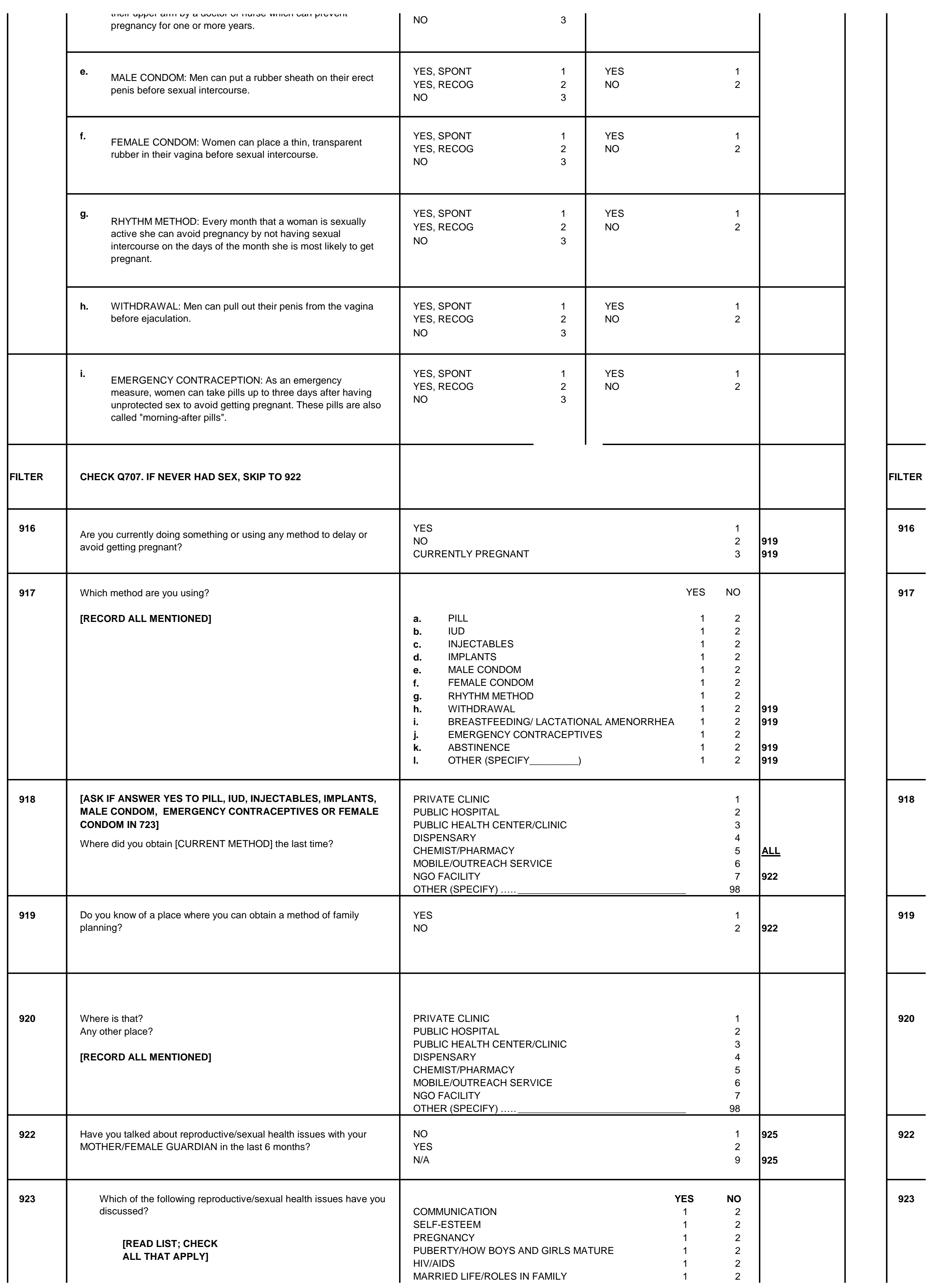




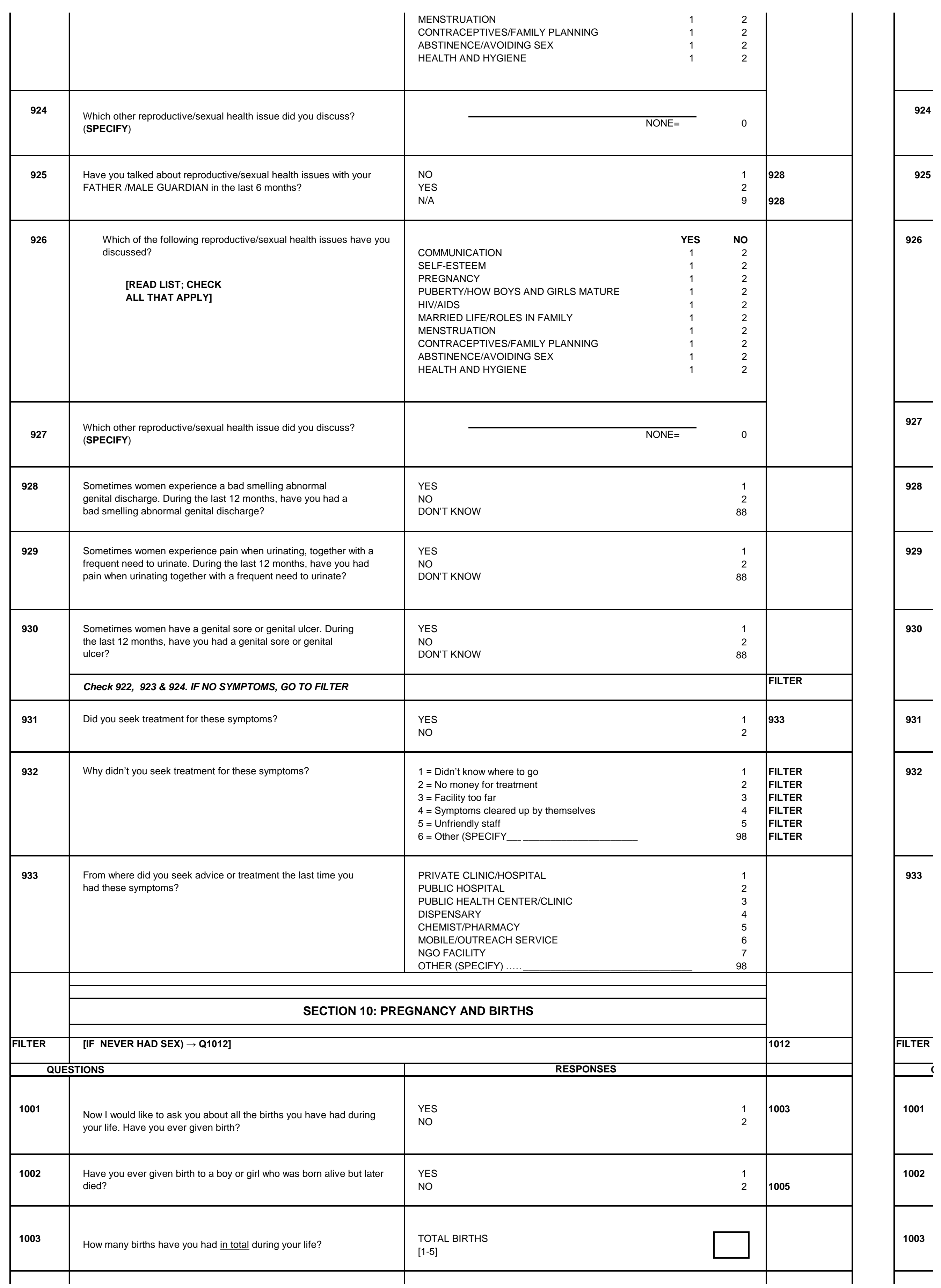


Version 8MAR2017

\begin{tabular}{|c|c|c|c|c|c|}
\hline 1005 & $\begin{array}{l}\text { How old were you when you first gave birth/had a } \\
\text { miscarriage/still birth }\end{array}$ & & $\begin{array}{l}\text { Age } \\
\text { Don't Know }\end{array}$ & & 1005 \\
\hline 1004 & $\begin{array}{l}\text { Have you ever had a pregnancy that miscarried, or ended in a still } \\
\text { birth? }\end{array}$ & $\begin{array}{l}\text { YES } \\
\text { NO }\end{array}$ & $\begin{array}{ll}1 & \square \\
2 & 88 \\
& {[1-19]}\end{array}$ & & 1004 \\
\hline 1006 & Are you pregnant now? & $\begin{array}{l}\text { YES } \\
\text { NO } \\
\text { UNSURE/DON'T KNOW }\end{array}$ & $\begin{array}{r}1 \\
2 \\
88\end{array}$ & $\begin{array}{l}\text { F3 } \\
\text { F3 }\end{array}$ & 1006 \\
\hline 1007 & $\begin{array}{l}\text { How many months pregnant are you? } \\
\text { [RECORD NUMBER OF COMPLETED MONTHS] }\end{array}$ & $\begin{array}{l}\text { MONTHS } \\
{[0-10]} \\
\text { DON'T KNOW }\end{array}$ & 88 & & 1007 \\
\hline F3 & [IF ALL OF 1001, 1002, 1005, AND $1006=\mathrm{NO} \rightarrow 1012]$ & & & & F3 \\
\hline 1008 & $\begin{array}{l}\text { When you found out you were pregnant for the very first time, were } \\
\text { you still attending school? }\end{array}$ & $\begin{array}{l}\text { YES } \\
\text { NO }\end{array}$ & $\begin{array}{l}1 \\
2\end{array}$ & & 1008 \\
\hline 1009 & $\begin{array}{l}\text { When you found out you were pregnant for the very first time, were } \\
\text { you single, engaged or married? }\end{array}$ & $\begin{array}{l}\text { SINGLE } \\
\text { ENGAGED } \\
\text { MARRIED }\end{array}$ & $\begin{array}{l}1 \\
2 \\
3\end{array}$ & & 1009 \\
\hline 1010 & $\begin{array}{l}\text { At the time you first became pregnant, did you want to become } \\
\text { pregnant then, did you want to wait until later, or did you not want the } \\
\text { pregnancy at all? }\end{array}$ & $\begin{array}{l}\text { THEN } \\
\text { ONE TO TWO YEARS LATER } \\
\text { THREE OR MORE YEARS LATER } \\
\text { NOT AT ALL }\end{array}$ & $\begin{array}{l}1 \\
2 \\
3 \\
4\end{array}$ & & 1010 \\
\hline 1011 & $\begin{array}{l}\text { Sometimes a girl becomes pregnant when she does not want to be. } \\
\text { Have you ever been pregnant when you did not want to be? }\end{array}$ & $\begin{array}{l}\text { YES } \\
\text { NO }\end{array}$ & $\begin{array}{l}1 \\
2\end{array}$ & & 1011 \\
\hline 1012 & $\begin{array}{l}\text { Now I have a question about the future. Would you like to have } \\
\text { (a/another) child, or would you prefer not to have any (more) } \\
\text { children? }\end{array}$ & $\begin{array}{l}\text { YES } \\
\text { NO } \\
\text { DON'T KNOW }\end{array}$ & $\begin{array}{r}1 \\
2 \\
88\end{array}$ & 1014 & 1012 \\
\hline 1013 & At what age would you like to have (a/another) child? & 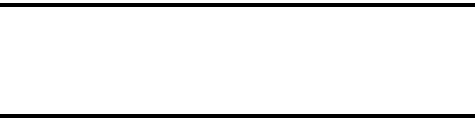 & $\begin{array}{l}\text { Age } \\
\text { Don't Know }\end{array}$ & & 1013 \\
\hline 1014 & $\begin{array}{l}\text { If you became pregnant now, how happy would you be? Would you } \\
\text { say, very happy, somewhat happy, or not happy at all? }\end{array}$ & $\begin{array}{l}\text { VERY HAPPY } \\
\text { SOMEWHAT HAPPY } \\
\text { NOT HAPPY AT ALL }\end{array}$ & $\begin{array}{l}1 \\
2 \\
3\end{array}$ & & 1014 \\
\hline & SECTION 11: HI & IDS AND OTHER STIS & NSES & & \\
\hline 1101 & $\begin{array}{l}\text { Now I would like to talk about something else. Have you ever heard } \\
\text { of an illness called AIDS? }\end{array}$ & $\begin{array}{l}\text { YES } \\
\text { NO }\end{array}$ & $\begin{array}{l}1 \\
2\end{array}$ & 1117 & 1101 \\
\hline 1102 & $\begin{array}{l}\text { Can people reduce their chances of getting the AIDS virus by having } \\
\text { just one uninfected sex partner who has no other sex partners? }\end{array}$ & $\begin{array}{l}\text { YES } \\
\text { NO } \\
\text { DON'T KNOW }\end{array}$ & $\begin{array}{l}1 \\
2 \\
88\end{array}$ & & 1102 \\
\hline 1103 & Can people get the AIDS virus from mosquito bites? & $\begin{array}{l}\text { YES } \\
\text { NO } \\
\text { DON'T KNOW }\end{array}$ & $\begin{array}{l}1 \\
2 \\
88\end{array}$ & & 1103 \\
\hline 1104 & $\begin{array}{l}\text { Can people reduce their chance of getting the AIDS virus by using a } \\
\text { condom every time they have sex? }\end{array}$ & $\begin{array}{l}\text { YES } \\
\text { NO } \\
\text { DON'T KNOW }\end{array}$ & $\begin{array}{l}1 \\
2 \\
88\end{array}$ & & 1104 \\
\hline 1105 & $\begin{array}{l}\text { Can people get the AIDS virus by sharing food with a person who has } \\
\text { AIDS? }\end{array}$ & $\begin{array}{l}\text { YES } \\
\text { NO } \\
\text { DON'T KNOW }\end{array}$ & $\begin{array}{l}1 \\
2 \\
88\end{array}$ & & 1105 \\
\hline 1106 & $\begin{array}{l}\text { Can people reduce their chance of getting the AIDS virus by not } \\
\text { having sexual intercourse at all? }\end{array}$ & $\begin{array}{l}\text { YES } \\
\text { NO } \\
\text { DON'T KNOW }\end{array}$ & $\begin{array}{c}1 \\
2 \\
88\end{array}$ & & 1106 \\
\hline 1107 & $\begin{array}{l}\text { Can people get the AIDS virus because of witchcraft or other } \\
\text { supernatural means? }\end{array}$ & $\begin{array}{l}\text { YES } \\
\text { NO } \\
\text { DON'T KNOW }\end{array}$ & $\begin{array}{c}1 \\
2 \\
88\end{array}$ & & 1107 \\
\hline 1108 & ant & YES & 1 & & 1108 \\
\hline
\end{tabular}




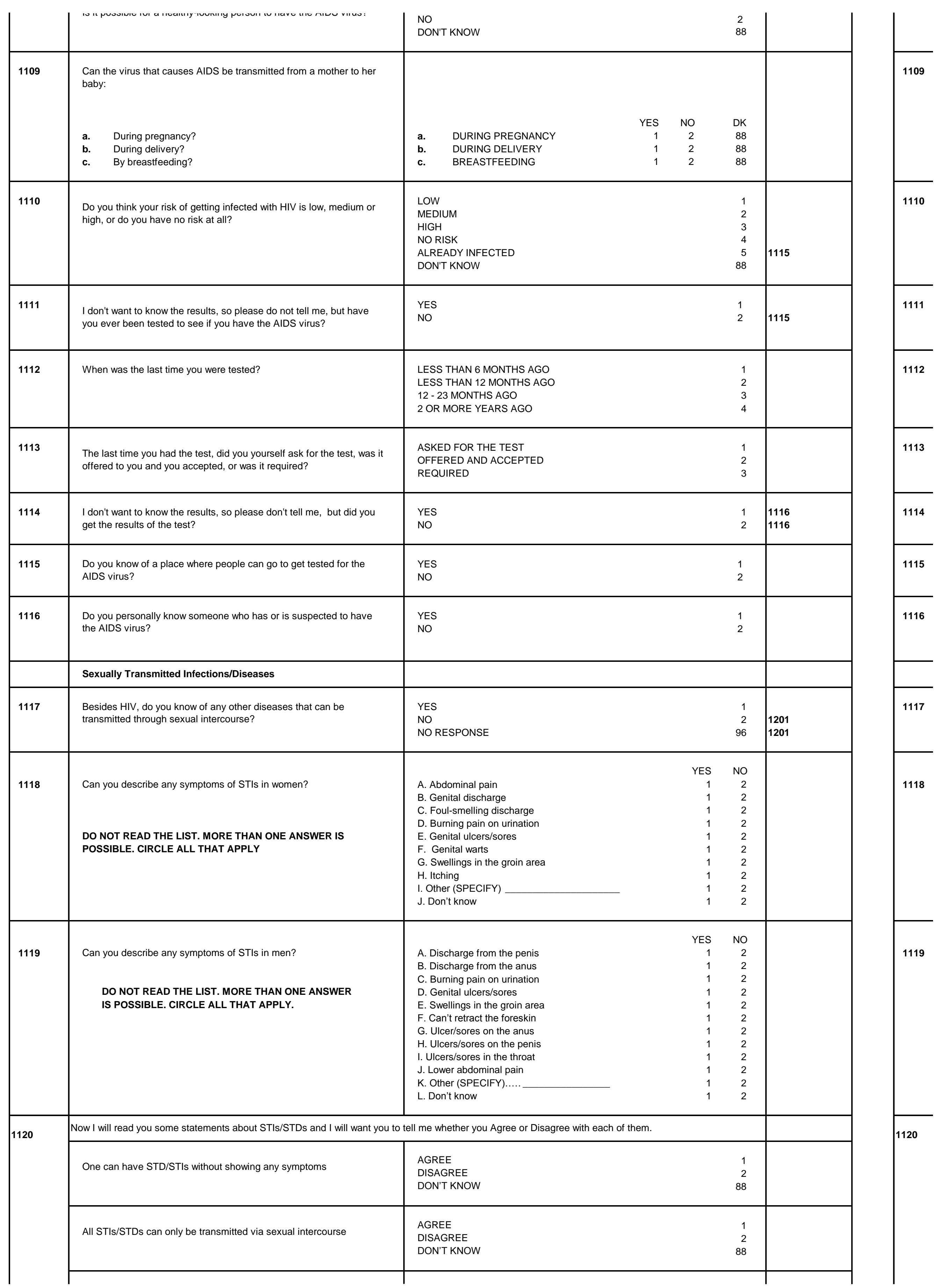




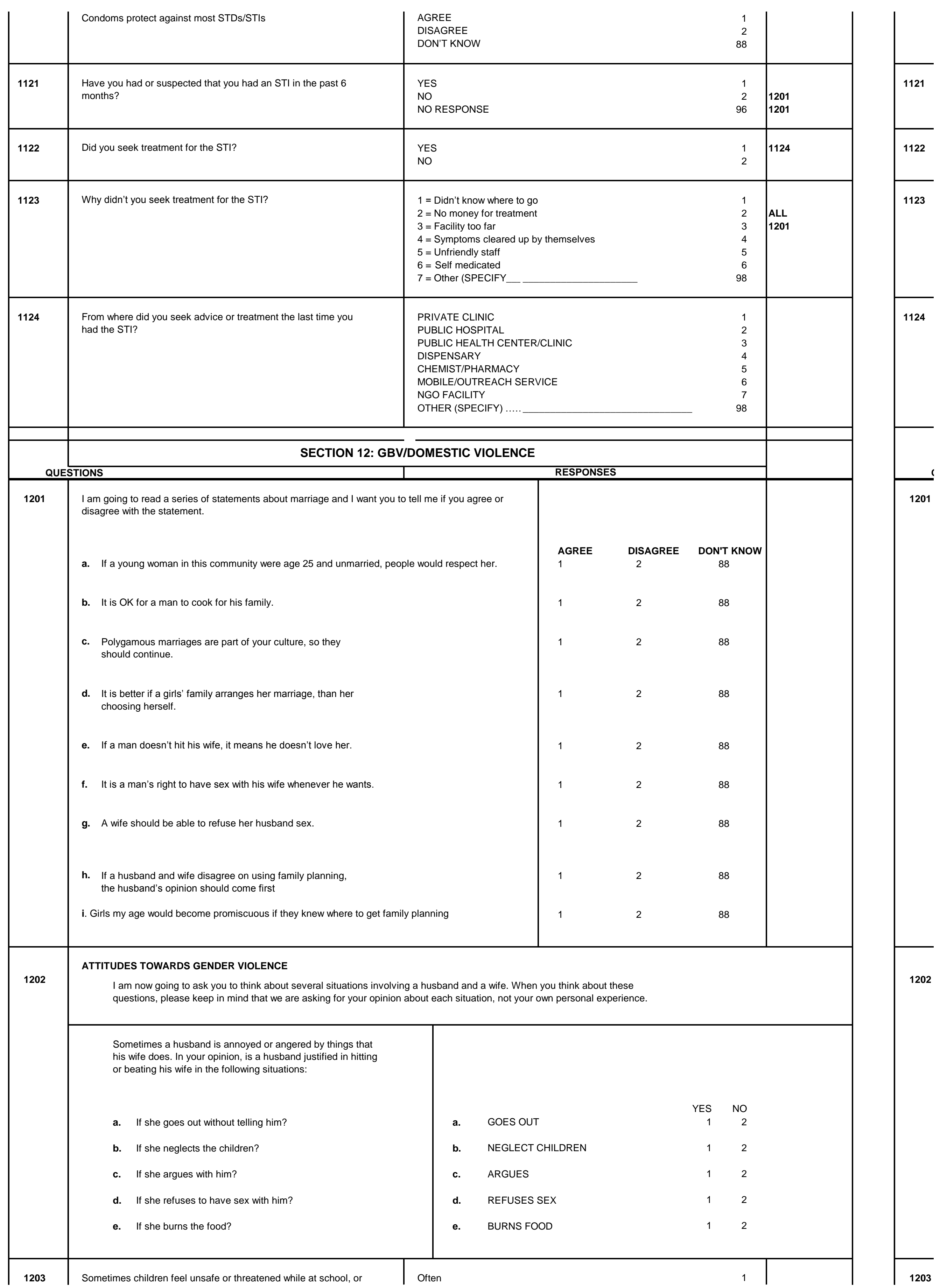




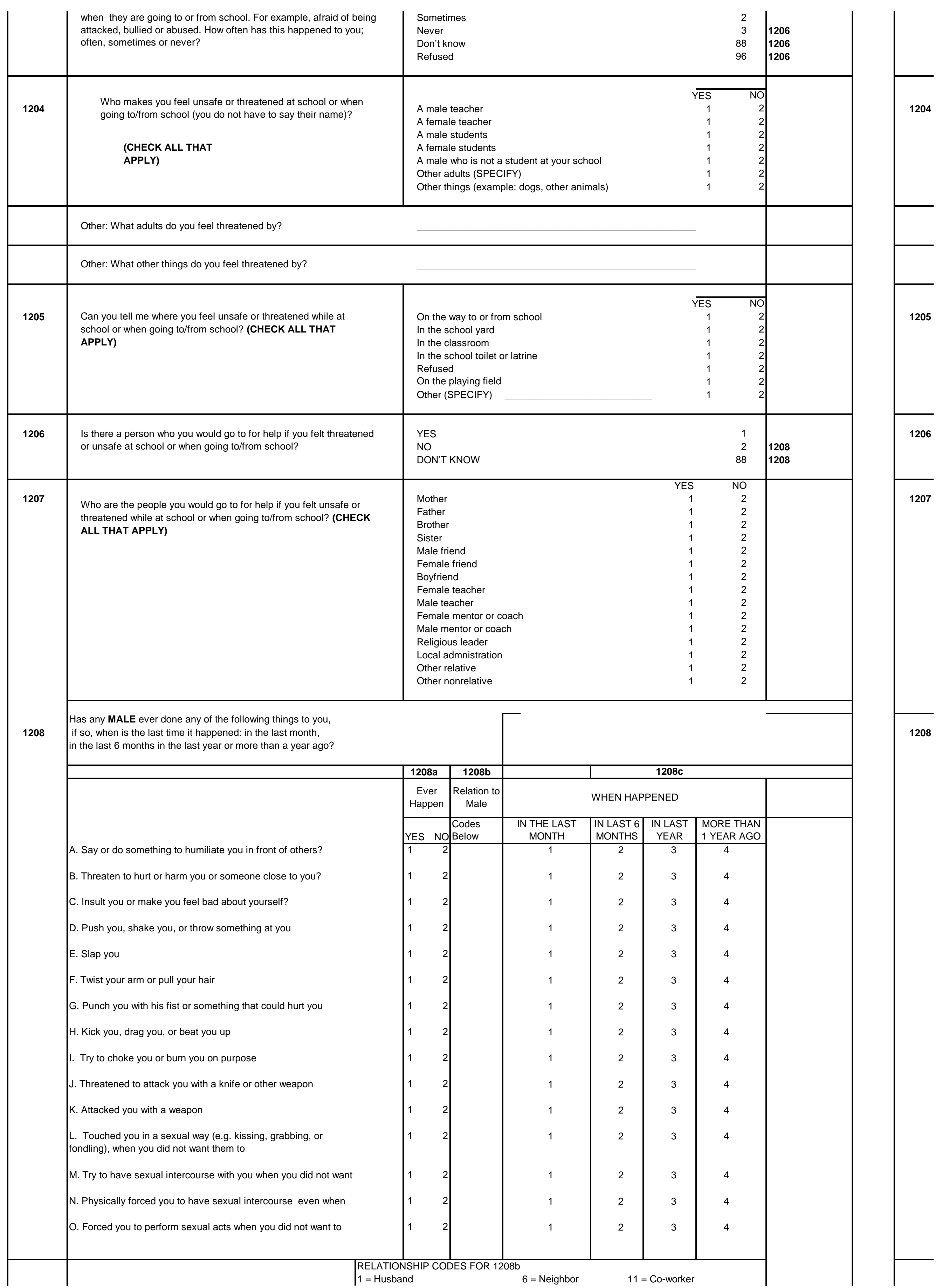




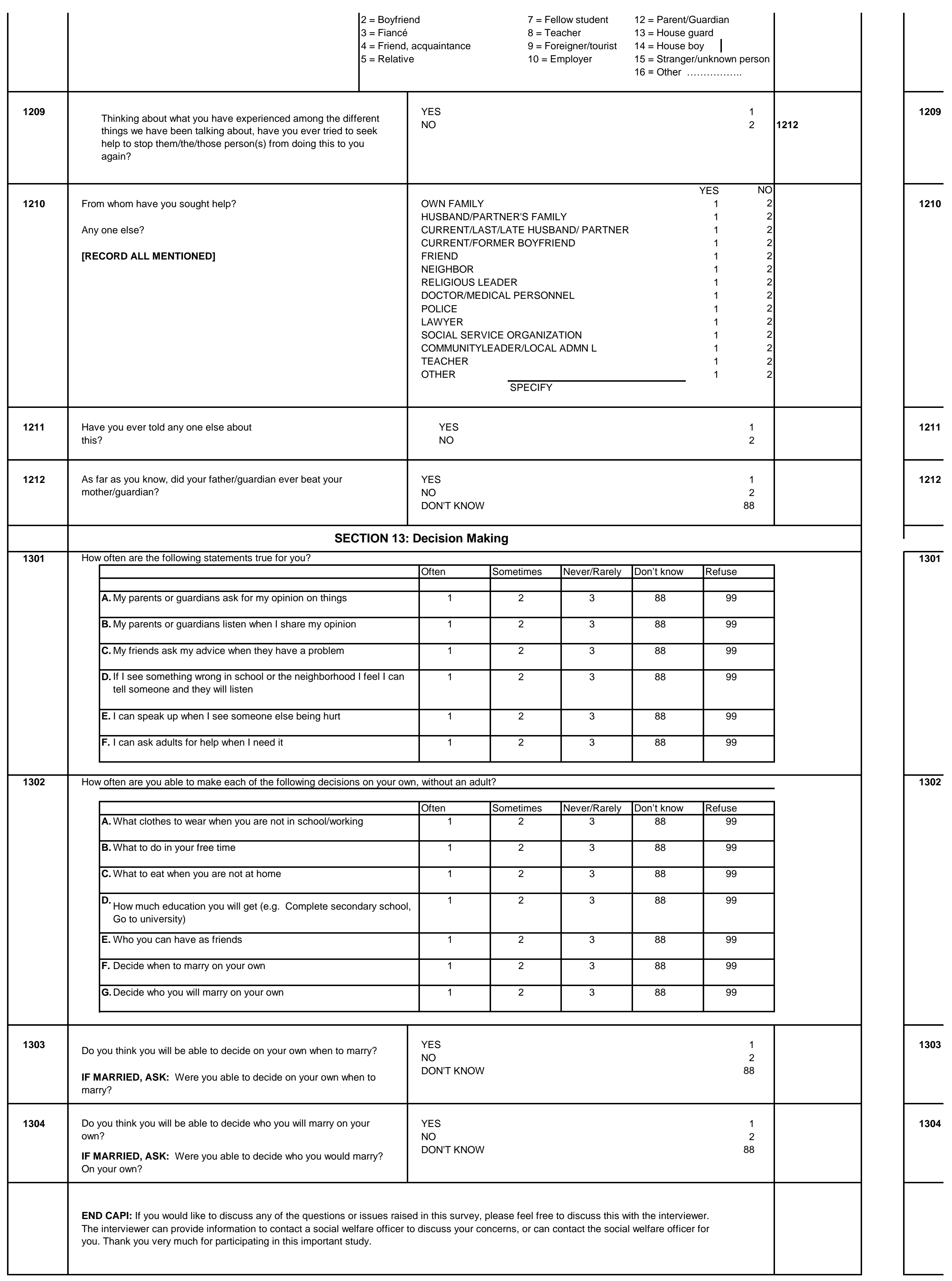


SWAHILI

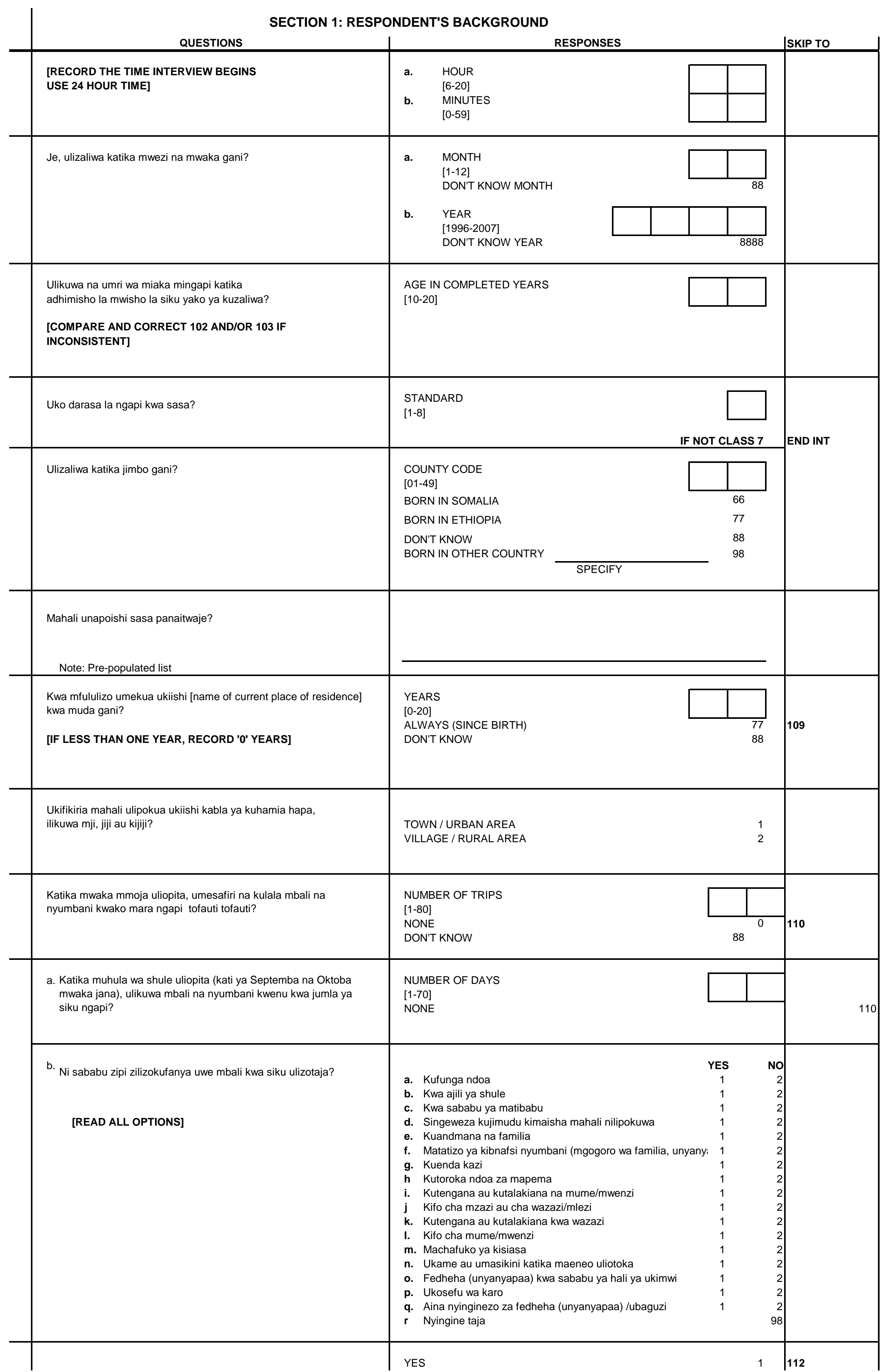




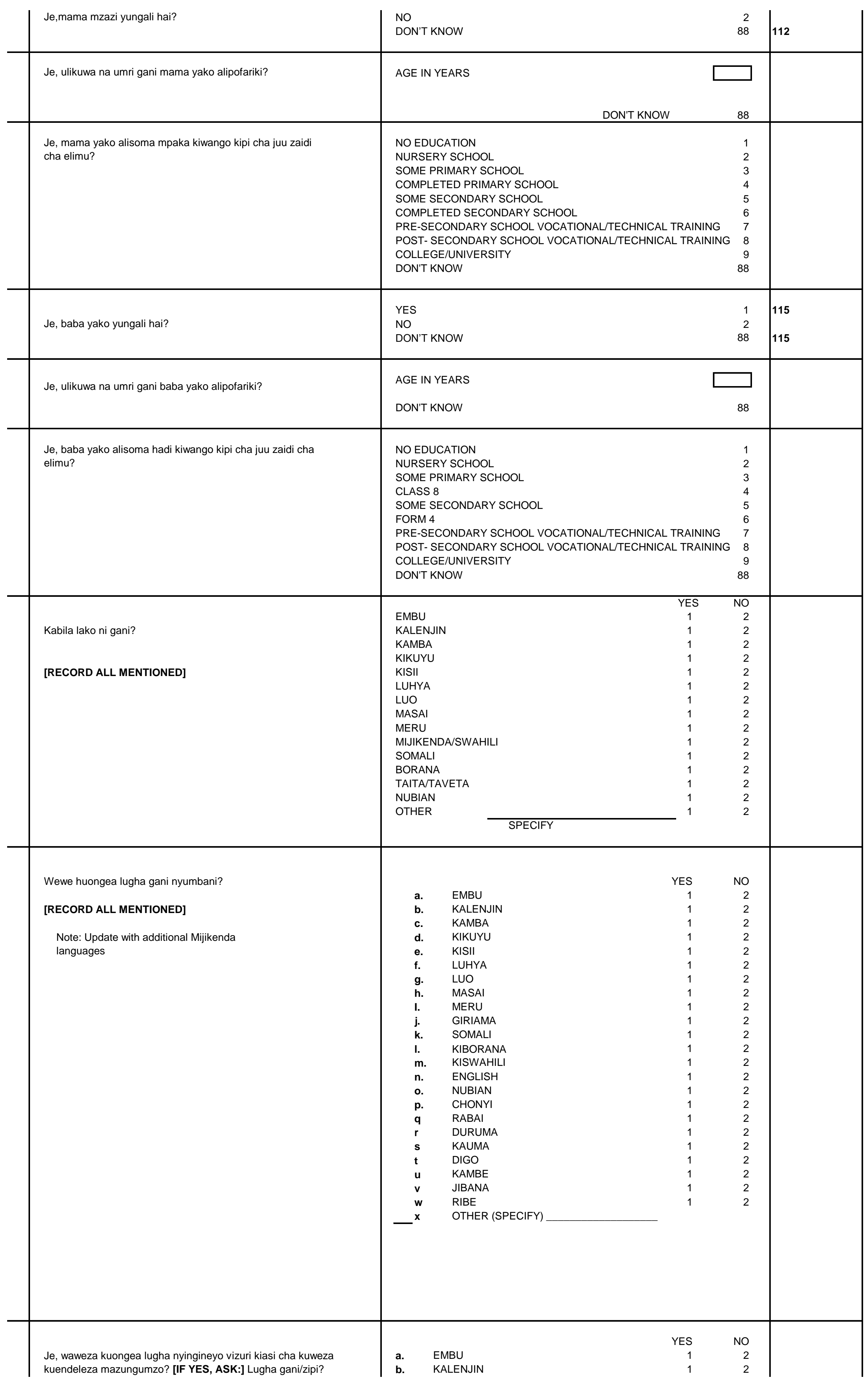




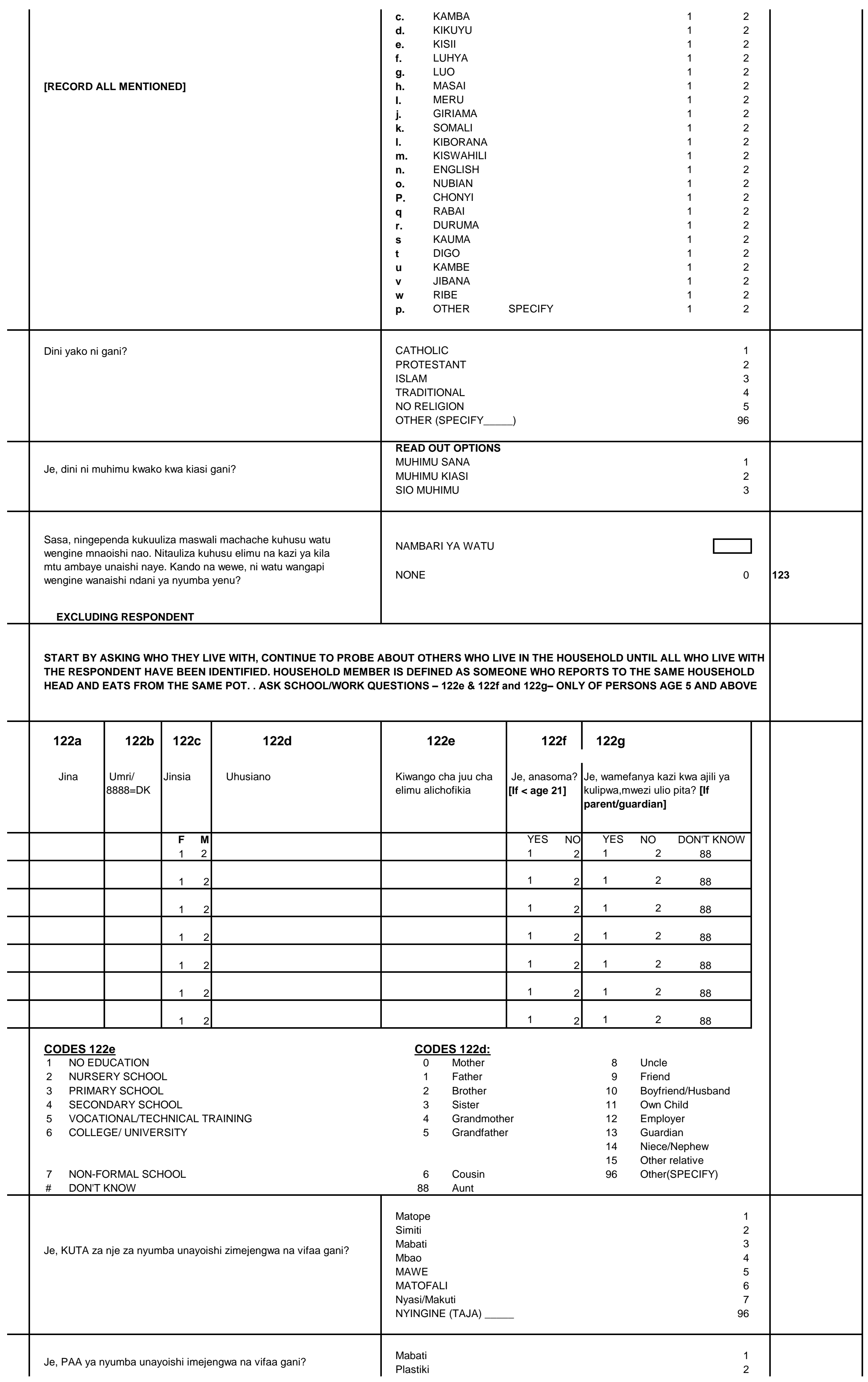




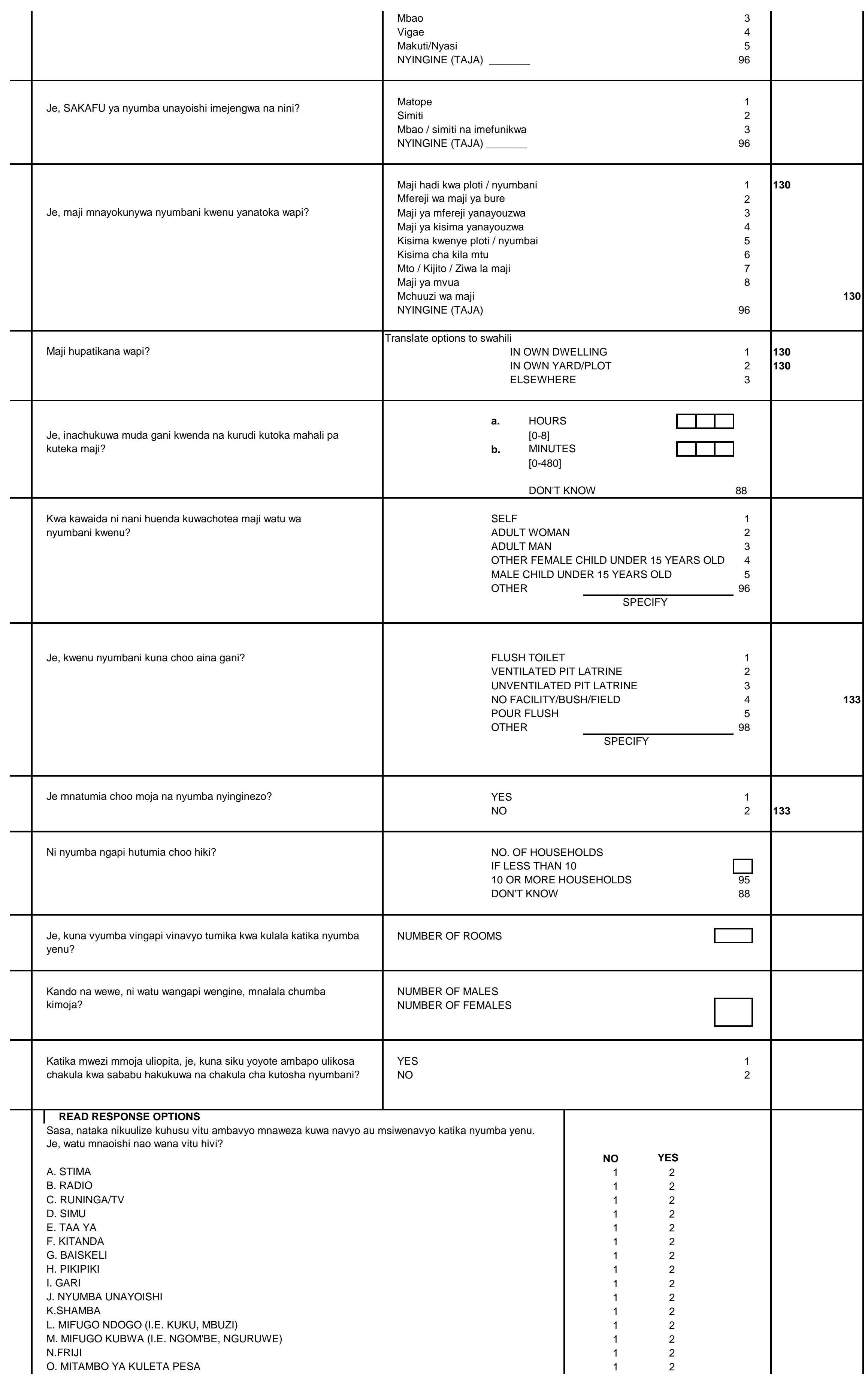




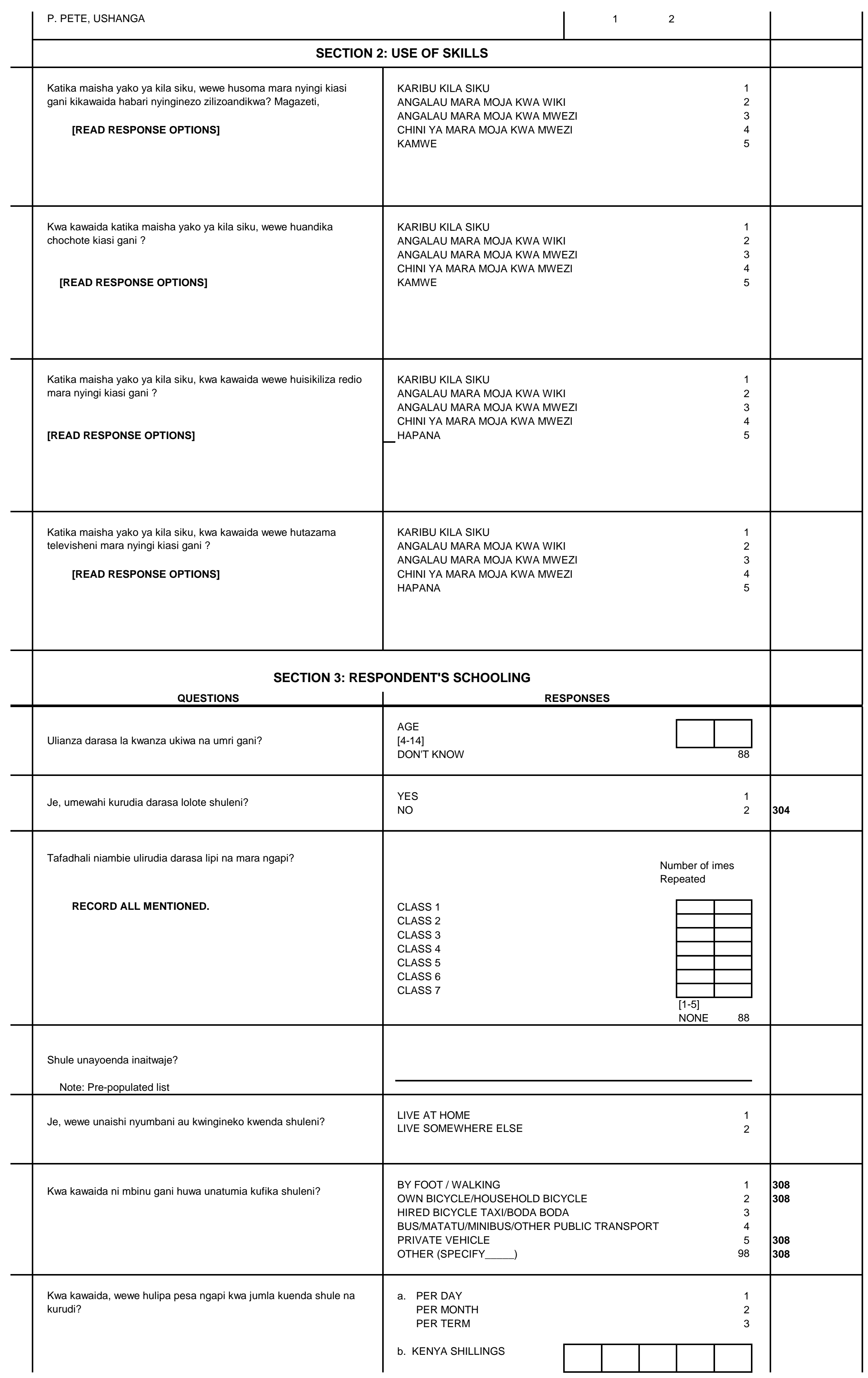




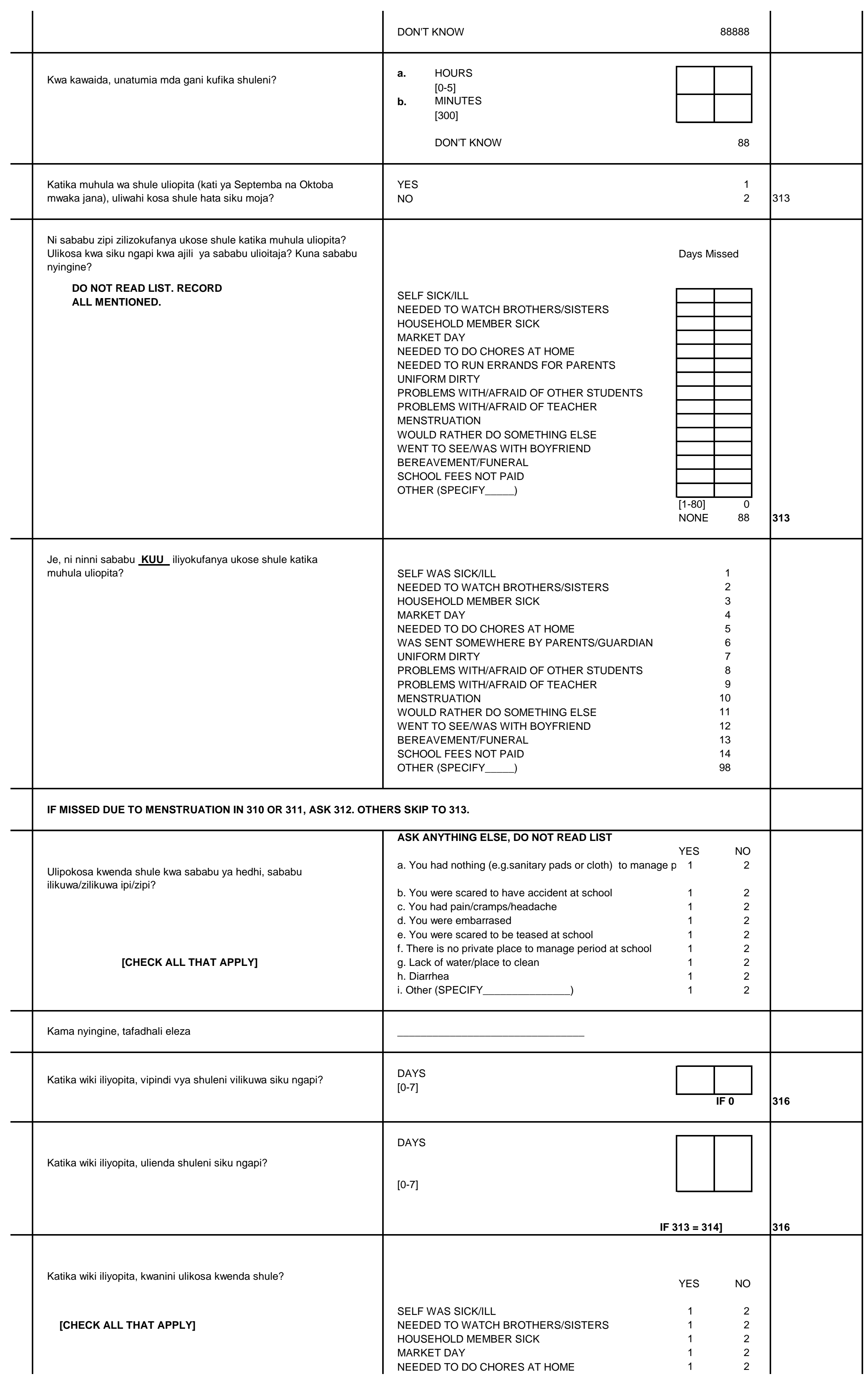




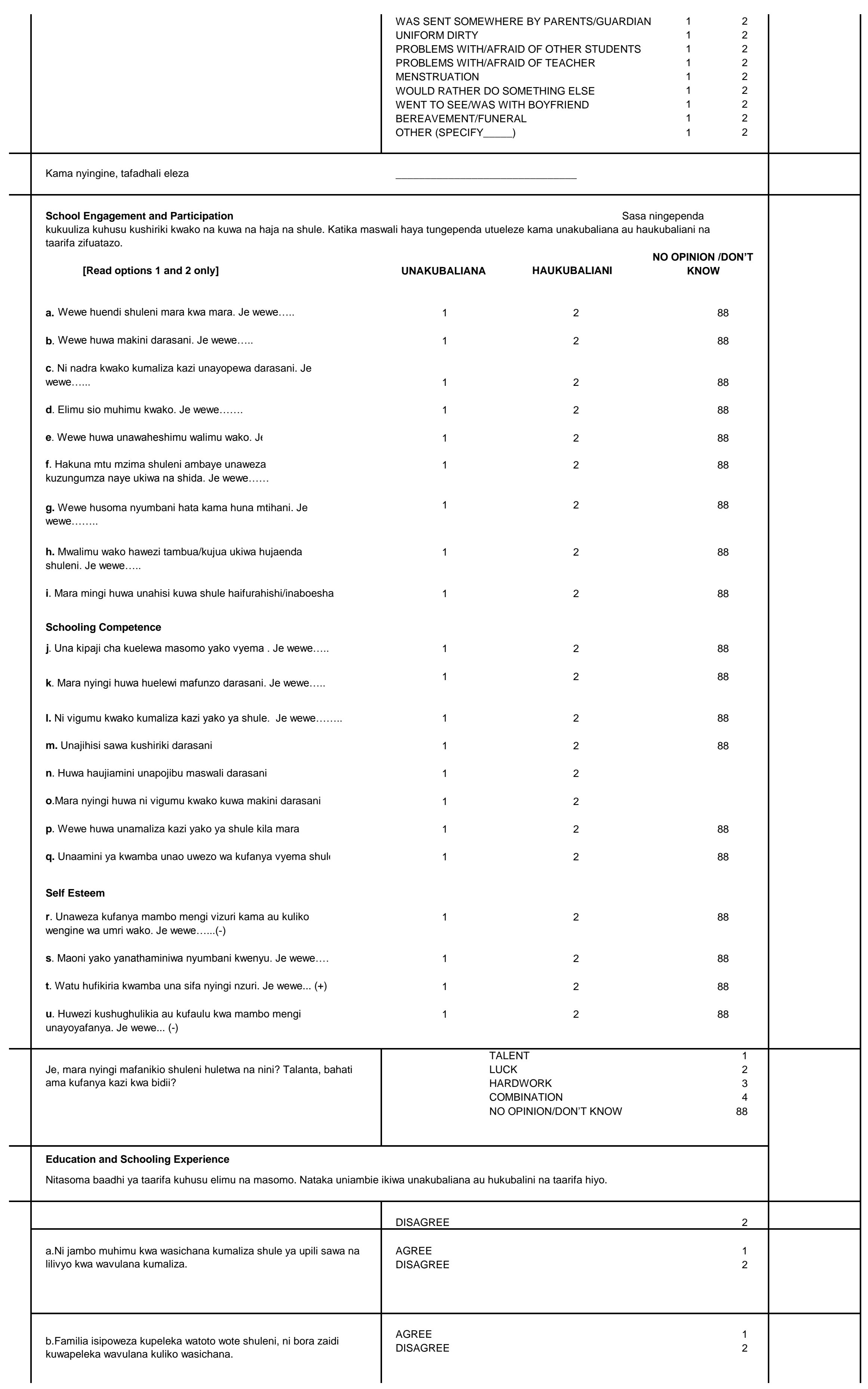




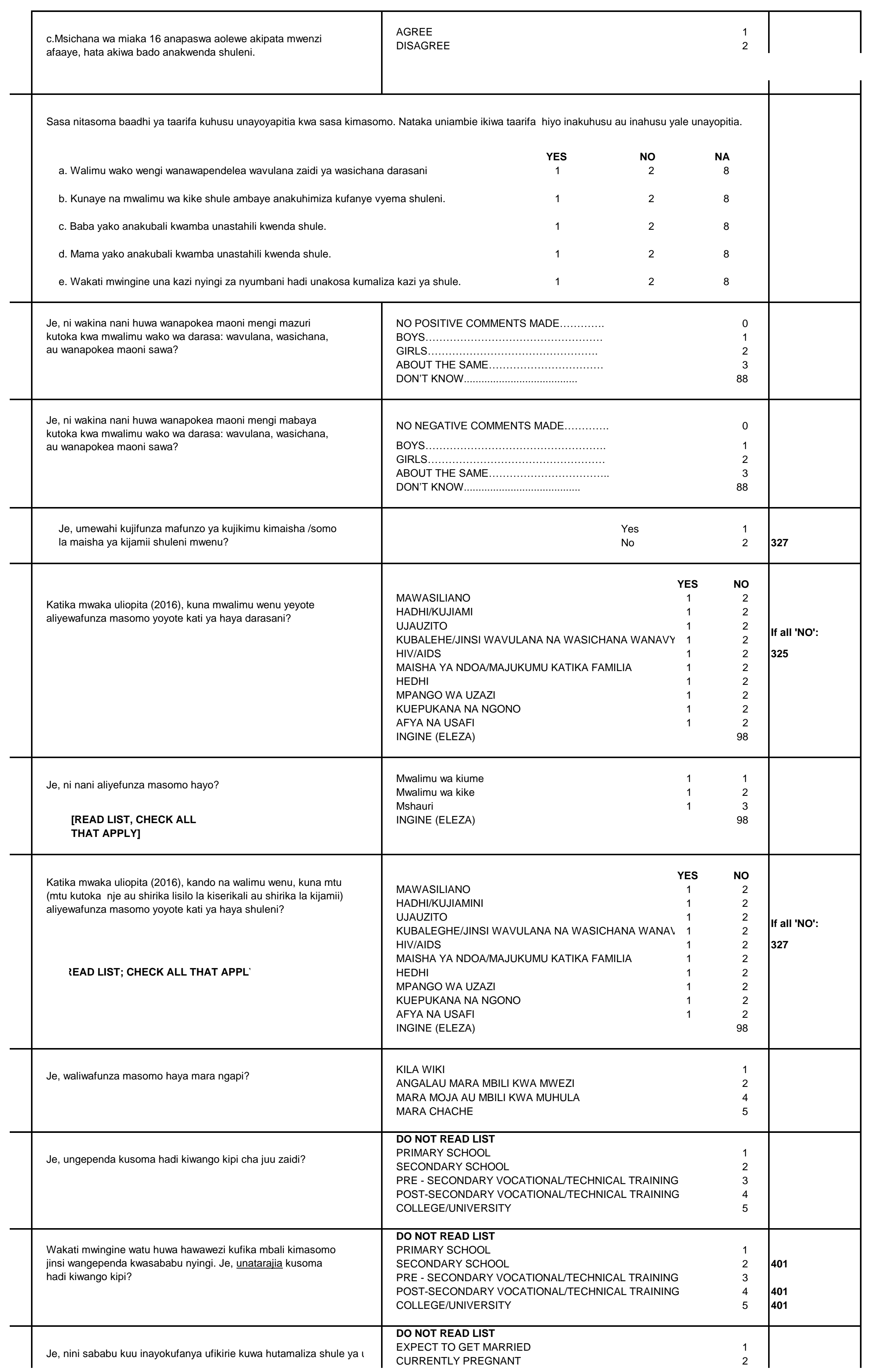




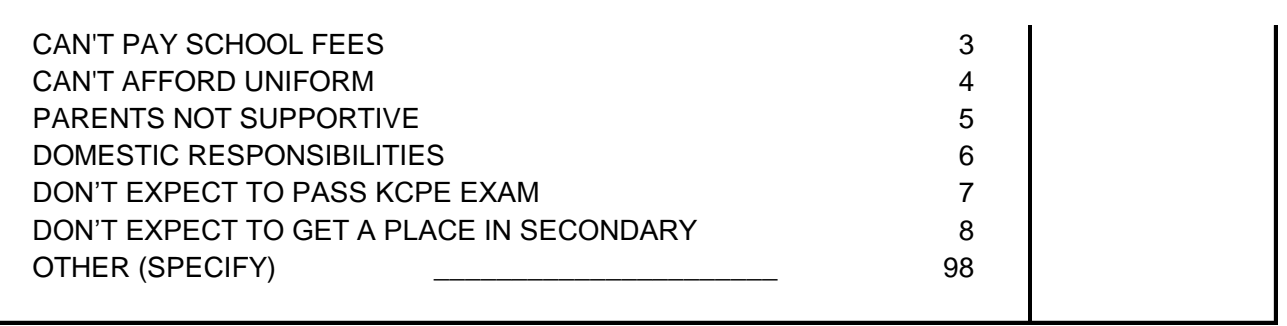

SECTION 4: WORK, SAVINGS, AND FINANCIAL LITERACY

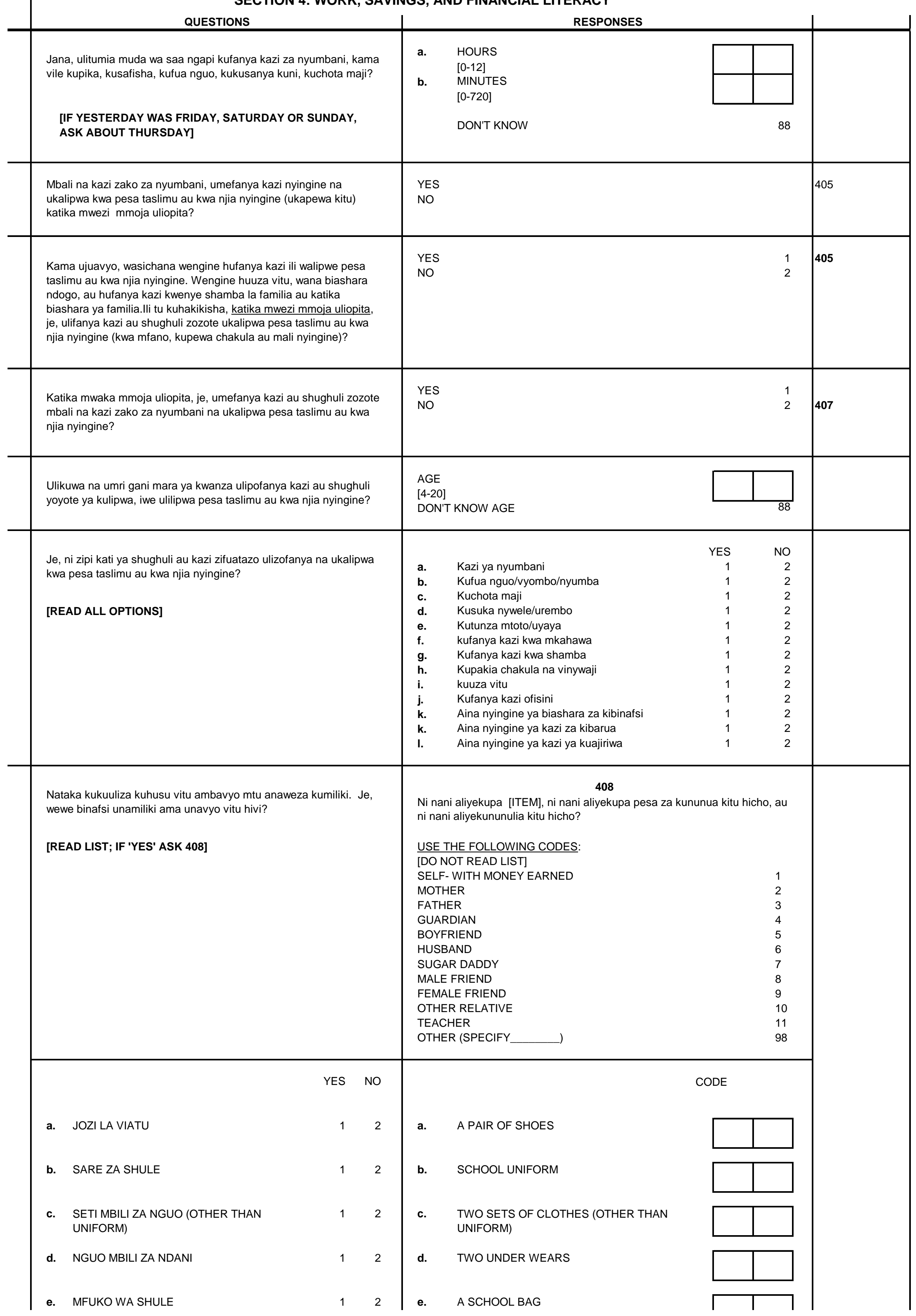




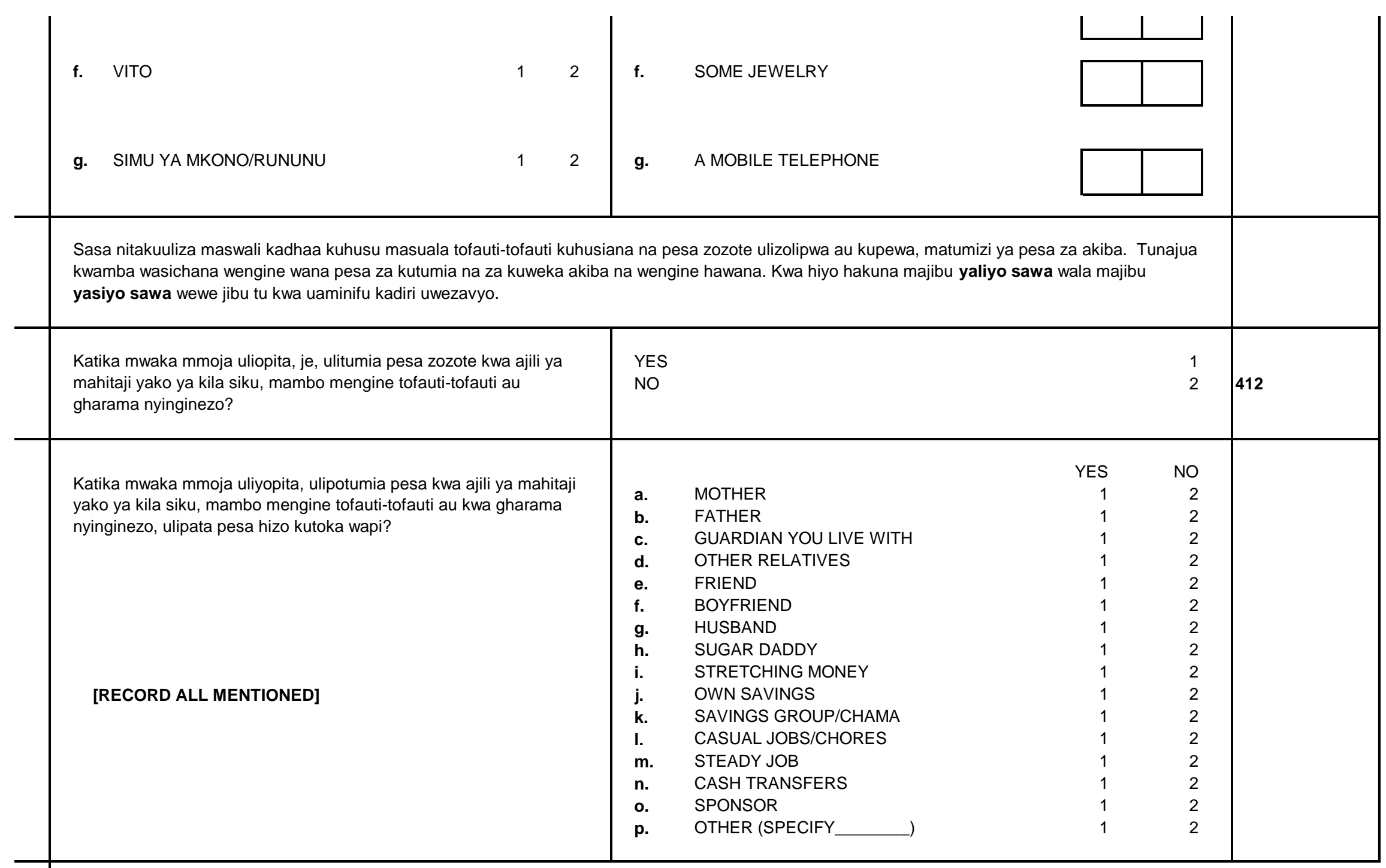

Katika MWEZI mmoja uliopita, ulitumia pesa kununua hiki kitu?

(READ EACH ITEM ALOUD. ASK YES OR NO)

(IF NO ON A, GO TO NEXT ITEM, SKIP B, C)

NOTE: Clarify if it is a personal spending need or for someone else if it is not clear from

the type of expenditure)

\begin{tabular}{|c|c|c|c|}
\hline & $\begin{array}{l}\text { A. } \\
\text { MWEZI mmoja uliopita, } \\
\text { ulitumia pesa kununua } \\
\text { hii kitu? }\end{array}$ & $\begin{array}{l}\text { B. } \\
\text { Ulitumia takriban } \\
\text { kiasi gani cha pesa kwa hii kitu } \\
\text { katika MWEZI } \\
\text { mmoja? }\end{array}$ & $\begin{array}{l}\text { C. } \\
\text { Wewe mwenyewe hujiamulia kununua kitu } \\
\text { hiki, huamua } \\
\text { pamoja na mtu mwengine au mtu } \\
\text { mwengine hukuamulia? }\end{array}$ \\
\hline & & Ksh & $\begin{array}{l}1=\text { YOU ALONE } \\
2=\text { YOU TOGETHER WITH SOMEONE } \\
3=\text { SOMEONE ELSE }\end{array}$ \\
\hline $\begin{array}{l}\text { a CHAKULA, } \\
\text { CHIPS, } \\
\text { PEREMENDE,VI } \\
\text { NYWAJI/SODA } \\
\text { ZAKO }\end{array}$ & $\begin{array}{ll}\text { YES } & 1 \\
\text { NO } & 2\end{array}$ & & \\
\hline $\begin{array}{l}\text { b } \text { CHAKULA, } \\
\text { CHIPS, PIPI, } \\
\text { VINYWAJI/SODA } \\
\text { ZA MTU } \\
\text { MWENGINE }\end{array}$ & $\begin{array}{ll}\text { YES } & 1 \\
\text { NO } & 2\end{array}$ & & \\
\hline $\begin{array}{l}\text { NGUO/VIATU } \\
\text { ZAKO }\end{array}$ & 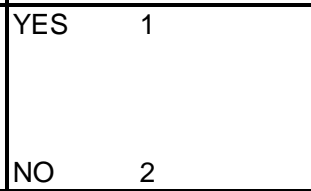 & & \\
\hline $\begin{array}{l}\text { d NGUO/VIATU ZA } \\
\text { MTU } \\
\text { MWENGINE }\end{array}$ & $\begin{array}{ll}\text { YES } & 1 \\
\text { NO } & 2\end{array}$ & & \\
\hline $\begin{array}{l}\text { e TAULO YA } \\
\text { HEDHI }\end{array}$ & \begin{tabular}{|ll} 
YES & 1 \\
NO & 2
\end{tabular} & & \\
\hline $\begin{array}{l}\text { f } \text { BIDHAA ZA } \\
\text { UREMBO/ } \\
\text { HUDUMA YA } \\
\text { UREMBO }\end{array}$ & $\begin{array}{ll}\text { YES } & 1 \\
\text { NO } & 2\end{array}$ & & \\
\hline $\begin{array}{l}\text { g CREDIT/AIRTIM } \\
\mathrm{E}\end{array}$ & $\begin{array}{ll}\text { YES } & 1 \\
\text { NO } & 2\end{array}$ & & \\
\hline
\end{tabular}




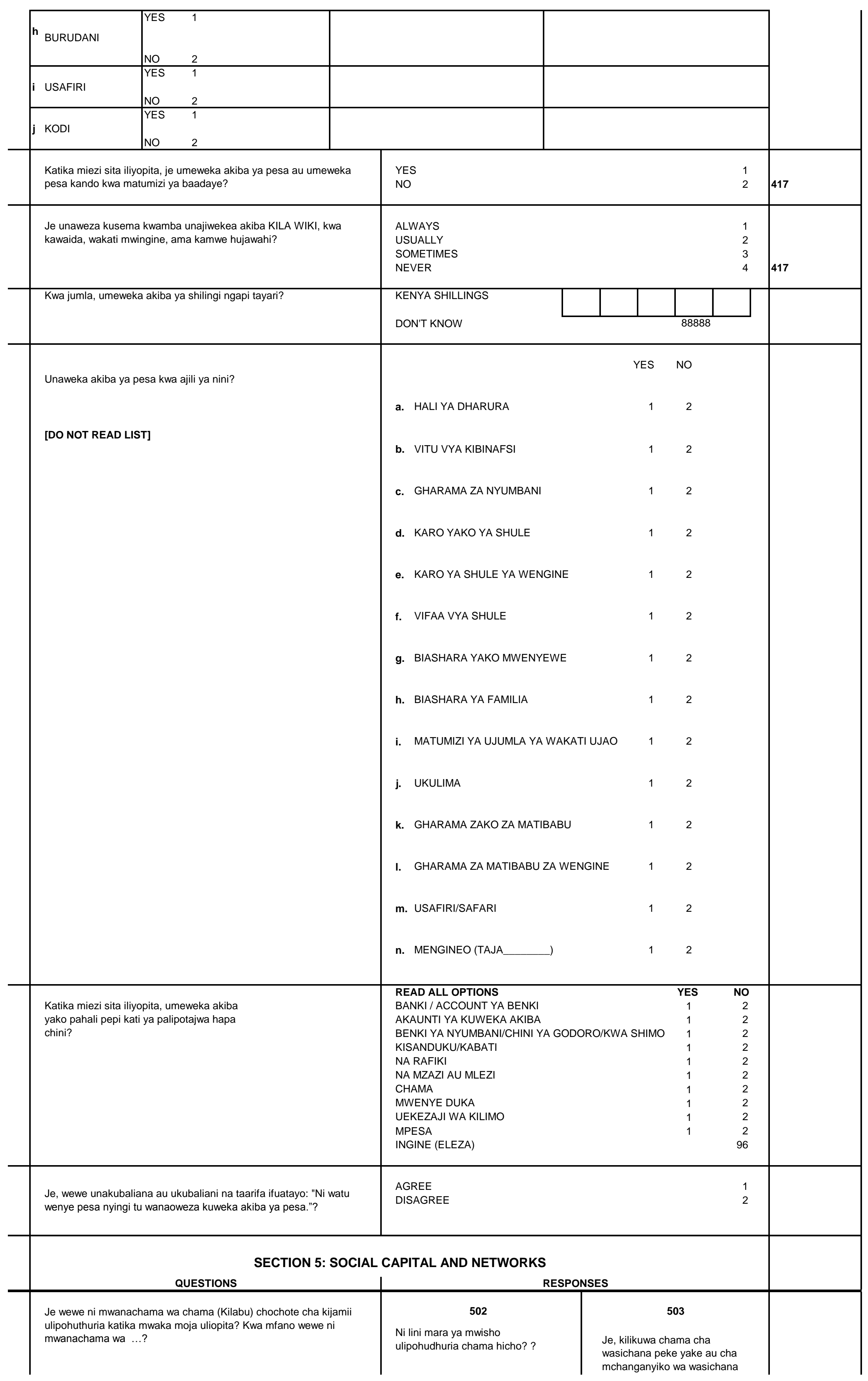




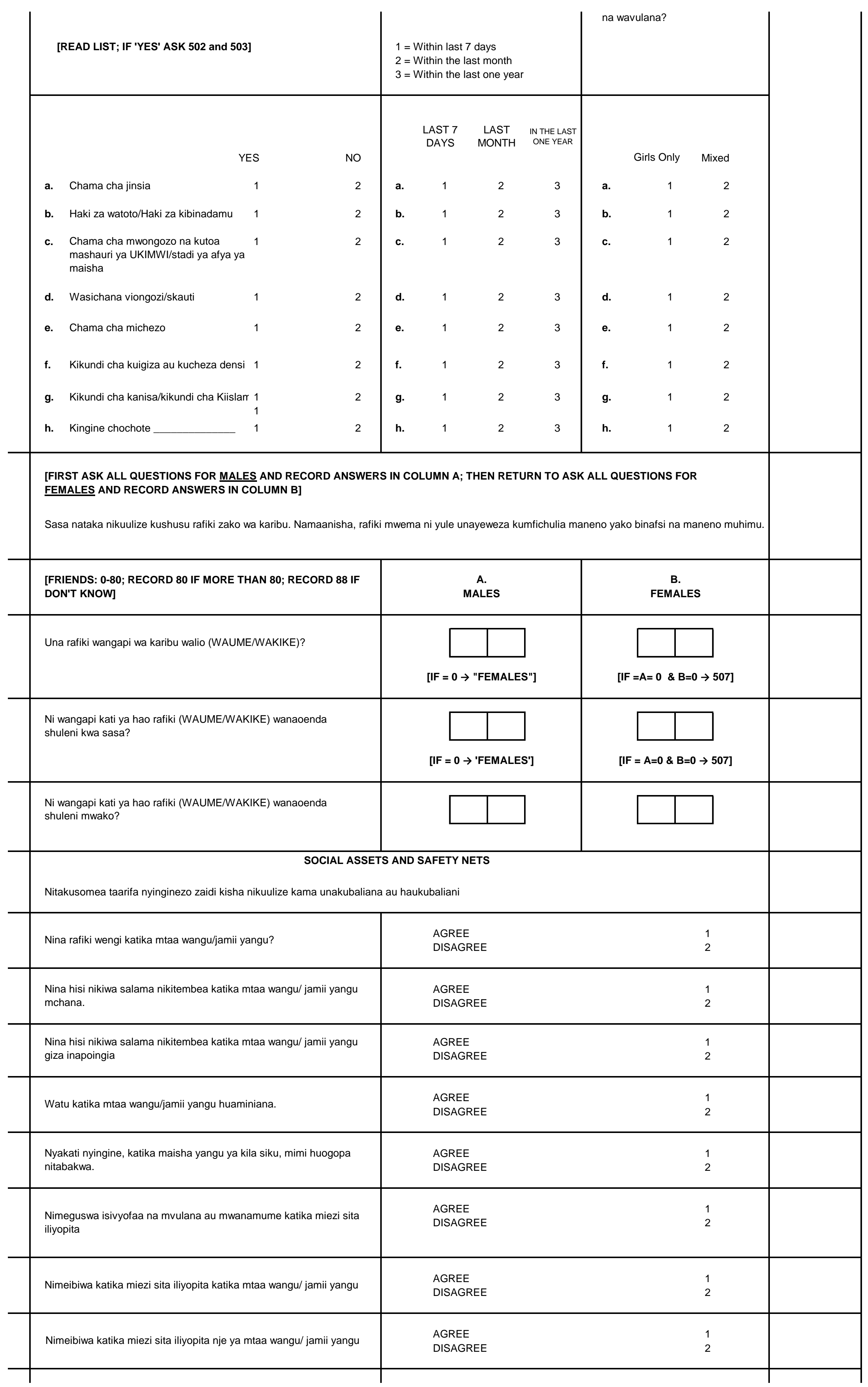




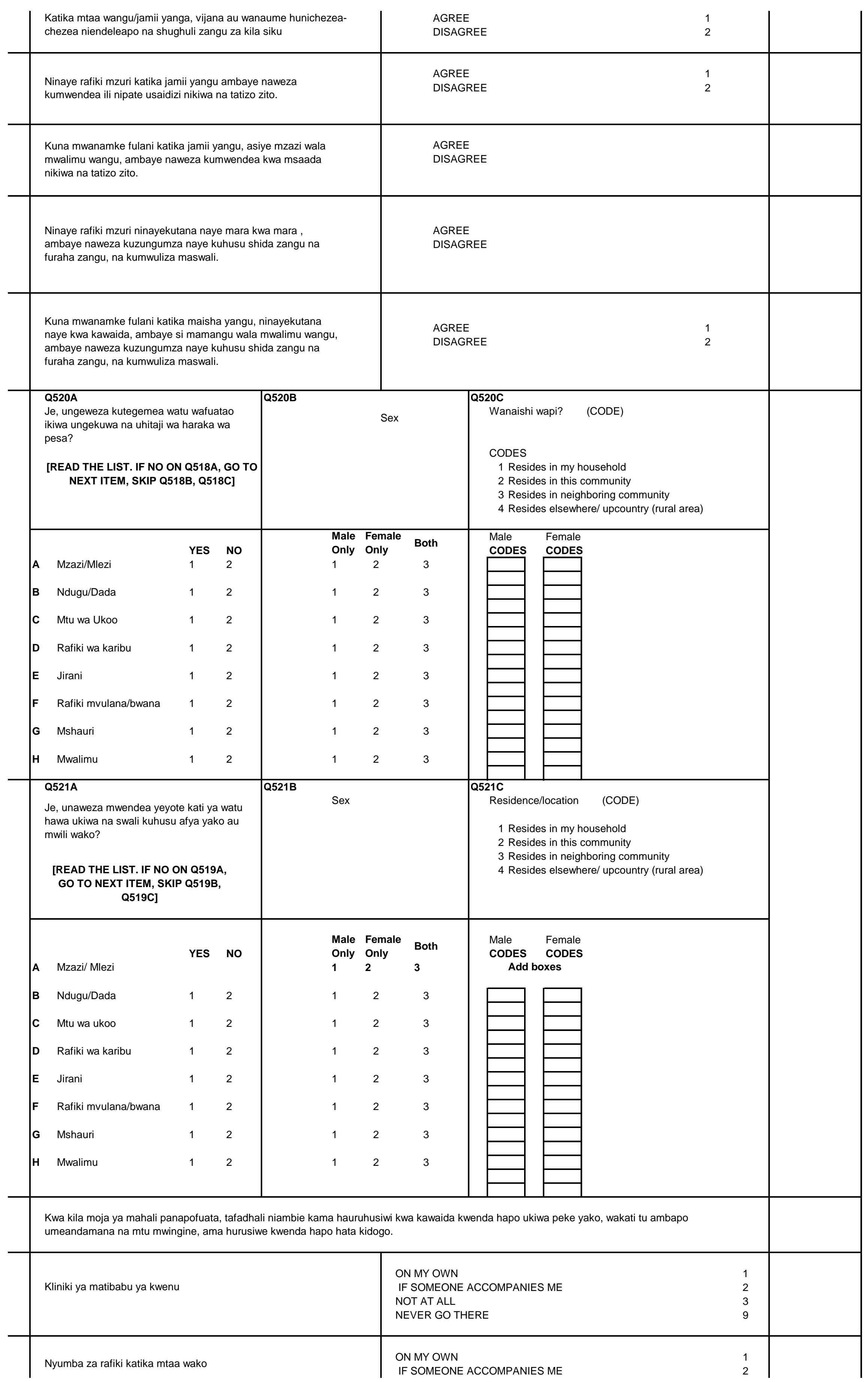




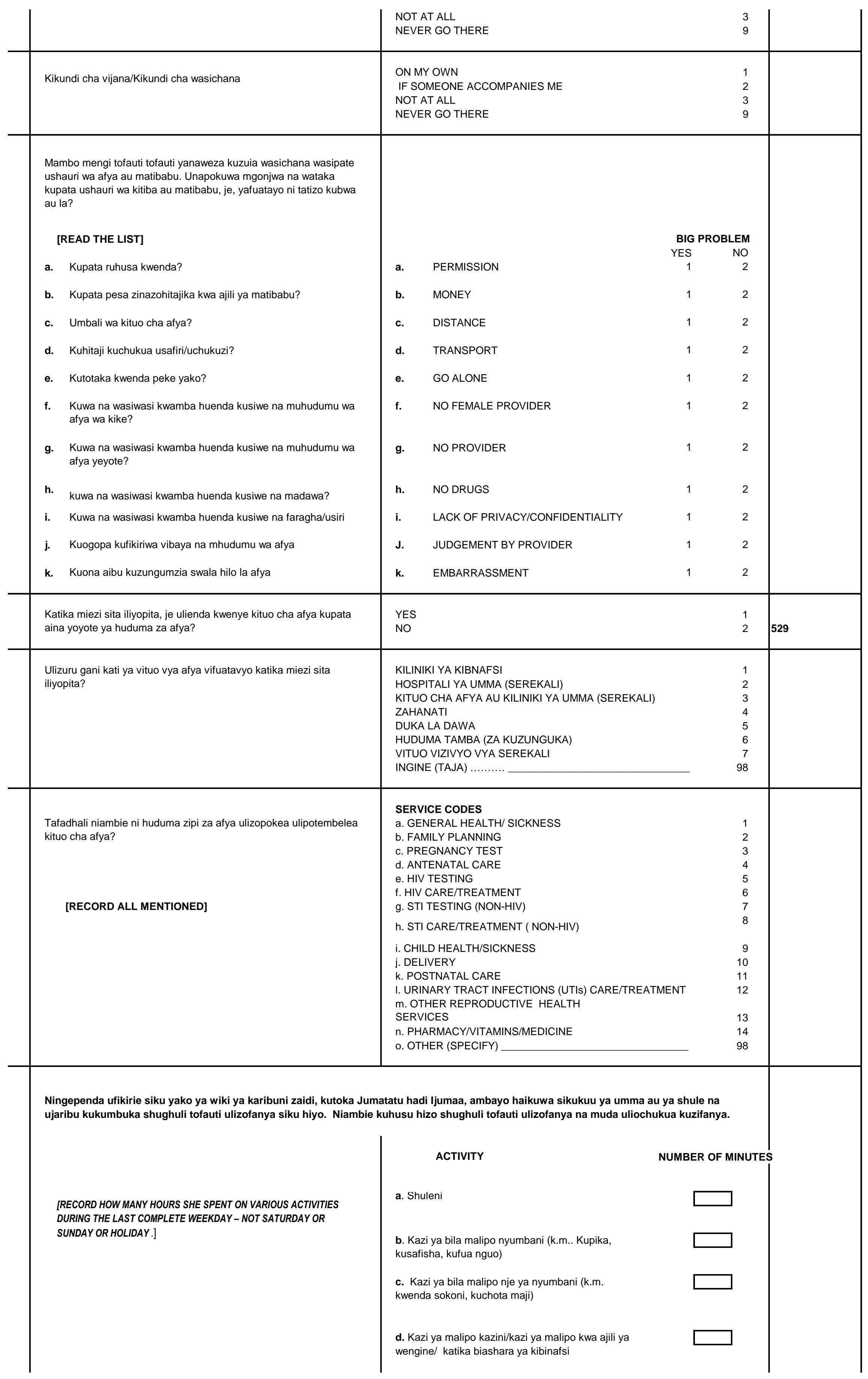




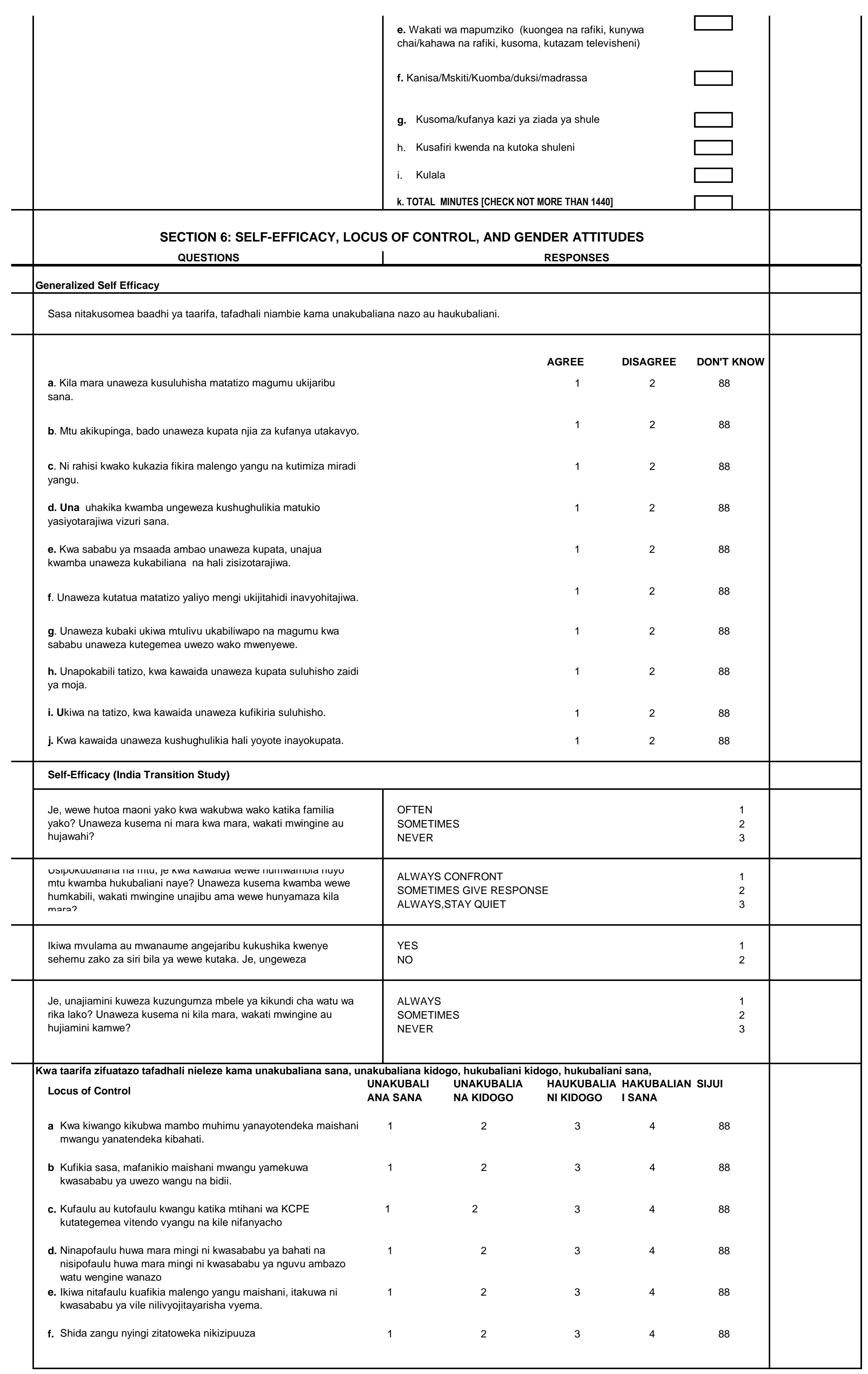


GENDER NORMS (GEAS)

Kwa taarifa zifuatazo tafadhali nieleze kama unakubaliana sana, unakubaliana kidogo, hukubaliani kidogo, hukubaliani sana,

Girls Freedom Versus Lack of Independence

UNAKUBAL UNAKUBALIA HAUKUBALIA HAUKUBALIA SIJUI ANA SANA NA KIDOGO NI KIDOGO NI SANA

a. Wasichana wanafaa kujitegemea kama wavulana

b. Wasichana hawafai kutoka na marafiki zao isipokuwa tu kama kuna mtu mzima.

c. Wasichana huwa wanahisi kwamba uhuru wao ni mdogo ukilinganisha na wa wavulana kuhusiana na kile

wanachoweza kufanya na pahali wanapoweza kwenda

d. Wasichana wanafaa kuwa na nafasi sawa na wavulana

e. Wasichana wanafaa kuwa na uhuru wa kutembea kama wavulana

Girls Responsibilities

f. Ni muhimu kwa wasichana kufanya vyema shuleni jinsi ilivyo muhimu kwa wavulana

g. Wavulana na wasichana wanafaa kujukumika kwa usawa katika
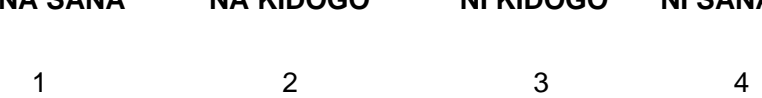

kazi za nyumbani

\section{Deference/Proper/Composed}

h. Wasichana wanafaa kujiwekea fikira zao na wasiseme wanachofikiria kwa umma

i. Wasichana wanatarajiwa kuwa wanyenyekevu

j. Wasichana hawafai kutoa madai mengi sana kwa wengine

k. Msichana anafaa kusema anachofikiria hata kama kitaumiza hisia za mtu

$\begin{array}{lllll}1 & 2 & 3 & 4 & 88 \\ 1 & 2 & 3 & 4 & 88 \\ 1 & 2 & 3 & 4 & 88 \\ 1 & 2 & 3 & 4 & 88 \\ 1 & 2 & 3 & 4 & 88\end{array}$

I. Wasichana wanaobishana na rafiki zao hadharani hawana tabia za 1 kike.

Girls are Responsible for Arousing Boys

m Wasichana wanafaa kujifunika, la sivyo watavutia kimapenzi isivyohitajika

n. Wasichana wanafaa kuwa waangalifu kuhusu jinsi wanavyo onekana ili wasionekane ni kama wanajaribu kuwatongoza

o. Ni makosa yake msichana wavulana wakimtongoza

p. Wasichana huvaa nguo fupi ili kuwavutia wavulana

q. Wasichana wanafaa kuwa huru kuvaa wanayotaka

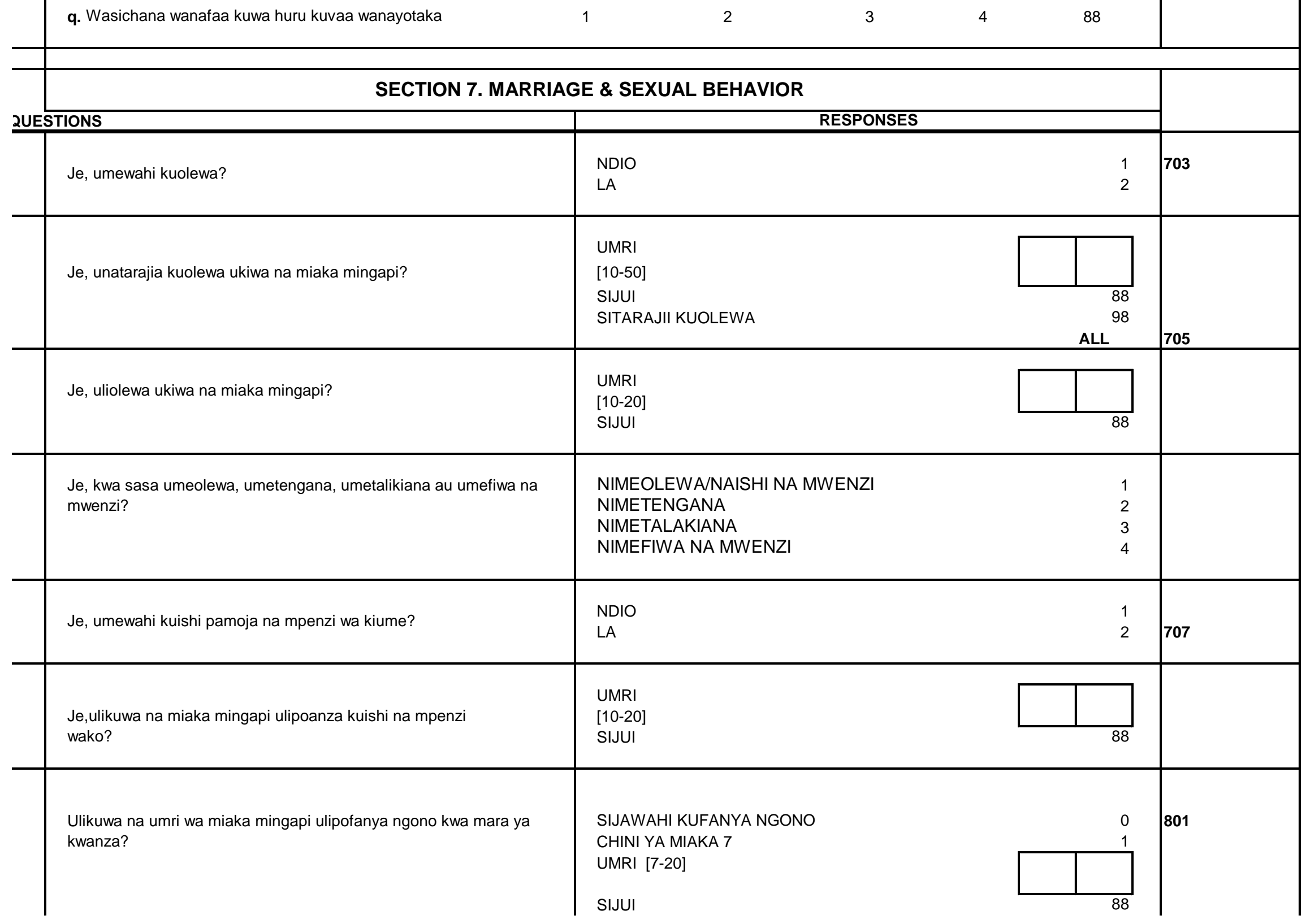




\begin{tabular}{|c|c|c|c|}
\hline $\begin{array}{l}\text { Ulikuwa na uhusiano gani na mtu wa kwanza uliyefanya ngono } \\
\text { naye? } \\
\text { [DO NOT READ OPTIONS] }\end{array}$ & $\begin{array}{l}\text { MUME } \\
\text { MPENZI } \\
\text { "MZEE MPENZI" (BUZI) } \\
\text { MTU UNAYEMJUA } \\
\text { JAMAA YAKO } \\
\text { MWALIMU } \\
\text { MTU USIYEMJUA } \\
\text { MTU MWINGINE }\end{array}$ & $\begin{array}{l}1 \\
2 \\
3 \\
4 \\
5 \\
6 \\
7 \\
8\end{array}$ & \\
\hline $\begin{array}{l}\text { Je, mtu wa kwanza uliyefanya ngono naye alikuwa na umri mkubwa } \\
\text { kuliko wewe, alikuwa mchanga kuliko wewe au alikuwa na umri } \\
\text { karibu sawa na wewe? }\end{array}$ & $\begin{array}{l}\text { UMRI MKUBWA KULIKO WEWE } \\
\text { MCHANGA KULIKO WEWE } \\
\text { UMRI KARIBU SAWA NA WEWE } \\
\text { SIJUI / SIKUMBUKI }\end{array}$ & $\begin{array}{r}1 \\
2 \\
3 \\
88\end{array}$ & $\begin{array}{l}711 \\
711 \\
711\end{array}$ \\
\hline Je, alikuwa na miaka ngapi zaidi yako? & MKUBWA KWA MIAKA MINGAPI & 88 & \\
\hline Mara ya kwanza ulipofanya ngono ulitumia kondomu/mpira? & $\begin{array}{l}\text { NDIO } \\
\text { LA } \\
\text { SIJUI / SIKUMBUKI }\end{array}$ & $\begin{array}{r}1 \\
2 \\
88\end{array}$ & \\
\hline $\begin{array}{l}\text { Mara ya kwanza ulipofanya ngono, je, ulitaka kufanya ngono, au } \\
\text { haukutaka kufanya ngono, ama haukuwa na uhakika kama ulitaka } \\
\text { kufanya ngono? }\end{array}$ & $\begin{array}{l}\text { ULITAKA KUFANYA NGONO } \\
\text { HUKUTAKA KUFANYA NGONO } \\
\text { HAUKUWA NA HAKIKA }\end{array}$ & $\begin{array}{l}1 \\
2 \\
3\end{array}$ & \\
\hline $\begin{array}{l}\text { Sasa ningependa kukuuliza baadhi ya maswali kuhusu utendaji } \\
\text { wako wa ngono wa hivi karibuni. Ni lini mara ya mwisho ulipofanya } \\
\text { ngono? }\end{array}$ & $\begin{array}{l}\text { LEO/WIKI MOJA HAIJAPITA } \\
\text { WIKI MOJA AU ZAIDI ILIYOPITA } \\
\text { MWEZI MMOJA ULIOPITA AU ZAIDI } \\
\text { MWAKA MMOJA ULIOPITA AU ZAIDI }\end{array}$ & $\begin{array}{l}1 \\
2 \\
3 \\
4\end{array}$ & $\begin{array}{l}716 \\
716 \\
716\end{array}$ \\
\hline Katika wiki moja iliyopita, ulifanya ngono mara ngapi? & $\begin{array}{l}\text { MARA NGAPI ULIFANYA NGONO [1-35] } \\
\text { SIJUI }\end{array}$ & 88 & \\
\hline $\begin{array}{l}\text { Nyakati ulipofanya ngono katika wiki iliyopita, ulitumia kondomu } \\
\text { mara ngapi? } \\
\text { [Consistency check: Maximum = previous question] }\end{array}$ & $\begin{array}{l}\text { MARA NGAPI ULITUMIA KONDOMU [1-35] } \\
\text { HUKUTUMIA KONDOMU } \\
\text { SIJUI }\end{array}$ & $\begin{array}{l}77 \\
88\end{array}$ & \\
\hline Ni nini uhusiano wako na mtu wa mwisho uliyefanya ngono naye? & $\begin{array}{l}\text { MUME } \\
\text { MPENZI } \\
\text { "MZEE MPENZI" (BUZI) } \\
\text { MTU UNAYEMJUA } \\
\text { JAMAA } \\
\text { MWALIMU } \\
\text { MTU USIYEMJUA } \\
\text { MTU MWINGINE }\end{array}$ & $\begin{array}{l}1 \\
2 \\
3 \\
4 \\
5 \\
6 \\
7 \\
8\end{array}$ & \\
\hline $\begin{array}{l}\text { Je, yule mtu wa mwisho uliyefanya ngono naye alikuwa na umri } \\
\text { mkubwa kuliko wewe, alikuwa mchanga kuliko wewe, au alikuwa na } \\
\text { umri karibu sawa na wewe? }\end{array}$ & $\begin{array}{l}\text { UMRI MKUBWA KULIKO WEWE } \\
\text { MCHANGA KULIKO WEWE } \\
\text { UMRI KARIBU SAWA NA WEWE } \\
\text { SIJUI / SIKUMBUKI }\end{array}$ & $\begin{array}{r}1 \\
2 \\
3 \\
88\end{array}$ & $\begin{array}{l}720 \\
720 \\
720\end{array}$ \\
\hline Je, alikuwa na miaka ngapi zaidi yako? & $\begin{array}{l}\text { MKUBWA KWA MIAKA MINGAPI } \\
\text { SIJUI }\end{array}$ & 88 & \\
\hline $\begin{array}{l}\text { Mara ya mwisho ulipofanya ngono, je, ulitaka kufanya ngono, au } \\
\text { haukutaka kufanya ngono, ama haukuwa na uhakika kama ulitaka } \\
\text { kufanya ngono? }\end{array}$ & $\begin{array}{l}\text { ULITAKA KUFANYA NGONO } \\
\text { HUKUTAKA KUFANYA NGONO } \\
\text { HAUKUWA NA HAKIKA }\end{array}$ & $\begin{array}{l}1 \\
2 \\
3\end{array}$ & \\
\hline Je, mara ya mwisho ulipofanya ngono, kondomu ilitumiwa? & $\begin{array}{l}\text { NDIO } \\
\text { LA } \\
\text { SIJUI / SIKUMBUKI }\end{array}$ & $\begin{array}{r}1 \\
2 \\
88\end{array}$ & \\
\hline $\begin{array}{l}\text { Kwa wastani, ulitumia kondomu mara nyingi kadri gani katika } \\
\text { mwaka mmoja uliopita ulipofanya ngono na mtu huyo? Unaweza } \\
\text { kusema ni kila mara, wakati mwingine ama hukutumia kamwe? }\end{array}$ & $\begin{array}{l}\text { KILA MARA } \\
\text { WAKATI MWINGINE } \\
\text { HUKUTUMIA KAMWE }\end{array}$ & $\begin{array}{l}1 \\
2 \\
3\end{array}$ & \\
\hline $\begin{array}{l}\text { Kama ungependa kupata njia ya kupanga uzazi, je waona kama } \\
\text { ingekuwa rahisi, vigumu au isingewezekana kwenda mahali } \\
\text { ambapo waweza kupata njia ya kupanga uzazi? }\end{array}$ & $\begin{array}{l}\text { RAHISI } \\
\text { VIGUMU } \\
\text { ISINGEWEZEKANA } \\
\text { SIJUI }\end{array}$ & $\begin{array}{r}1 \\
2 \\
3 \\
88\end{array}$ & \\
\hline [SKIP Q728 IF Q713 IS A YEAR OR MORE AGO] & & & \\
\hline iumla umafanva nnnnn na uratu umannani tnfauti katika miazi & IDADI YA WAPENZI KATIKA MIEZI 6 & & \\
\hline
\end{tabular}




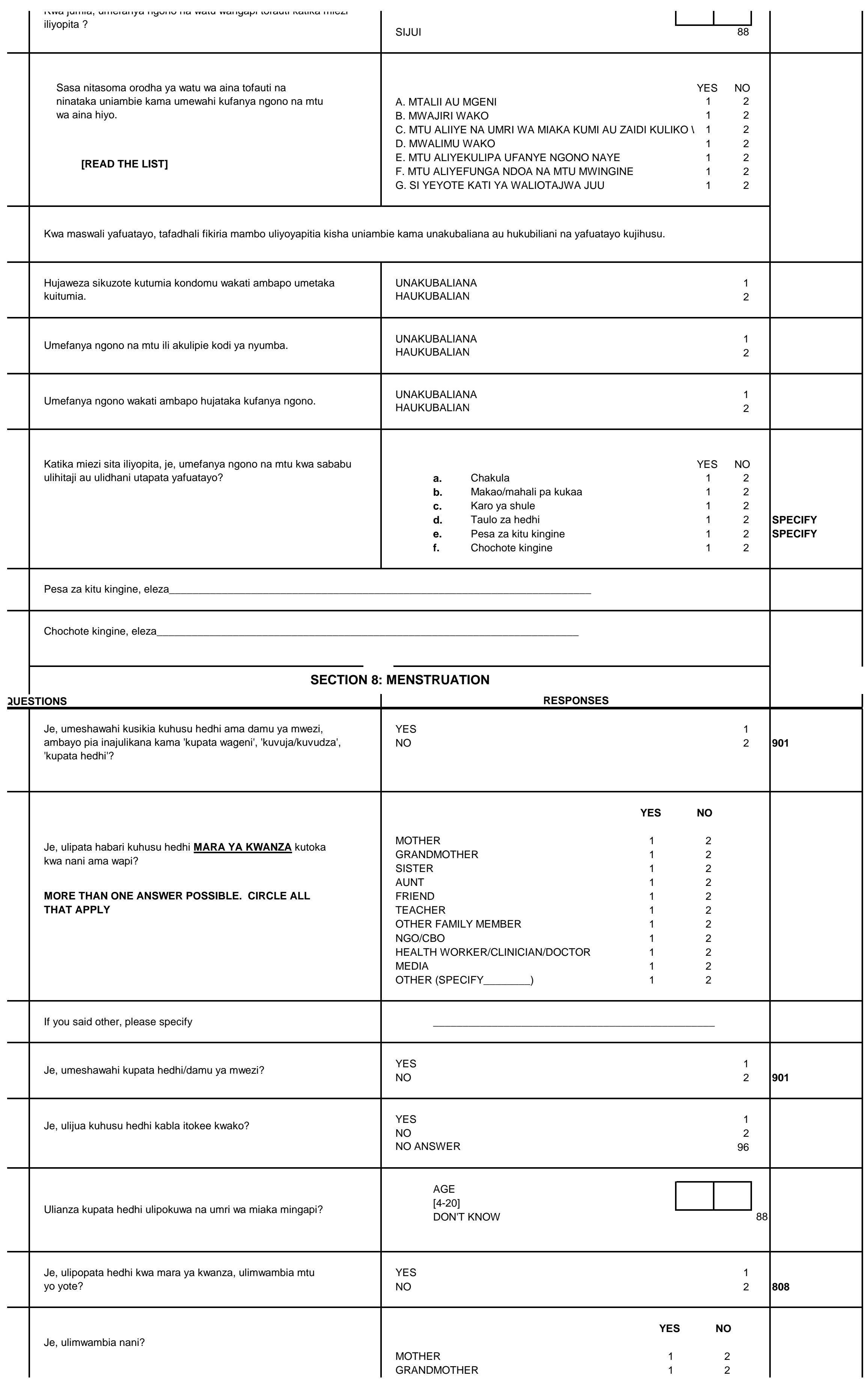




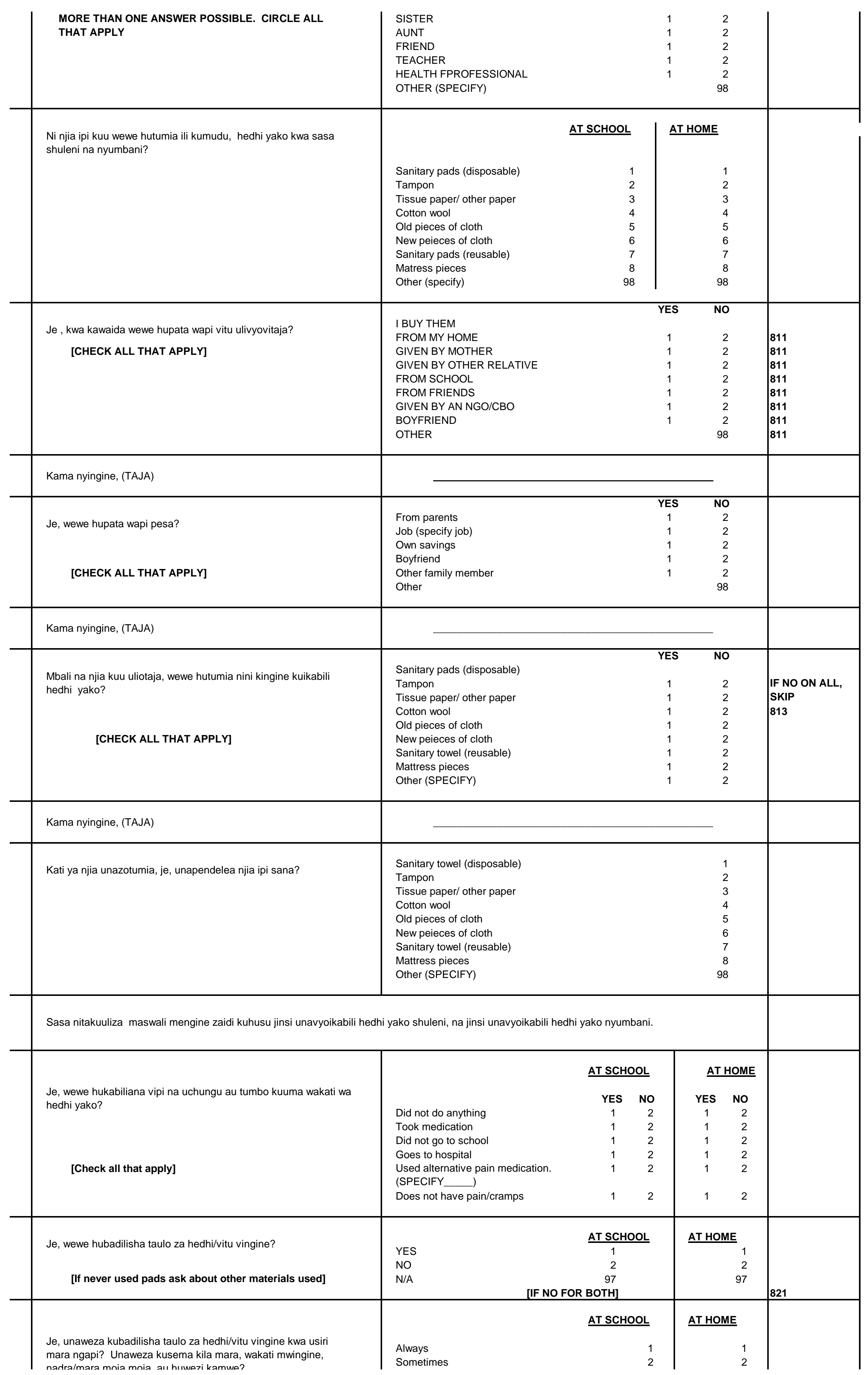




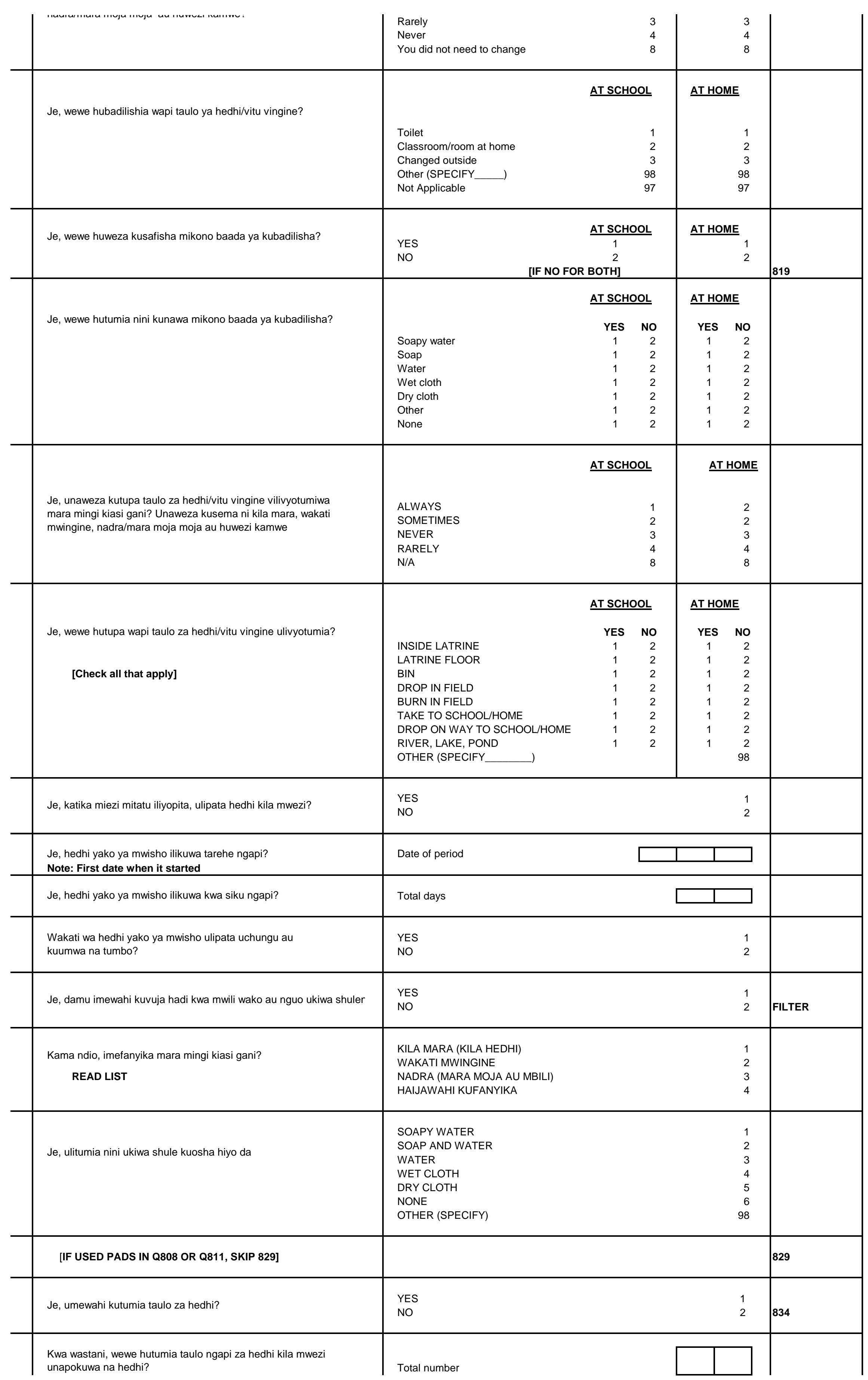




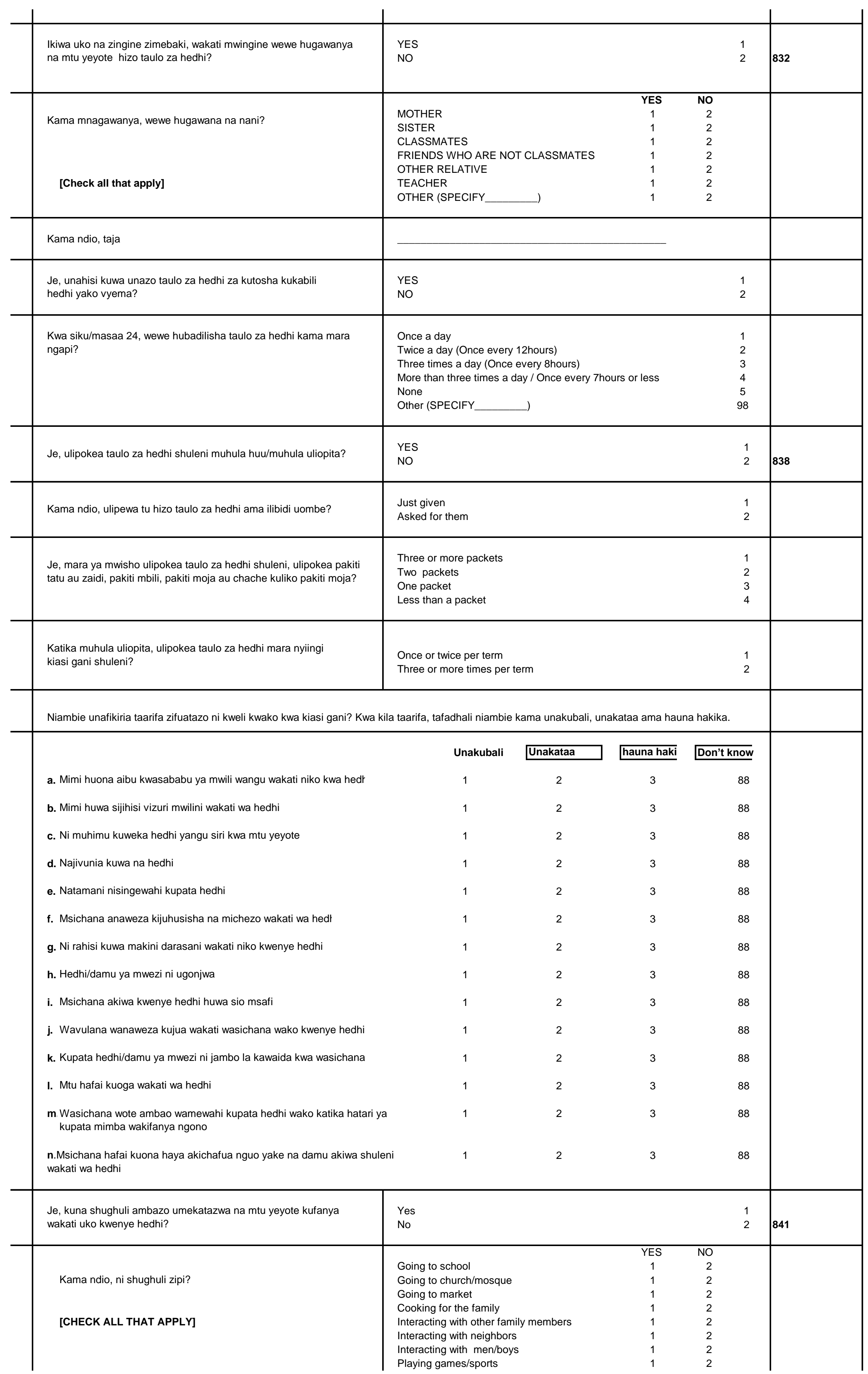




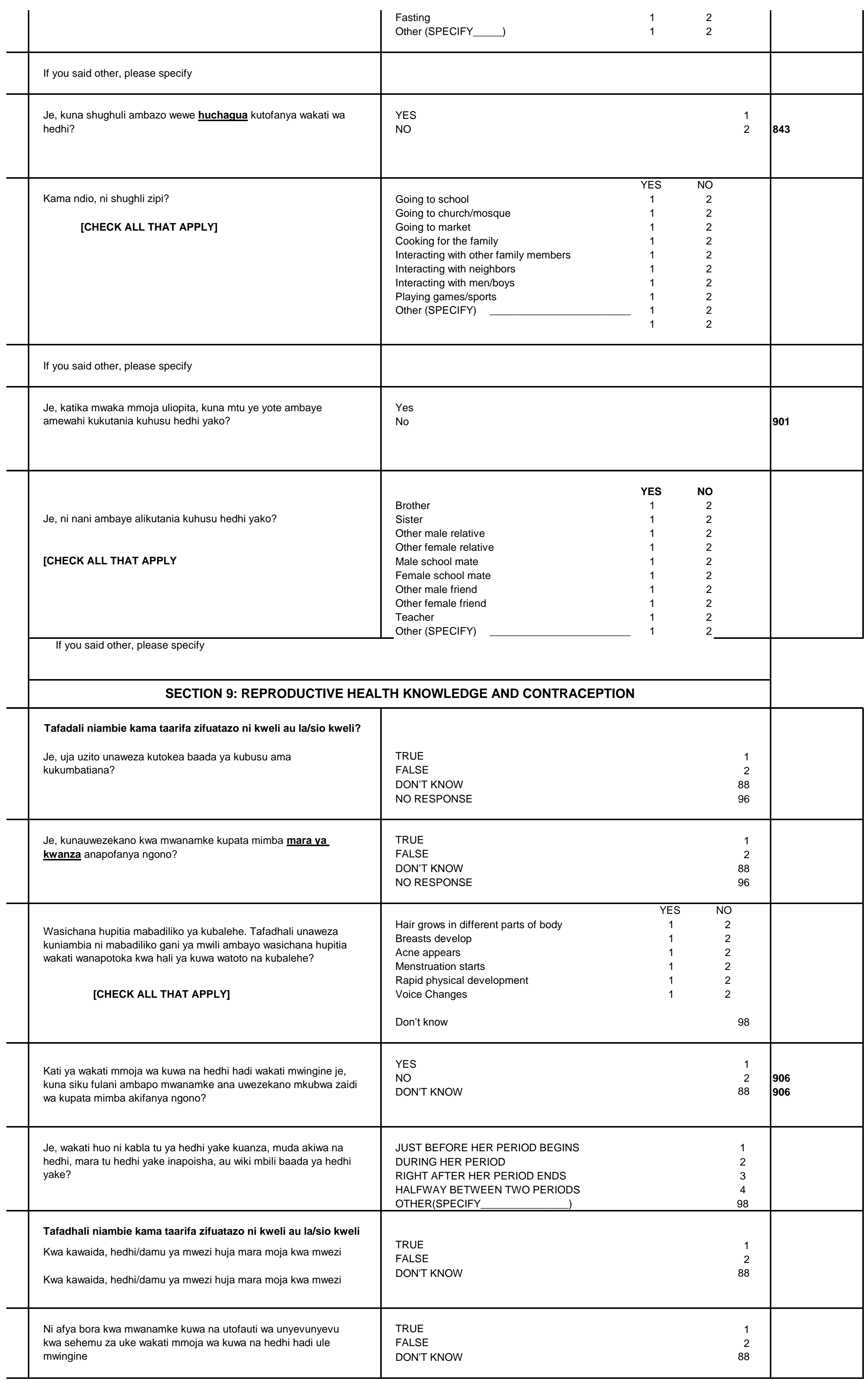




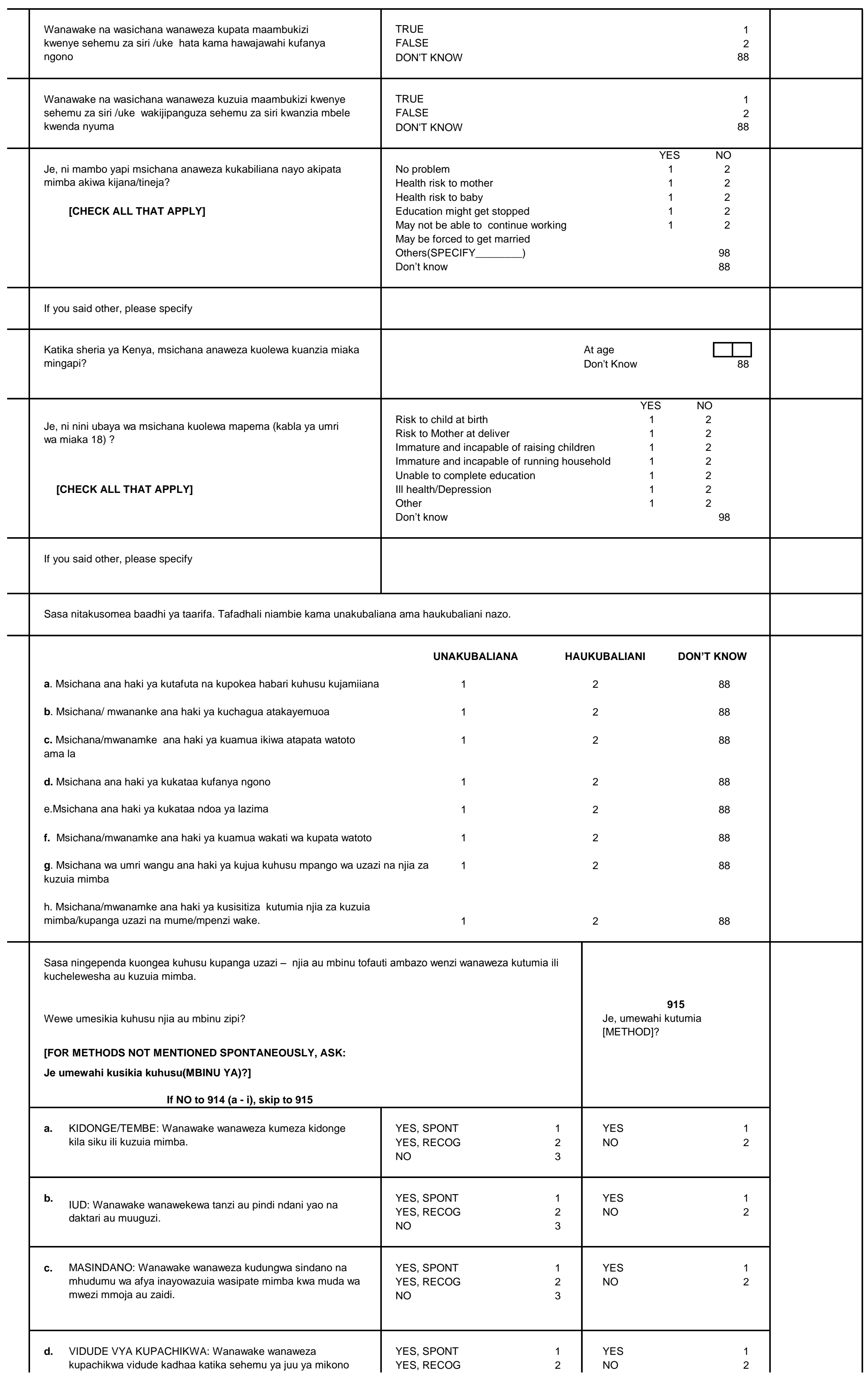




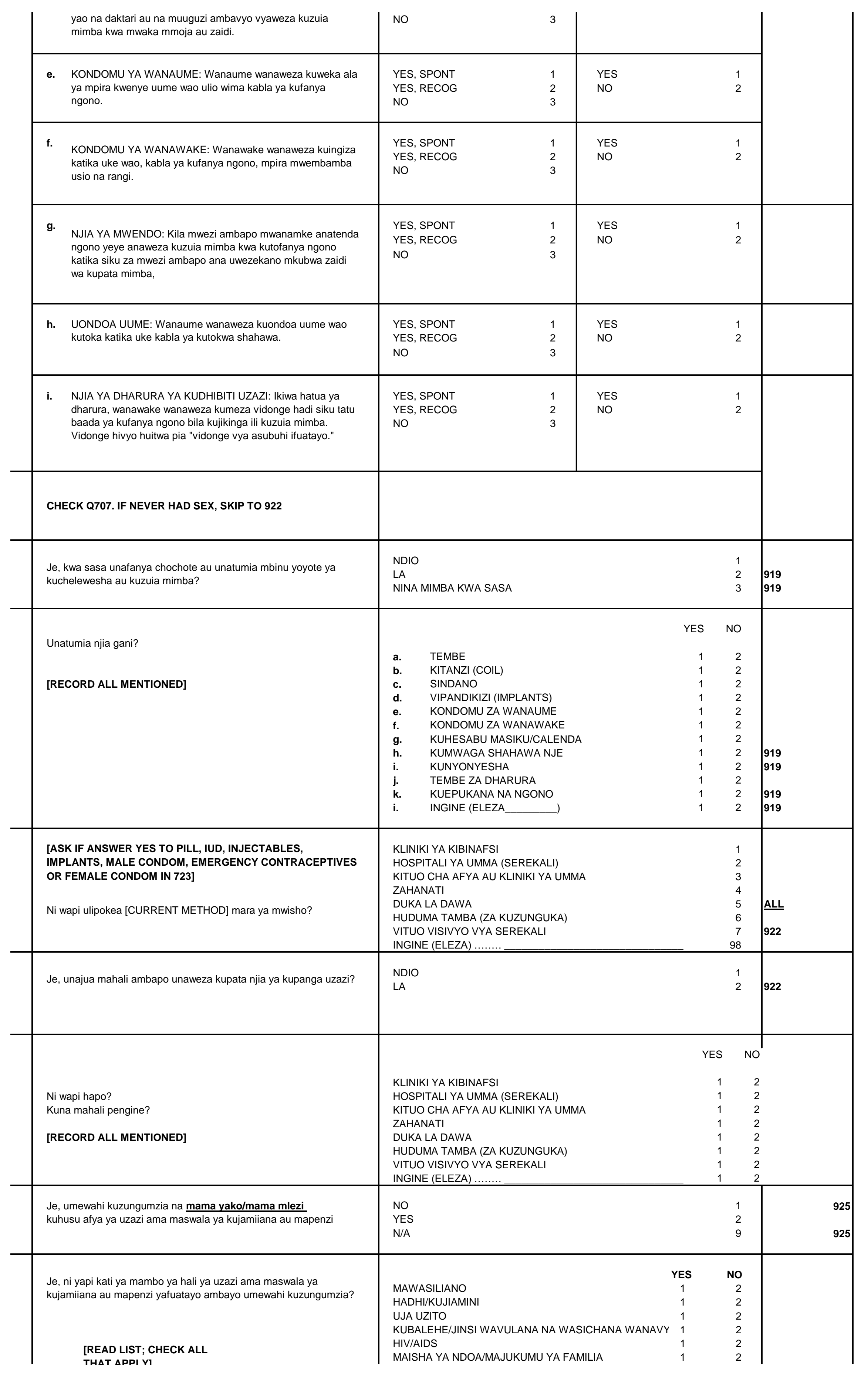




\begin{tabular}{|c|c|c|c|c|c|}
\hline 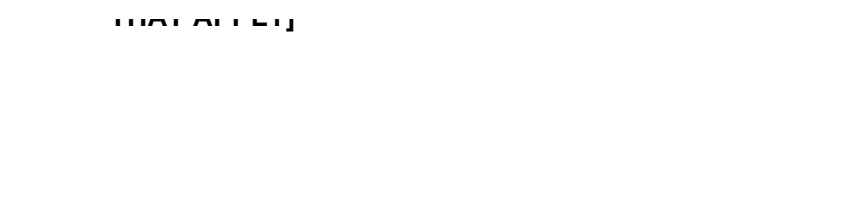 & $\begin{array}{l}\text { HEDHI } \\
\text { MPANGO WA UZAZI } \\
\text { KUEPUKANA NA NGONO } \\
\text { AFYA NA USAFI } \\
\text { INGINE (ELEZA) }\end{array}$ & $\begin{array}{l}1 \\
1 \\
1\end{array}$ & $\begin{array}{r}2 \\
2 \\
2 \\
98\end{array}$ & & \\
\hline $\begin{array}{l}\text { Je, ni nini ingine ulizungumzia kuhusu afya ya uzazi ama maswala } \\
\text { ya kujamiiana au mapenzi? (ELEZA) }\end{array}$ & $\mathrm{NONE}=$ & & 0 & & \\
\hline $\begin{array}{l}\text { Je, umewahi kuzungumzia na baba yako/baba mlezi kuhusu } \\
\text { hali ya uzazi ama maswala ya kujamiiana au mapenzi miezi }\end{array}$ & $\begin{array}{l}\text { NO } \\
\text { YES } \\
\text { N/A }\end{array}$ & & $\begin{array}{l}1 \\
2 \\
9\end{array}$ & & $\begin{array}{l}928 \\
928\end{array}$ \\
\hline $\begin{array}{l}\text { Je, ni yapi kati ya mambo ya afya ya uzazi ama maswala ya } \\
\text { kujamiiana au mapenzi yafuatayo ambayo umewahi kuzungumzia? } \\
\text { [READ LIST; CHECK ALL } \\
\text { THAT APPLY] }\end{array}$ & $\begin{array}{l}\text { MAWASILIANO } \\
\text { HADHI/KUJIAMINI } \\
\text { UJA UZITO } \\
\text { KUBALEHE/JINSI WAVULANA NA WASICHANA WANAVY } \\
\text { HIV/AIDS } \\
\text { MAISHA YA NDOA/MAJUKUMU YA FAMILIA } \\
\text { HEDHI } \\
\text { MPANGO WA UZAZI } \\
\text { KUEPUKANA NA NGONO } \\
\text { AFYA NA USAFI } \\
\text { INGINE (ELEZA) }\end{array}$ & $\begin{array}{c}\text { YES } \\
1 \\
1 \\
1 \\
1 \\
1 \\
1 \\
1 \\
1 \\
1\end{array}$ & $\begin{array}{r}\text { NO } \\
2 \\
2 \\
2 \\
2 \\
2 \\
2 \\
2 \\
2 \\
\\
2 \\
98\end{array}$ & & \\
\hline $\begin{array}{l}\text { Je, ni nini ingine ulizungumzia kuhusu afya ya uzazi ama maswala } \\
\text { ya kujamiiana au mapenzi? (ELEZA) }\end{array}$ & $\mathrm{NONE}=$ & & 0 & & \\
\hline $\begin{array}{l}\text { Wakati mwingine wanawake hupata utoko/unyevu usio wa kawaida } \\
\text { na wenye harufu mbaya katika sehemu za siri. Je, umeshawahi } \\
\text { kupata utoko usiowakawaida na wenye harufu mbaya kwa sehemu } \\
\text { zako za siri katika miezi kumi na mbili iliyopita? }\end{array}$ & $\begin{array}{l}\text { YES } \\
\text { NO } \\
\text { DON'T KNOW }\end{array}$ & & $\begin{array}{r}1 \\
2 \\
88\end{array}$ & & \\
\hline $\begin{array}{l}\text { Wakati mwingine wanawake hupata uchungu wakati wanakojoa } \\
\text { pamoja na haja ya kukojoa mara kwa mara. Je, katika miezi kumi } \\
\text { na mbili iliyopita, umepata uchungu unapokojoa pamoja na haja ya } \\
\text { kukojoa mara kwa mara? }\end{array}$ & $\begin{array}{l}\text { YES } \\
\text { NO } \\
\text { DON'T KNOW }\end{array}$ & & $\begin{array}{r}1 \\
2 \\
88\end{array}$ & & \\
\hline $\begin{array}{l}\text { Wakati mwingine wanawake hupata vidonda kwenye sehemu za } \\
\text { siri. Je, umeshawahi kuwa na vidonda kwa sehemu zako za siri } \\
\text { katika miezi kumi na mbili iliyopita? }\end{array}$ & $\begin{array}{l}\text { YES } \\
\text { NO } \\
\text { DON'T KNOW }\end{array}$ & & $\begin{array}{r}1 \\
2 \\
88\end{array}$ & & \\
\hline $\begin{array}{l}\text { Check 922, } 923 \text { \& 924. IF NO SYMPTOMS, GO TO } \\
\text { FILTER }\end{array}$ & & & & FILTER & \\
\hline Ulitafuta matibabu kwa hizi dalili? & $\begin{array}{l}\text { YES } \\
\text { NO }\end{array}$ & & $\begin{array}{l}1 \\
2\end{array}$ & 933 & \\
\hline Kwa nini hukutafuta matibabu kwa hizi dalili? & $\begin{array}{l}1=\text { Didn't know where to go } \\
2=\text { No money for treatment } \\
3=\text { Facility too far } \\
4=\text { Symptoms cleared up by themselves } \\
5=\text { Unfriendly staff } \\
6=\text { Other (SPECIFY }\end{array}$ & & $\begin{array}{r}1 \\
2 \\
3 \\
4 \\
5 \\
98\end{array}$ & $\begin{array}{l}\text { FILTER } \\
\text { FILTER } \\
\text { FILTER } \\
\text { FILTER } \\
\text { FILTER } \\
\text { FILTER }\end{array}$ & \\
\hline $\begin{array}{l}\text { Ni wapi ulitafuta ushauri ama matibabu mara ya mwisho } \\
\text { ulipokuwa na hizi dalili? }\end{array}$ & $\begin{array}{l}\text { PRIVATE CLINIC/HOSPITAL } \\
\text { PUBLIC HOSPITAL } \\
\text { PUBLIC HEALTH CENTER/CLINIC } \\
\text { DISPENSARY } \\
\text { CHEMIST/PHARMACY } \\
\text { MOBILE/OUTREACH SERVICE } \\
\text { NGO FACILITY } \\
\text { OTHER (SPECIFY) ...... }\end{array}$ & & $\begin{array}{r}1 \\
2 \\
3 \\
4 \\
5 \\
6 \\
7 \\
98\end{array}$ & & \\
\hline \multicolumn{4}{|c|}{ SECTION 10: PREGNANCY AND BIRTHS } & & \\
\hline [IF NEVER HAD SEX) $\rightarrow$ Q1012] & & & & 1012 & \\
\hline $\begin{array}{l}\text { Sasa ningependa kukuuliza kuhusu matukio ya kuzaa watoto } \\
\text { ambao umekuwa nao muda wa maisha yako. Je, umewahi kuzaa } \\
\text { mtoto? }\end{array}$ & $\begin{array}{l}\text { YES } \\
\text { NO }\end{array}$ & & $\begin{array}{l}1 \\
2\end{array}$ & 1003 & \\
\hline $\begin{array}{l}\text { Je, umewahi kuzaa mvulana au msichana aliyezaliwa akiwa hai } \\
\text { lakini aliyekufa baadaye? }\end{array}$ & $\begin{array}{l}\text { YES } \\
\text { NO }\end{array}$ & & $\begin{array}{l}1 \\
2\end{array}$ & 1005 & \\
\hline Umezaa watoto mara ngapi kwa jumla maishani mwako? & $\begin{array}{l}\text { TOTAL BIRTHS } \\
{[1-5]}\end{array}$ & & & & \\
\hline
\end{tabular}




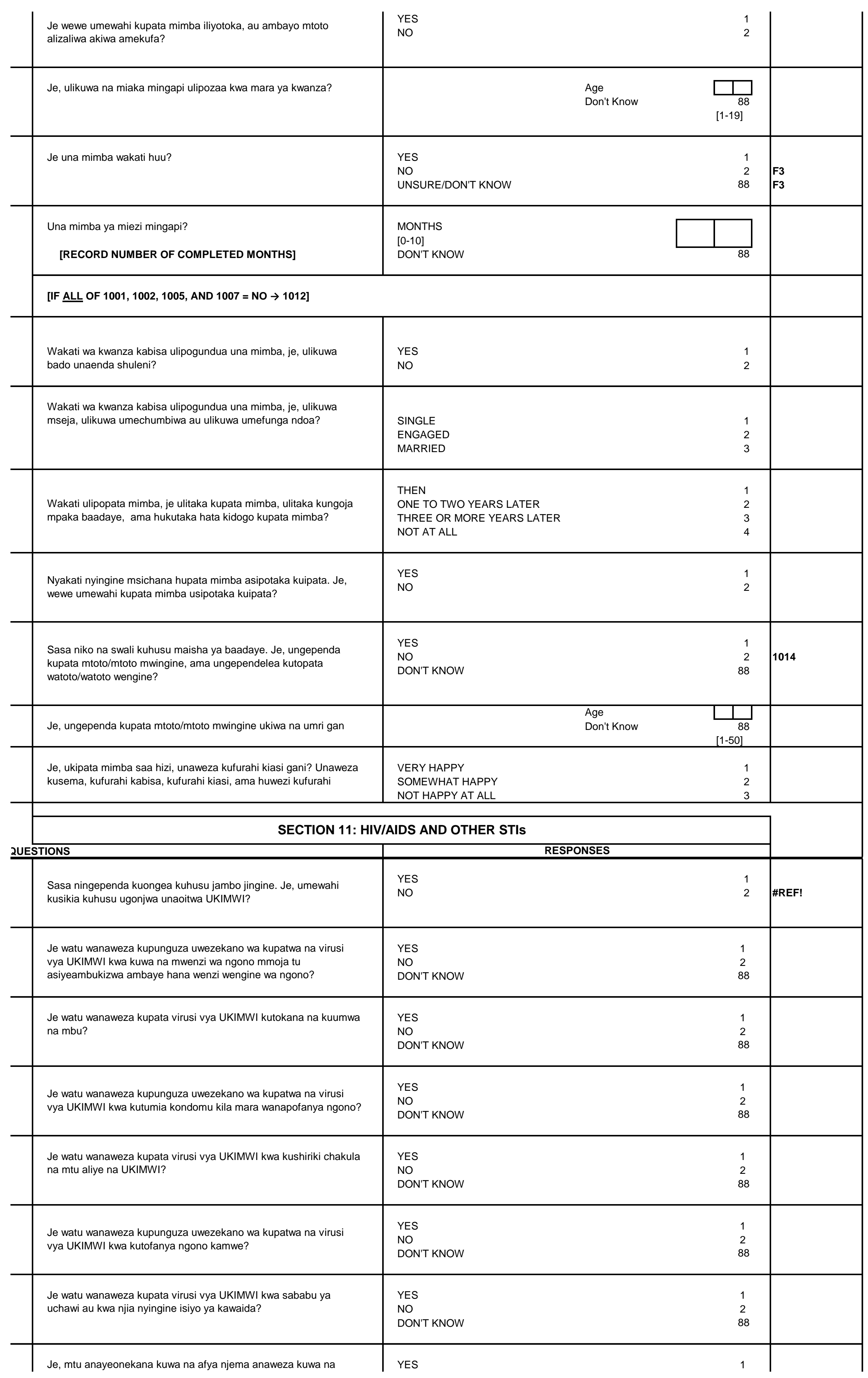




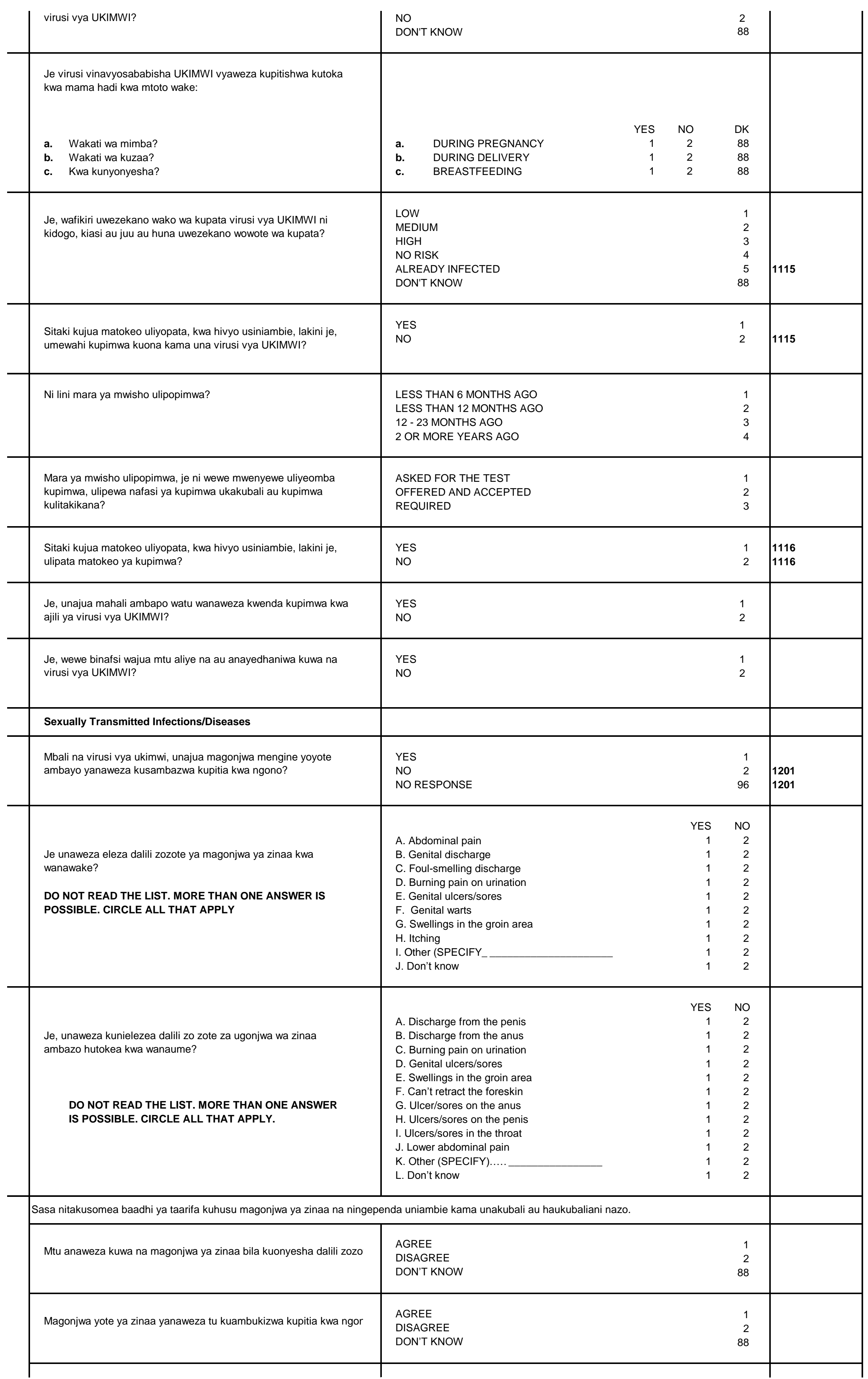




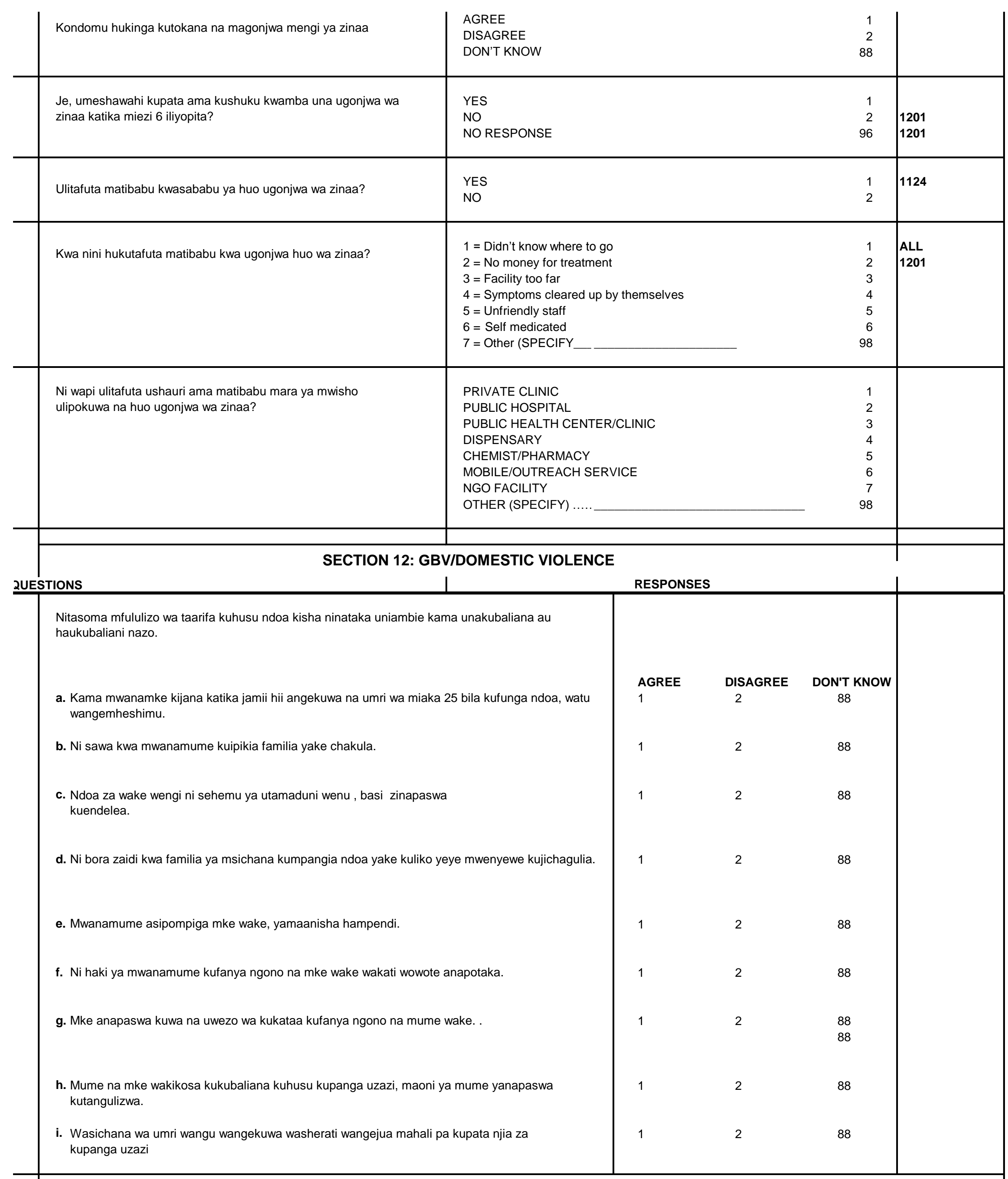

\section{ATTITUDES TOWARDS GENDER VIOLENCE}

Nitakuuliza ufikirie kuhusu hali kadhaa zinazohusisha mume na mke. Unapofikiria maswali hayo, tafadhali kumbuka kwamba tunakuuliza utoe maoni yako kuhusu kila moja ya hali hizo, wala si kuhusu mambo uliyoyapitia kibinafsi.

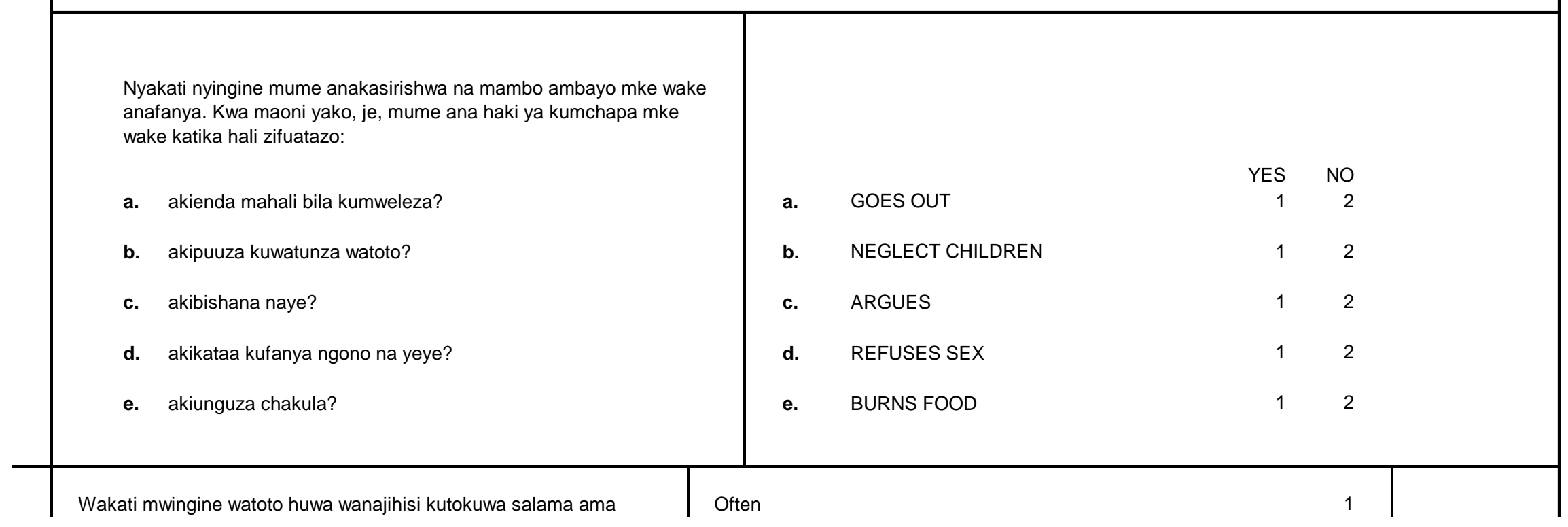




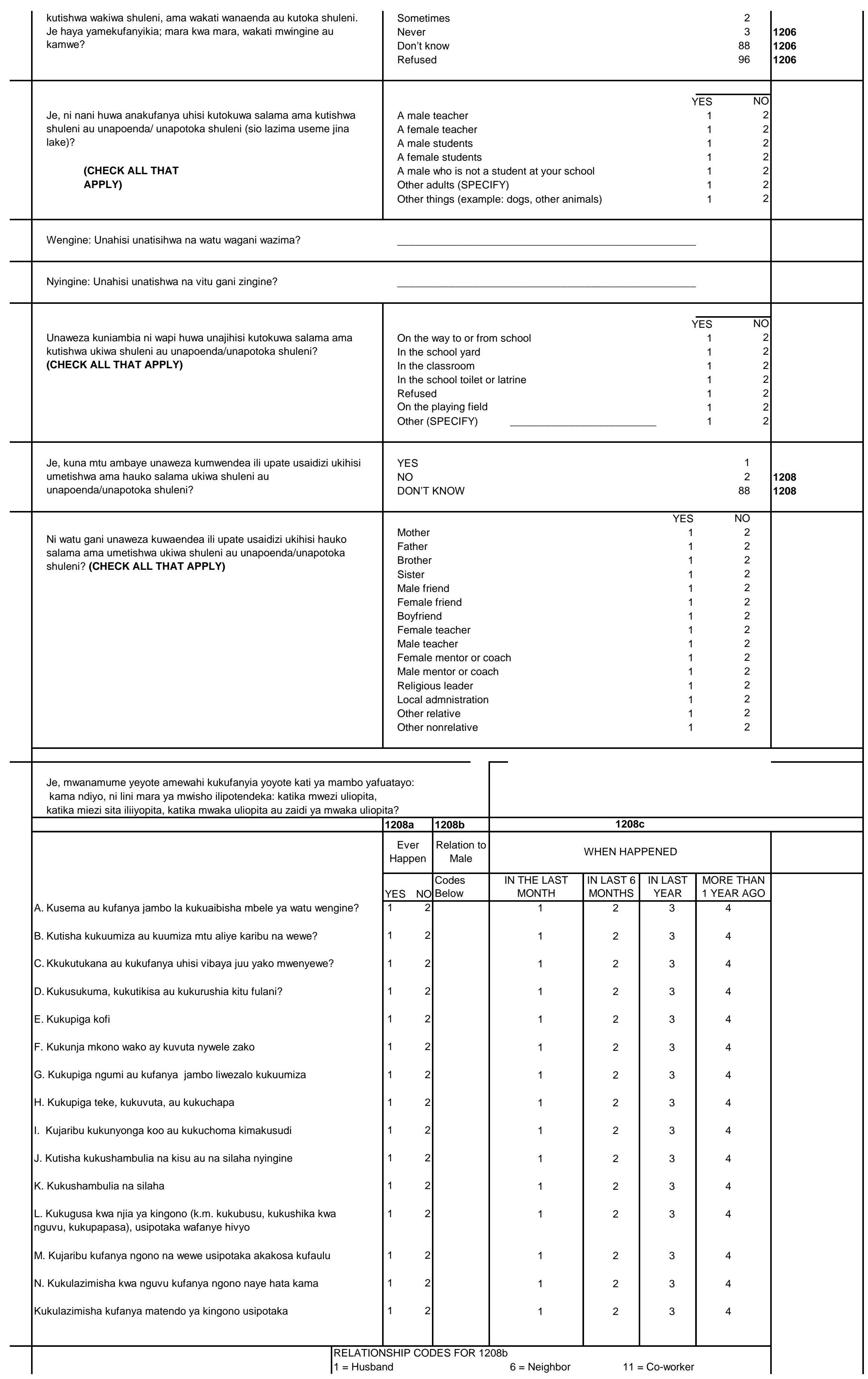




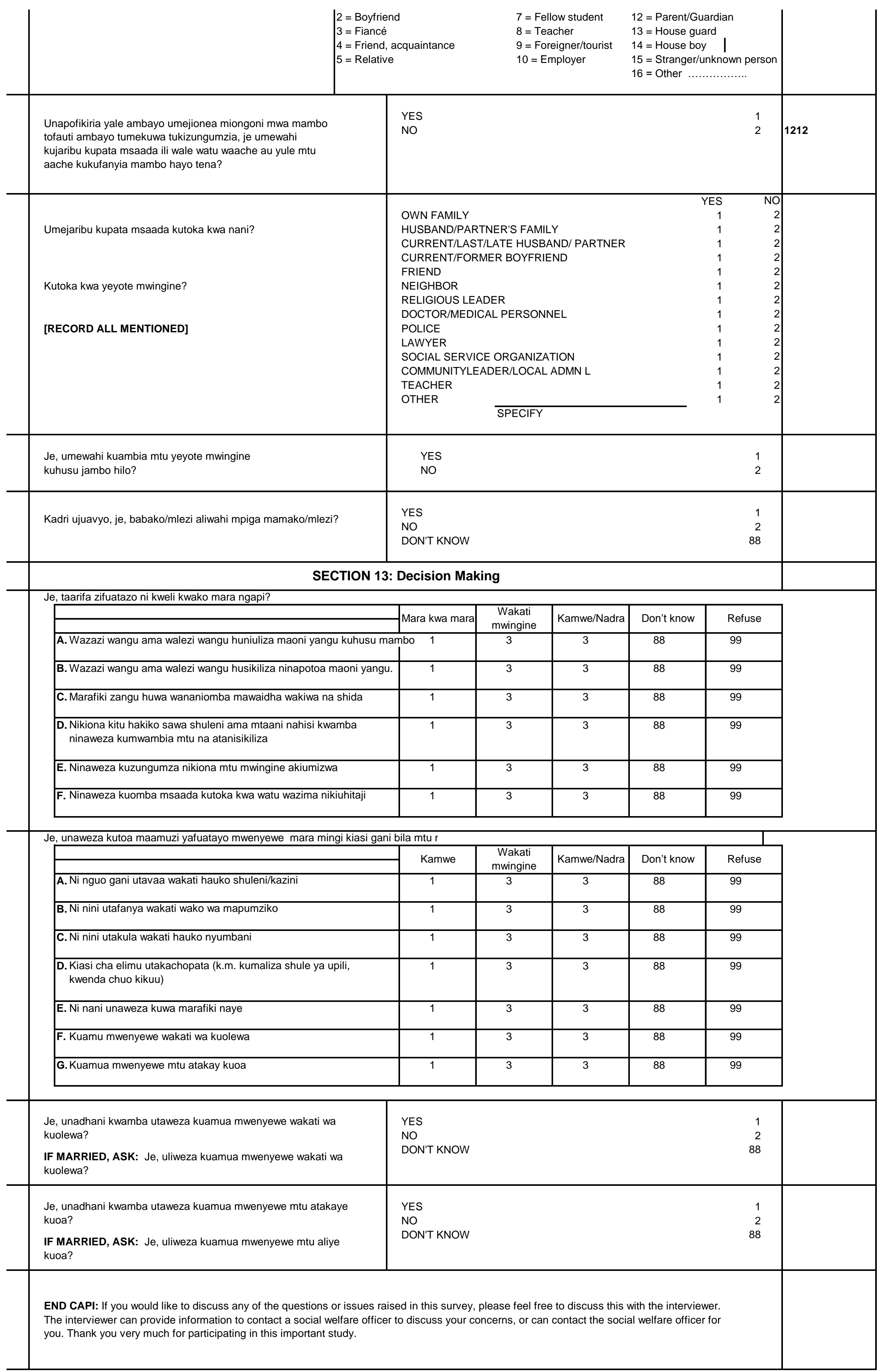

